\title{
New Insights into the Effectiveness of Front-of-Package Nutrition Label Formats: Situational Processing Perspective
}

\author{
Dissertation \\ zur Erlangung des Doktorgrades \\ der Wirtschaftswissenschaftlichen Fakultät \\ der Universität Göttingen \\ (Dr. rer. pol.) \\ vorgelegt von \\ MBA S. Setareh Sanjari \\ geboren in Tehran, Iran
}

Göttingen, 2018 
Erstgutachter:

Prof. Dr. Yasemin Boztuğ, Professorin für Marketing und Konsumentenforschung

Georg-August-Universität Göttingen

Zweitgutachter:

Prof. Dr. Till Dannewald, Professur für Business Analytics / Business Intelligence

Hochschule RheinMain

Drittgutachter:

Prof. Dr. Waldemar Toporowski, Professur für Handelsbetriebslehre, Georg-August-Universität Göttingen

Tag der mündlichen Prüfung: $\quad$ 02. März 2018 

This thesis is dedicated to my husband, friend and love, Hadi, who has been a constant source of support and encouragement during the challenges of research and life.

I am truly thankful for having you in my life.

This work is also dedicated to my mother and the memory of my father, who have taught me to work hard for the things that I aspire to achieve. 


\section{Aknowledgements:}

I would like to express my sincere gratitude to my first supervisor Prof. Dr. Yasemin Boztug who provided me an opportunity to join the team of marketing and consumer behavior at Göttingen University, also for her continuous support, her patience, motivation, and immense knowledge.

Moreover, I would like to thank Dr. Steffen Jahn, for his patient guidance, encouragement, and insightful advice throughout my research project. 



\section{Table of Content:}

Table of Content: ...................................................................................................................... VII

List of Figures............................................................................................................................................. IX

List of Tables .....................................................................................................................

1. General Introduction ...................................................................................................................1

1.1 Relevance

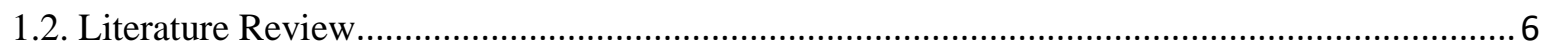

1.2.1. Information Processing Perspectives: Dual-Process Model .................................................... 8

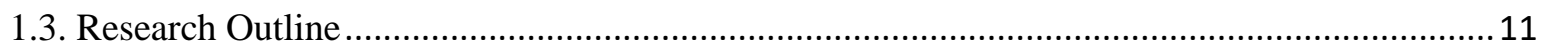

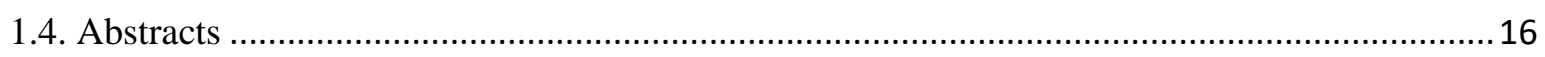

2. Paper \#1: Dual-process theory and consumer response to front-of-package nutrition label formats ..............................................................................................................................................19

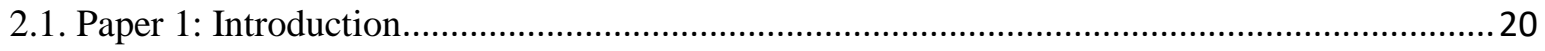

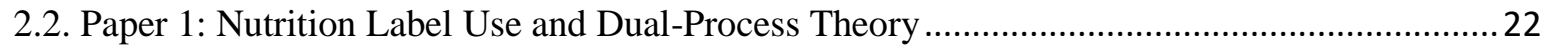

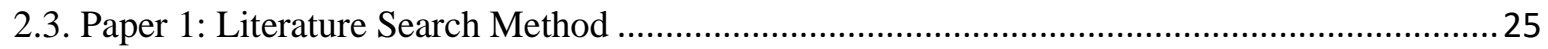

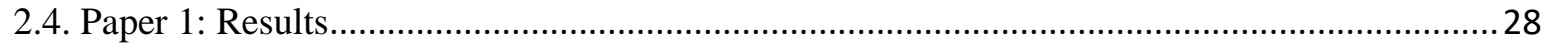

2.5. Paper 1: Contextual and Personal Variables ............................................................................ 30

2.6. Paper 1: Four Emerging Patterns of Nutrition Information Processing ........................................ 35

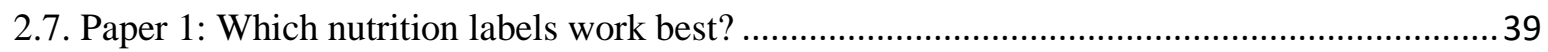

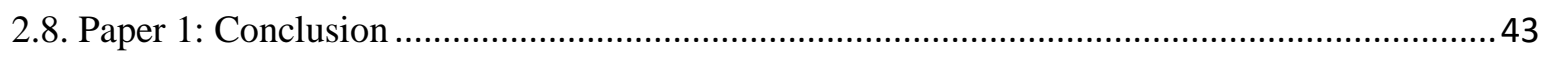

3. Paper \#2: One Label, Two Choices: How Time Pressure and Nutrition Knowledge Impact Use of Front-of-Package Nutrition Labels ...................................................................50

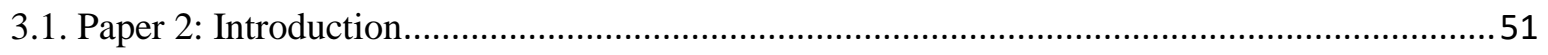

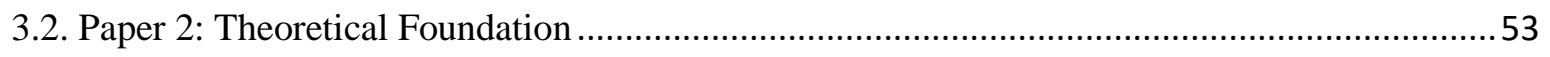

3.2.1 Dual-process theory and use of FOP nutrition label formats ............................................. 53

3.2.2 Impact of nutrition knowledge and time pressure on processing mode ...............................55

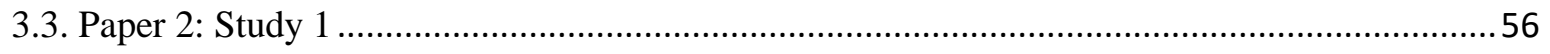

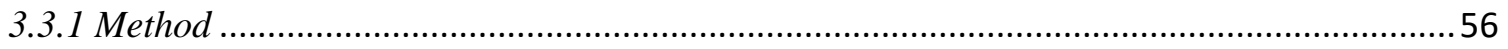

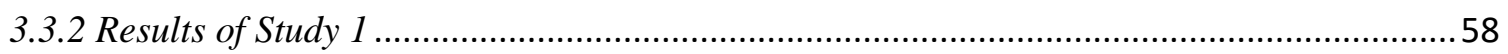

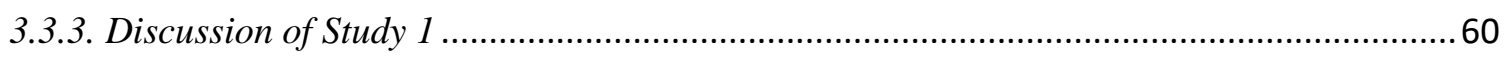

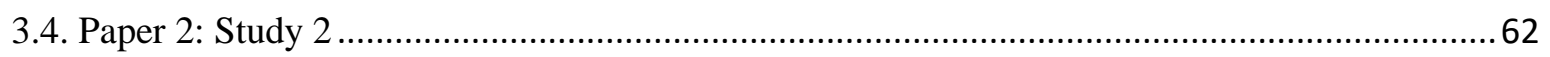


3.4.1 Method.

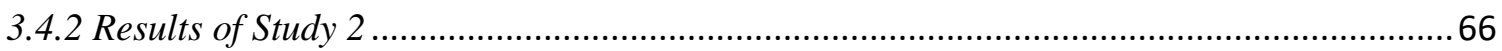

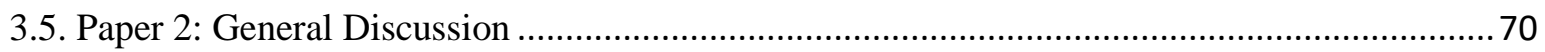

4. Paper \#3: Choosing Fast and Slow: Processing Mode and Consumer Response to FOP Nutrition Label Formats ....................................................................................................................75

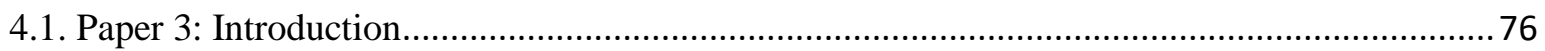

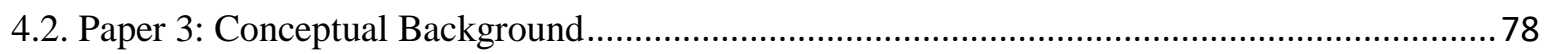

4.2.1. Deliberate and Intuitive Use of Nutrition Information ..................................................... 78

4.2.2. The Mediating Role of Processing Mode ……...................................................................... 79

4.2.3. The Role of Motivation and Nutrition Knowledge …..................................................... 80

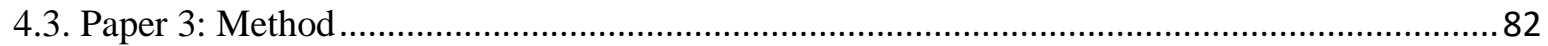

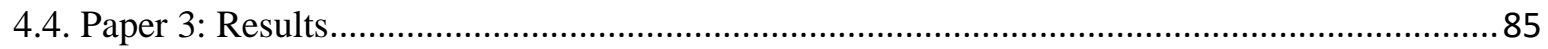

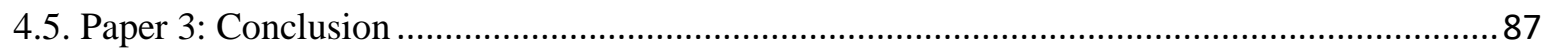

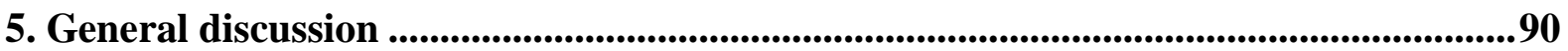

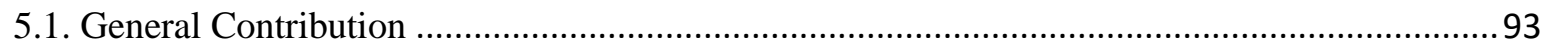

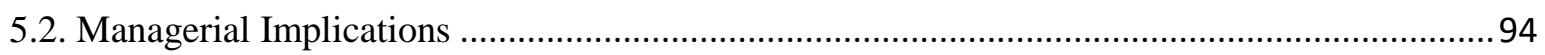

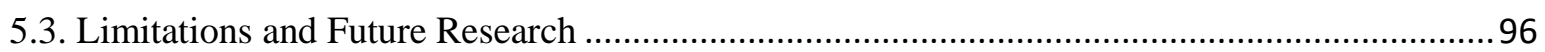

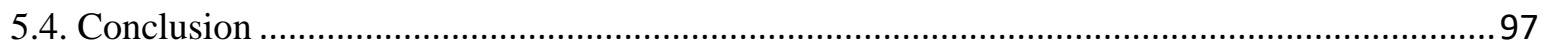

Appendix ........................................................................................................................................................ 100

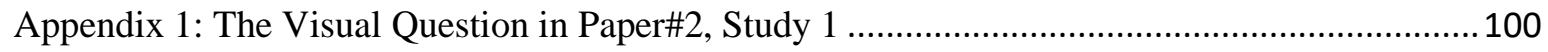

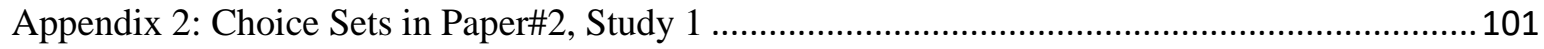

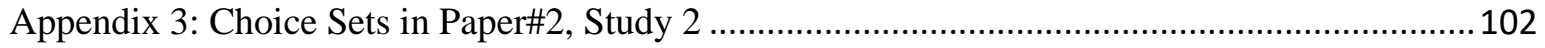

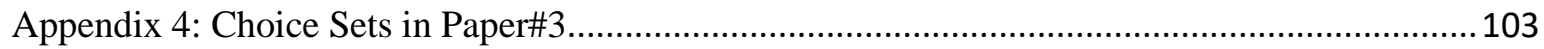

References....................................................................................................................................................106 


\section{List of Figures}

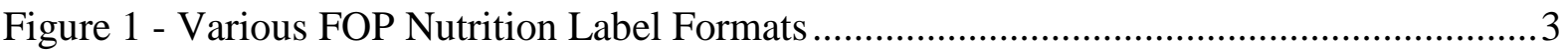

Figure 2 - Conceptual Model of Food Choice Process ...........................................................24

Figure 3 - Flow Diagram of the Literature Search Process ..................................................27

Figure 4 - Extended Model of Processing Information on Nutrition Labels ..........................29

Figure 5 - Interaction of Thinking Style and Nutrition Knowledge (Paper 2, study 1) .........59

Figure 6 - Interaction of Thinking Style and Nutrition Knowledge (Paper 2, study 1) ..........60

Figure 7 - Impact of Nutrition Knowledge and Processing Mode on Choice........................67

Figure 8 - Impact of Nutrition Knowledge and Processing Mode on Choice (study2, choice set 2)

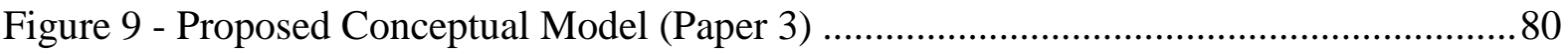

Figure 10 - Effect of FOP Nutrition Label Formats and Motivation on Processing Mode ..... 86 


\section{List of Tables}

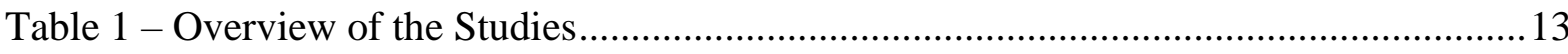

Table 2 - Data, Sample, and Methodology of the Studies................................................... 15

Table 3 - Key Words Used in the Electronic Literature Search .........................................26

Table 4 - Criteria for Identifying the Dominant Processing System ...................................28

Table 5 - Integrative Framework for the Situational Processing of Nutrition Labels ............ 40

Table 6 - Description of the three choice sets in paper 2 , study 1 .....................................58

Table 7 - Stimuli Profile in terms of deliberate versus intutive cues. (in each pair, the

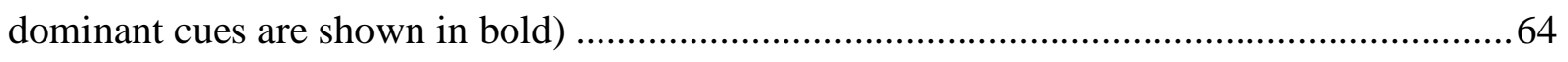

Table 8 - Mediating role of processing mode for the effect of time pressure on choice

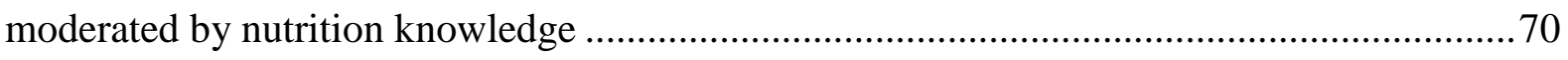




\section{General Introduction}

\subsection{Relevance}

A recent report from the WHO (World Health Organization 2015) warns of increasing obesity rates, revealing that obesity worldwide has nearly tripled since 1975, with more than 1.9 billion overweight or obese. Overweight and obesity are linked to more deaths worldwide than underweight is. Diabetes, heart disease, stroke, and certain cancers are attributable to overweight and obesity. It has been demonstrated that the increased production of processed food, rapid urbanization, and changing lifestyles have led to a shift in dietary patterns (World Health Organization 2015). For example, consumers tend to choose more foods that are high in energy, fats, free sugars, or salt/sodium, while many have an inadequate intake of fruit, vegetables, and dietary fiber. Overweight and obesity, as well as their related diseases, are largely preventable. Consuming a healthy diet on a daily basis helps prevent obesity and malnutrition.

Consumers' dietary patterns are influenced by many interrelated factors and complex interactions, such as individual preferences and beliefs, cultural traditions, as well as environmental, social, and economic aspects. Thus, promoting a healthy diet requires the involvement of multiple sectors, such as policymakers, government, and the public and private sectors. For example, policymakers attempt to reduce the general intake of risky nutrients (such as sugars, salt, and fat) through a range of public health interventions including food and nutrition labeling, consumer education, and marketing regulations for food and non-alcoholic beverages that are high in risky nutrients. Implementing these interventions requires communication regarding public health and nutrition. 
One way of incorporating these interventions in daily life is to provide consumers with supportive nutritional information to guide food choices. By providing information to consumers, nutrition labels can contribute to achieving public health objectives and preventing obesity and overweight. Nutrition labels aim to assist consumers by providing them with information to help for making healthy food choices (Emrich et al. 2015; Helfer and Shultz 2014). Nutrition labeling is defined as "an attempt to provide consumers, at the point of purchase, with information about nutritional content of individual food products, in order to enable consumers to choose nutritionally appropriate food" (Grunert and Wills 2007). Nutrition labels aim to facilitate the food decision-making process (Cowburn and Stockley 2005) by informing consumers about the nutritional benefits and costs afforded by a particular food item (Rothman, Sheeran, and Wood 2009) while preserving freedom of choice (Grunert, Bolton, and Raats 2012). Front-of-package (FOP) nutrition label formats communicate nutrition information through their prominent placement on the front of food packages (Talati et al. 2016).

In 1990, the Nutrition Labeling and Education Act (NLEA) (Public Law 101-535) was established in the United States. This law gives the Food and Drug Administration (FDA) authority to require nutrition labeling of most foods regulated by the Agency, and to require that all nutrient content claims and health claims meet FDA regulations (U.S. Food \& Drug Administration 1994). Since then, different FOP nutrition labels have been introduced, varying greatly in terms of information content and presentation format (Newman, Howlett, and Burton 2016). For example, the Guideline Daily Amount (GDA) label presents numerical information about the contents' calories, fat, saturated fat, sugar, sodium, and salt in both grams and percentage of daily value. Traffic light labels use colors to display a ranking (i.e. high, medium, or low) of risky nutrients (Hersey et al. 2013). Similarly to the GDA, when employed, the traffic light label appears on all food products (Hodgkins et al. 2012). The traffic light label 
moves beyond traditional information-based approaches by using colors to interpret complicated numeric information for the consumer (Roberto and Khandpur 2014). Summary label formats (e.g., health logo and scoring system and Smart Choices) provide a general evaluation of product healthfulness (Nikolova and Inman 2015). The presence of a health logo quickly communicates the healthfulness of the product without the need for numerical processing at the point of purchase (Hodgkins et al. 2012). Similarly, the Smart Choices icon is a simple and easy-to-use label that provides a summary recommendation on the overall nutritional value of the product (Andrews et al. 2011), whereas the NuVal system computes a summary nutrition score for each food item. The score of this FOP nutrition label ranges from 1 to 100, with higher scores signifying healthier and more nutritious foods (Nikolova and Inman 2015). The examples of common FOP nutrition labels are shown in figure 1.

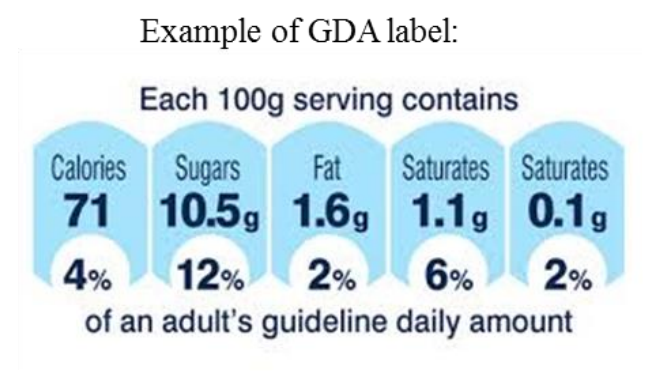

Example of traffic lights label:
Example of summary labels:
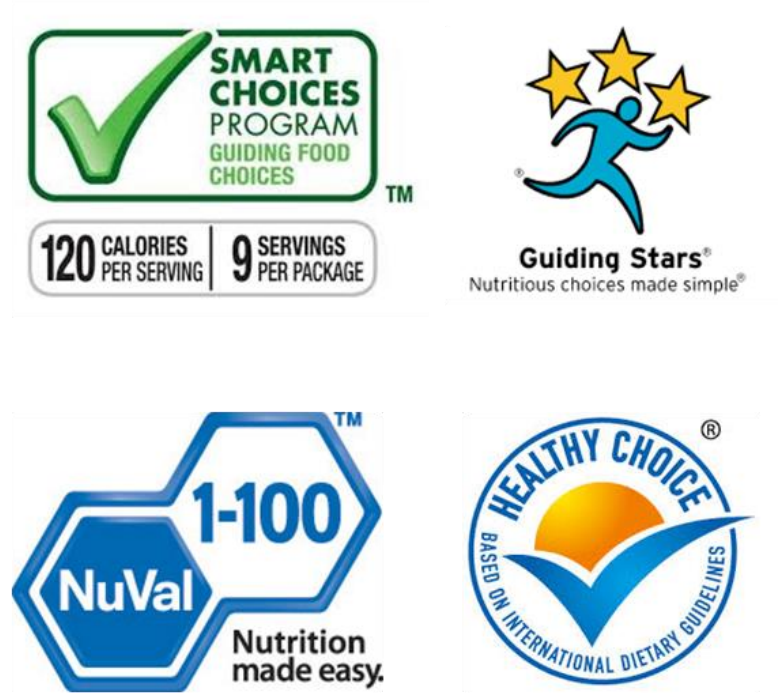

\section{Figure 1 - Various FOP Nutrition Label Formats}

The first generation of nutrition labeling research has shown that nutrition labeling is used widely and yields positive effects on healthy food choice (e.g., Balcombe, Fraser, and Di 
Falco 2010; Basil, Basil, and Deshpande 2009; Burton, Howlett, and Tangari 2009; Koenigstorfer, Groeppel-Klein, and Kamm 2014; van Herpen and van Trijp 2011). These studies rely on a prevailing premise that consumers intensively search and deeply process the nutrition information (e.g., Ares et al. 2012; Aschemann-Witzel et al. 2013; Balasubramanian and Cole 2002). This line of research assumes that consumers process nutrition information deliberately and progress through a sequence of steps that include active search or accidental exposure, perception, liking, understanding, and, ultimately, use of the nutrition label (Becker et al. 2015; Grunert and Wills 2007; Grunert, Wills, and Fernandez-Celemin 2010; Kiesel and Villas-Boas 2013).

However, recent studies have found out that in many purchase situations, consumers lack the cognitive attention, time, and computing capacity necessary to process all nutrition information (Becker et al. 2015; Orquin and Scholderer 2015). Furthermore, many consumers possess neither high nutrition knowledge nor the motivation to use this information for making a healthful choice (Cowburn and Stockley 2005). Therefore, recent literature has questioned the effectiveness of nutrition labels and implied that FOP nutrition labels are not always effective for making healthful choices (e.g., Ares et al. 2012; Boztug et al. 2015; Chandon and Wansink 2012; Grunert, Bolton, and Raats 2012; Hersey et al. 2013; van Kleef and Dagevos 2015; van 't Riet 2012). These studies demonstrate that a label's effectiveness depends on the type of label (Hodgkins et al. 2012), consumers' nutrition knowledge (Drichoutis, Lazaridis, and Nayga 2006; Grunert, Wills, and Fernandez-Celemin 2010), motivation to use nutrition labels (Miller and Cassady 2012; Visschers, Hess, and Siegrist 2010), as well as contextual variables such as number of items in the choice set (Newman, Howlett, and Burton 2016) and time pressure (van Herpen and van Trijp 2011). Previous studies have examined the impact of each of these variables in isolation. However, in a real shopping situation, consumers often encounter the simultaneous interplay of these variables. Specifically, evidence from real 
shopping situations suggests that the effect of nutrition labeling on food choice is not linear but rather a result of the complex and multi-dimensional interaction of different variables (Nikolova and Inman 2015; Saarela et al. 2013).

Given the interplay of consumers' personal variables, contextual variables, and the different FOP nutrition labels in making a food choice, there is a need for an overarching framework that allows for a complete assessment of nutrition label use, their effectiveness for healthy food choice, and the influence of these interplaying variables. Although previous studies have already pinpointed the need for such a comprehensive framework to explain the influence of nutrition labeling on food choice (e.g., Grunert, Bolton, and Raats 2012; Newman, Howlett, and Burton 2016), research has yet to address this necessity conclusively. Therefore, for the first time, this dissertation offers an integrative framework for the effectiveness of FOP labels, relying on the dual-process model to explain when and how the various FOP nutrition labels are processed and used and result in a food choice. The current research suggests situational processing perspective as a novel point of view, representing a fundamental shift in the domain of nutrition labeling research. This integrative framework explains the boundary conditions under which a FOP label is used/not used as well as how the personal and contextual variables impact the way in which a FOP nutrition label is employed.

To shed light on the how and when questions, this dissertation focuses on the underlying process of the effectiveness of FOP labels under consideration of various personal and contextual variables. This dissertation contains three papers that contribute to the theory and practice. The first, as a conceptual review paper, provides a novel view on the effectiveness of FOP nutrition labels based on the dual-process model (Kahneman 2003). The findings of this paper deliver new conceptual insights into the situational processing perspective of FOP nutrition labels. Specifically, the framework offered identifies four situations based on various 
combinations of personal and contextual variables, proposing that in each situation the dominance of one processing mode (intuitive versus deliberate) leads to specific use and consequently the effectiveness of FOP nutrition label for healthful food choice. The second paper provides empirical support for the conceptual framework of the effectiveness of FOP nutrition labels and demonstrates how a single FOP nutrition label is used differently. Specifically, the second paper demonstrates how the interplay of contextual variables (time pressure) and personal variables (nutrition knowledge) leads to a specific processing mode (intuitive versus deliberate) and consequently a specific choice. The third paper focuses on the difference in processing of two types of FOP nutrition labels, namely the GDA and traffic light labels. The findings of these two empirical papers contribute to the practice of the conceptual framework offered in the first paper by examining the mediating role of processing mode (intuitive versus deliberate). Furthermore, they explore the impact of processing mode on the effectiveness of nutrition label formats for healthful food choice, which itself is a function of specific contextual and personal variables.

Overall, the outcome of this dissertation enables policymakers and retailers to identify the situations in which FOP labels are effective for healthful choice and develop relevant strategies for enhancing the use and effectiveness of FOP label formats. The next chapter presents an overview of the relevant nutrition labeling literature and serves to highlight the related concepts of the dual-process model.

\subsection{Literature Review}

To combat obesity issues, nutrition label formats aim to assist consumers by providing them with information to help differentiate between healthy and unhealthy food products (Boztug et al. 2015; Savoie et al. 2013). In nutrition labeling literature, there is a vast amount 
of articles that have attempted to determine whether one FOP nutrition label outperforms another in guiding consumers towards healthy choices (e.g., Maubach, Hoek, and Mather 2014; Siegrist, Leins-Hess, and Keller 2015). Some of these studies have shown that consumers prefer summary nutrition label formats, which offer easy-to-process and fluent nutrition information (Andrews, Burton, and Kees 2011; Berning and Sprott 2011; Nikolova and Inman 2015). In contrast, others reveal that consumers sometimes favor detailed nutrition information because they provide sufficient detailed nutrition information (Bussell 2005). In general, studies report that consumers have conflicting preferences for nutrition information, such as 'simplified and easy to use yet highly detailed' or 'directive yet not pushing the choice' (Grunert and Wills 2007; Hieke and Taylor 2012; Pham, Mandel, and Morales 2016). Therefore, there is disagreement about which type of front-of-package nutrition label format (e.g., GDA, traffic light) is more effective for healthful choice (Hersey et al. 2013).

Studies have shown that preferences for nutrition label formats vary across sociodemographic attributes such as age, gender, income, employment, education, and household size (Campos, Doxey, and Hammond 2011; Drichoutis, Lazaridis, and Nayga 2006; Grunert and Wills 2007; Grunert, Wills, and Fernandez-Celemin 2010; Hieke and Taylor 2012). In addition, consumers' nutrition knowledge and motivation to use nutrition information have profound effects on which type of label format is most effective and how is used (Andrews, Netemeyer, and Burton 2009; Hieke and Taylor 2012; Moorman and Matulich 1993). Moreover, contextual variables such as time pressure and depletion impact the use and effectiveness of FOP nutrition labels. However, nutrition labeling literature lacks a comprehensive explanation of how these personal and contextual variables interact to influence the effectiveness of nutrition label formats on choice. In this dissertation, Paper 1 provides an integrative framework to address this question. 


\subsubsection{Information Processing Perspectives: Dual-Process Model}

Previous nutrition labeling articles have offered classical information processing models to explain the use and effectiveness of FOP nutrition labels. These information processing models have mainly been concerned with interpersonal differences in cognitive outcomes, such as attention, acquisition, and encoding of nutrition information (Bialkova et al. 2014; Cowburn and Stockley 2005; Hersey et al. 2013). These classical models include the processes of need recognition, pre-purchase search, and evaluation of alternatives (van der Merwee et al. 2010). However, recent findings in food choice literature imply that when faced with time pressure, distraction, and stress, consumers often skip these sequential processes (Hieke and Taylor 2012; Schulte-Mecklenbeck et al. 2013), relying instead on the fast and frugal heuristics (Gomez 2013; Jacquier et al. 2012; Scheibehenne, Miesler, and Todd 2007). When making food choices, only a minority of consumers actively search for and use nutrition labels (Chandon and Wansink 2012) or even read nutrition information on packages (Borgmeier and Westenhoefer 2009). These findings are compatible with the principles of the dual-process model of choice (Kahneman 2003).

While the standard information processing approach essentially assumes a unitary decision process, dual-process approach distinguishes between two underlying cognitive processes: one automatic and heuristic-based and the other controlled and subject to reasoning (Chance, Gorlin, and Dhar 2014; Kahneman 2011; Muller and Prevost 2016). Importantly, the dual-process model integrates automatic response and careful deliberation (Chance, Gorlin, and Dhar 2014). Specifically, this model distinguishes between two modes of thinking or processing - "System 1" and "System 2" (Kahneman and Frederick 2005) - to portray intuitive and deliberate processes, respectively. Particularly relevant for the present research is that the cognitive processes adopted by Systems 1 and 2 are different (Kahneman 2003, 2011). System 1 is heuristic-based in nature; it prefers a dominant option that stands out in a choice set. 
However, it can run into difficulty proposing a choice due to, for example, low fluency or lack of a dominant option (Dhar and Gorlin 2013; Kahneman 2011). Contrary to System 1 processing, which is rapid, automatic, and nonconscious, System 2 is slow, deliberate, conscious, and controlled (Dhar and Gorlin 2013). Its processing relies on the comparison of attributes' values and chooses in line with the goal to justify its choice. Specifically, System 2 makes a choice by using either heuristics or deep processing, depending on time available, processing capacity, the level of accuracy desired, and fatigue (Dhar and Gorlin 2013). Taken altogether, System 1 processing usually applies appeal-based heuristics, whereas System 2 processing applies either reason-based heuristics or deep processing. Furthermore, System 1 processing corresponds with intuitive processing, while System 2 processing is associated with deliberate processing.

Consistent with the dual-process model, recent articles rely on the concept of heuristic processing to explain the role of FOP labels on food choice (e.g., Cohen and Babey 2012; Gomez 2013). For example, Newman, Howlett, and Burton (2016) argue that depending on the context, consumers use FOP nutrition labels heuristically to make a healthful choice. Specifically, when consumers compare different food products at once (comparative choice context), evaluative cues (which provide interpretive information about a product's overall healthfulness) have a greater impact on purchase intention of healthful foods than that of objective cues (which offer specific quantitative information). Other contextual variables such as time pressure also affect the use and effectiveness of FOP nutrition labels. Under time pressure, consumers fail to read all the information in detail, relying instead on heuristics (Newman, Howlett, and Burton 2014; Scheibehenne, Miesler, and Todd 2007; van Herpen and van Trijp 2011). 
Specific personal variables, including motivation and nutrition knowledge, also lead to the heuristic use of FOP nutrition labels (Andrews, Netemeyer, and Burton 2009; Hieke and Taylor 2012). Studies have shown that specific levels of nutrition knowledge lead to heuristic processing of nutrition information. These studies maintain that highly knowledgeable consumers believe they can accurately determine the healthiness of a product, leading them to forego deep processing and rely on key nutrient information (Grunert, Bolton, and Raats 2012; Hess, Visschers, and Siegrist 2012; Hieke and Taylor 2012). Similarly, those with low levels of nutrition knowledge use nutrition information heuristically by focusing on the key nutrient information or relevant nutrition label (Bublitz, Peracchio, and Block 2010), whereas consumers with moderate nutrition knowledge apply it more effectively by processing the information deeply (Miller and Cassady 2012). Contrarily, other studies argue that highly knowledgeable consumers make choice based on detailed nutrition information while less knowledgeable ones rely on heuristics to make food choice (for a review see Miller and Cassady 2012).

In general, the findings of some previous studies have implicitly pinpointed the first insight about the effect of heuristics in the effectiveness of nutrition information and food choice. However, no study has offered a comprehensive model to show how nutrition labels are used (heuristically or deliberately) and when they are effective for making a healthful food choice. In sum, the literature lacks an overarching framework to explain the use of FOP labels under different context variables and personal variables. To address this need, this dissertation proposes applying the situational view to the use and effectiveness of FOP label formats and uses the dual-process model to address the question of which labels under which personal and contextual variables impact food choice. These questions are answered in the three subsequent articles. 


\subsection{Research Outline}

This dissertation is a cumulative thesis and comprises three full papers. The first $-\mathrm{a}$ conceptual review paper providing a framework for the use and effectiveness of nutrition labels - had been published in Nutrition Reviews at the time of submitting this thesis (Sanjari, Jahn, and Boztug 2017). The two subsequent papers, which empirically examine this framework, are independent in terms of research questions and in line in terms of the conceptual basis.

The first paper was initiated with the goal of producing a review paper. However, investigation brought to light a huge disparity and fragmentation in the findings of the nutrition labeling literature, with the studies providing a disjointed picture of the effectiveness of FOP nutrition labels. This picture raises doubts about the effectiveness of FOP nutrition labels in all shopping situations, which have yet to be systematically allayed. After reviewing the findings of nutrition labeling literature, a systematic pattern of results compatible with the principles of dual-process modeling in choice literature appeared (see Kahneman 2011). By integrating the findings of previous papers and the dual-process model, we developed an integrative framework to explain when and how FOP nutrition labels are used and effective for healthful food choice. Specifically, we conducted a systematic review to identify food purchase situations and provide insights about consumers' responses to the FOP nutrition labels. This paper also links these insights with the effectiveness of various FOP nutrition label formats.

The second and third papers provide empirical evidence based on the dual-process model to support the proposed framework. The second paper focuses on how a single FOP nutrition label format (i.e., traffic light) can be used depending on the personal and contextual variables at play. The third paper uncovers the underlying processes to address the question of when each of the FOP nutrition label formats (i.e., GDA and traffic light) is more effective for healthy food choice. All three papers of this research project rely on the dual-process model to explain 
the use and effectiveness of nutrition labels. Table 1 summarizes the key interests, research questions, and contributions of the studies. The methodological attributes of these studies are presented in Table 2 .

These three papers contribute to the nutrition labeling literature by offering an overarching framework to explain how FOP nutrition labels are used and impact food choice. The results extend knowledge in this field in several ways: First, they provide insight into the mechanism underlying the impact of FOP nutrition label on choice. Furthermore, the findings explicitly explain how consumers' processing modes influence the effectiveness of different nutrition label formats. Second, they clarify how contextual variables and personal features lead to activation of a processing mode and thus impact food choice. Finally, the results herein address the disparity in the findings of the literature about how nutrition label format affects the choice. 
Table 1 - Overview of the Studies

\begin{tabular}{|c|c|c|c|c|}
\hline Papers & Key Interest & Research Questions & Key Findings & Contributions \\
\hline $\begin{array}{l}\text { \#1: Dual-process } \\
\text { Theory and } \\
\text { Consumer Response } \\
\text { to Front-of-Package } \\
\text { Nutrition Label } \\
\text { Formats }\end{array}$ & $\begin{array}{l}\text { - Systematically reviewing } \\
\text { the articles in food choice } \\
\text { literature. } \\
\text { - Developing an integrative } \\
\text { framework for assessing } \\
\text { FOP nutrition label } \\
\text { format effectiveness. } \\
\text { - Suggesting a situational } \\
\text { processing perspective to } \\
\text { examine effectiveness of } \\
\text { FOP labels. }\end{array}$ & $\begin{array}{l}\text { When (in which } \\
\text { situations) are nutrition } \\
\text { label formats effective } \\
\text { in fostering healthy } \\
\text { food choice? } \\
\text { - How are FOP nutrition } \\
\text { labels processed and } \\
\text { used? }\end{array}$ & $\begin{array}{l}\text { - Consumers are likely to use } \\
\text { nutrition label formats in } \\
\text { different ways. } \\
\text { - Effectiveness of nutrition label } \\
\text { formats is influenced by the } \\
\text { consumer's dominant } \\
\text { processing system, which is a } \\
\text { function of specific contexts } \\
\text { and personal variables (e.g., } \\
\text { motivation, nutrition } \\
\text { knowledge, time pressure, and } \\
\text { depletion). }\end{array}$ & $\begin{array}{l}\text { This review article offers } \\
\text { an integrative framework } \\
\text { for understanding how } \\
\text { consumers use FOP } \\
\text { nutrition labels. } \\
\\
\text { - While a nutrition label } \\
\text { format may lead to a } \\
\text { healthier choice in one } \\
\text { situation, its presence in } \\
\text { another situation may lead } \\
\text { to undesirable outcomes } \\
\text { (such as ignorance, } \\
\text { conflict, or bias). }\end{array}$ \\
\hline $\begin{array}{l}\text { \#2: One Label, Two } \\
\text { Choices: How Time } \\
\text { Pressure and } \\
\text { Nutrition Knowledge } \\
\text { Impact Use of Front- } \\
\text { of-Package Nutrition } \\
\text { Labels }\end{array}$ & $\begin{array}{l}\text { - Empirically examining } \\
\text { the various usages of one } \\
\text { label depending on } \\
\text { consumers' processing } \\
\text { modes. } \\
\text { - Investigating consumers' } \\
\text { responses to the FOP } \\
\text { nutrition labels when } \\
\text { facing conflicting } \\
\text { heuristics, i.e., packaging } \\
\text { cues and FOP label } \\
\text { heuristics such as green } \\
\text { light. }\end{array}$ & $\begin{array}{l}\text { - How does one label } \\
\text { impact food choice in } \\
\text { different situations } \\
\text { (depending on time } \\
\text { pressure and nutrition } \\
\text { knowledge)? }\end{array}$ & $\begin{array}{l}\text { - High time pressure leads to a } \\
\text { more intuitive processing mode } \\
\text { and choice based on packaging } \\
\text { cues, whereas low time } \\
\text { pressure leads to a more } \\
\text { deliberate processing mode and } \\
\text { choice based on nutrition } \\
\text { information. } \\
\text { - Highly knowledgeable } \\
\text { consumers with no time } \\
\text { pressure are more likely to } \\
\text { make a choice based on } \\
\text { nutrition information, whereas } \\
\text { those under high time pressure } \\
\text { are more likely to make a } \\
\text { choice based on heuristic cues. }\end{array}$ & $\begin{array}{l}\text { - Different uses of one FOP } \\
\text { nutrition label are } \\
\text { explained by processing } \\
\text { mode, which itself is a } \\
\text { function of nutrition } \\
\text { knowledge and time } \\
\text { pressure. } \\
\text { - Low nutrition knowledge } \\
\text { has a detrimental effect on } \\
\text { choice, even in deliberate } \\
\text { processing mode. } \\
\text { - Under high time pressure, } \\
\text { consumers rely on } \\
\text { packaging cues when faced } \\
\text { with conflicting heuristics. }\end{array}$ \\
\hline
\end{tabular}




\begin{tabular}{|c|c|c|c|c|}
\hline $\begin{array}{l}\text { \#3: Choosing Fast } \\
\text { and Slow: Processing } \\
\text { Mode and Consumer } \\
\text { Response to FOP } \\
\text { Nutrition Label } \\
\text { Formats }\end{array}$ & $\begin{array}{l}\text { Empirically examining } \\
\text { the effectiveness of } \\
\text { different FOP nutrition } \\
\text { labels depending on } \\
\text { consumers' processing } \\
\text { modes. }\end{array}$ & $\begin{array}{l}\text { How do different FOP } \\
\text { nutrition labels (e.g., } \\
\text { GDA and traffic light) } \\
\text { impact healthy choice? } \\
\\
\text { - What is the effect of } \\
\text { boundary conditions of } \\
\text { nutrition knowledge } \\
\text { and consumers' } \\
\text { motivation? }\end{array}$ & $\begin{array}{l}\text { - Processing mode mediates the } \\
\text { impact of FOP nutrition label } \\
\text { format on healthy choice. } \\
\text { - GDA labels impact healthy } \\
\text { food choice when they are } \\
\text { processed deliberately by } \\
\text { consumers with a medium } \\
\text { level of nutrition knowledge. } \\
\text { In contrast, traffic light labels } \\
\text { impact healthy choice when } \\
\text { they are processed intuitively } \\
\text { by consumers with high } \\
\text { nutrition knowledge. }\end{array}$ & $\begin{array}{l}\text { A consumer's dominant } \\
\text { processing mode, i.e., } \\
\text { intuitive vs. deliberate, } \\
\text { explains his or her response } \\
\text { to a FOP nutrition label } \\
\text { format. } \\
\text { - Consumers' motivation } \\
\text { and nutrition knowledge } \\
\text { lead to activation of a } \\
\text { processing mode and thus } \\
\text { affect food choice. }\end{array}$ \\
\hline
\end{tabular}


Table 2 - Data, Sample, and Methodology of the Studies

\begin{tabular}{|c|c|c|c|c|}
\hline Paper & Data Sources & Time Period & Observations & $\begin{array}{l}\text { Further Methodological } \\
\text { Considerations }\end{array}$ \\
\hline $\begin{array}{l}\# 1 \text { : Dual-process } \\
\text { Theory and Consumer } \\
\text { Response to Front-of- } \\
\text { Package Nutrition } \\
\text { Label Formats }\end{array}$ & $\begin{array}{l}\text { AgEcon, CAB Abstracts, } \\
\text { Emerald, Food Science } \\
\text { and Technology } \\
\text { Abstracts, Oxford } \\
\text { Journals, PubMed, } \\
\text { ScienceDirect, } \\
\text { PsycINFO, Scopus, } \\
\text { Springer Link, Web of } \\
\text { Science (SCI and SSCI), } \\
\text { and Wiley Interscience }\end{array}$ & $\begin{array}{l}\text { Articles published between } \\
\text { January } 1990 \text { and February } \\
2016\end{array}$ & 394 articles & Systematic review \\
\hline \multirow[b]{2}{*}{$\begin{array}{l}\text { \#2: One Label, Two } \\
\text { Choices: How Time } \\
\text { Pressure and Nutrition } \\
\text { Knowledge Impact } \\
\text { Use of Front-of- } \\
\text { Package Nutrition } \\
\text { Labels }\end{array}$} & Nacht des Wissens & February 2017 & 383 participants & Field experiment \\
\hline & $\begin{array}{l}\text { Amazon Mechanical } \\
\text { Turk (MTurk) }\end{array}$ & February 2017 & 369 participants & $\begin{array}{l}\text { Between-subjects online } \\
\text { experiment }\end{array}$ \\
\hline $\begin{array}{l}\text { \#3: Choosing Fast and } \\
\text { Slow: Processing } \\
\text { Mode and Consumer } \\
\text { Response to FOP } \\
\text { Nutrition Label } \\
\text { Formats }\end{array}$ & $\begin{array}{l}\text { Amazon Mechanical } \\
\text { Turk (MTurk) }\end{array}$ & May 2016 & 155 participants & $\begin{array}{l}\text { Between-subjects online } \\
\text { experiment }\end{array}$ \\
\hline
\end{tabular}




\subsection{Abstracts}

Study 1:

Nutrition labeling literature yields fragmented results about the effect of front-of-package (FOP) nutrition label formats on healthy food choice. Specifically, it is unclear which type of nutrition label format is effective across different shopping situations. To address this gap, the present review investigates the available nutrition labeling literature through the prism of dualprocess theory, which posits that decisions are made either quickly and automatically (system 1) or slowly and deliberately (system 2). A systematically performed review of nutrition labeling literature returned 59 papers that provide findings that can be explained according to dual-process theory. The findings of these studies suggest that the effectiveness of nutrition label formats is influenced by the consumer's dominant processing system, which is a function of specific contexts and personal variables (e.g., motivation, nutrition knowledge, time pressure, and depletion). Examination of reported findings through a situational processing perspective reveals that consumers might prefer different FOP nutrition label formats in different situations and can exhibit varying responses to the same label format across situations. This review offers several suggestions for policy makers and researchers to help improve current FOP nutrition label formats.

Study 2:

Prior nutrition labeling studies tried to find one label that best fits all choice contexts. In contrast, recent research offers a situational view to use front-of-package (FOP) labels and proposes that a label fits only in specific contexts. Building on dual-process theory, the current research proposes that a single label might be used in different ways, namely intuitively (by 
relying on inherent heuristic cues) or deliberately (by using detailed nutrition information) leading to different choices. Within two studies, we examined the interplay of time pressure and nutrition knowledge on processing mode (intuitive and deliberate) and the use of FOP labels. Interestingly, the findings confirm that depending on nutrition knowledge and time pressure, the detailed nutrition information or heuristic cues (e.g., colors on Traffic light label or packaging cues) are used. However, there are situations in which consumers use detailed information. In these situations, they are less vulnerable to health halos.

Study 3:

Studies have reported mixed results on whether a simplified label e.g., traffic light label is easier to interpret and more influential for healthy choice than a more complex one e.g., GDA (Drescher, Roosen, and Marette 2014; Hersey et al. 2013). This research empirically examined how consumers' processing mode impacts the effect of FOP nutrition label formats e.g., GDA and Traffic light labels on healthy food choice. We also investigate how consumers' personal features i.e. nutrition knowledge and motivation to read the labels impact their processing mode. The findings of this study empirically showed that processing mode mediates the impact of FOP nutrition label format on healthy choice. Specifically, consumers make a healthy choice by processing the GDA label deliberately and processing the Traffic light intuitively. The findings declared that GDA label impacts healthy food choice when it is processed deliberately by consumers with high motivation and a medium level of nutrition knowledge. On the other hand, the Traffic lights label impact healthy choice when it is intuitively processed by consumers with high motivation to read the label and high nutrition knowledge. 


\section{Paper \#1: Dual-process theory and consumer response to front-of-package nutrition label formats}

(With Steffen Jahn, and Yasemin Boztug) ${ }^{1}$

A prior version of the manuscript was presented as:

- Why One Does Not Fit All: Towards an Integrative Framework of Nutrition Label Formats Effectiveness. EMAC Doctoral Colloquium, Oslo, Norway. 2016, (paper and poster).

This article was submitted to the Nutrition Reviews in September 2016 and has been accepted for publication in Nutrition Reviews Published by Oxford University Press.

- Sanjari, S. Setareh, Steffen Jahn, and Yasemin Boztug (2017), "Dual-process theory and consumer response to front-of-package nutrition label formats," Nutrition Reviews, 75 (11), 871-82.

https://doi.org/10.1093/nutrit/nux043

\footnotetext{
${ }^{1}$ This paper was created in cooperation with the listed co-authors. Mr. Jahn and I equally contributed to this paper. I was responsible for the literature review, the theoretical foundation, the methodology, and the analysis.
} 


\section{Dual-process Theory and Consumer Response to Front-of-Package Nutrition Label Formats}

\subsection{Paper 1: Introduction}

The Nutrition Labeling and Education Act of 1990 (Public Law 101-535) was expected to reduce unhealthy food intake and obesity. However, with the number of obese adults more than doubling between 1980 and 2014 (World Health Organization 2015), this expectation was not met. This disparity raises some doubt about the effectiveness of nutrition labeling as a policy tool. Front-of-package (FOP) nutrition label formats are a policy tool that facilitates the food choice process at the point of purchase by providing consumers with information about the nutrition content of individual food products (Boztug et al. 2015; Cowburn and Stockley 2005; Grunert and Wills 2007; Siegrist, Leins-Hess, and Keller 2015). However, research that has examined nutrition label effectiveness is inconclusive and implies that nutrition information does not always promote healthier diets (Drichoutis, Lazaridis, and Nayga 2006; Grunert, Bolton, and Raats 2012; Hersey et al. 2013; van Kleef and Dagevos 2015; van 't Riet 2012). For example, evidence exists that FOP nutrition labeling has only a small effect on healthy choices (Boztug et al. 2015; Orquin and Scholderer 2015). Even the literature that has found a positive impact is not consistent about which nutrition label format (eg, guideline daily amount (GDA), traffic light system, scoring systems, health logo) works best (Balcombe, Fraser, and Di Falco 2010; Barreiro-Hurlé, Gracia, and de-Magistris 2010; Basil, Basil, and Deshpande 2009; Burton, Howlett, and Tangari 2009; Hassan, Shiu, and Michaelidou 2010). Specifically, some studies found that consumers have conflicting preferences for nutrition 
information such as "simplified and easy to use yet highly detailed" or "directive yet not pushing the choice (Grunert and Wills 2007; Hieke and Taylor 2012; Pham, Mandel, and Morales 2016).”

It is unclear in which situations nutrition label formats are effective at fostering healthy food choice. What is known, however, is that nutrition label effectiveness varies across sociodemographic segments (such as age, gender, income, employment, education, and household size; Campos, Doxey, and Hammond 2011; Drichoutis, Lazaridis, and Nayga 2006; Grunert, Wills, and Fernandez-Celemin 2010, Hieke and Taylor 2012; Siegrist, Leins-Hess, and Keller 2015); it also depends on consumers' motivation and ability to interpret nutrition information (Andrews, Netemeyer, and Burton 2009; Hieke and Taylor 2012; Moorman and Matulich 1993). It has been argued that consumer perspectives have received too little consideration in the development and implementation of FOP nutrition label formats (Szanyi 2010; van Kleef and Dagevos 2015). Despite the need for an overarching framework that allows for a complete assessment of nutrition label (format) effectiveness, the results of research performed to date lead to a fragmented knowledge.

This article reviews the literature according to a framework that builds on Kahneman's description of the dual-process theory of mental processing, which involves system 1 (thinking quickly and automatically) and system 2 (thinking slowly and deliberately) (Kahneman 2011). The present literature review was conducted to identify food purchase situations that activate these two systems and to link these insights with the benefits of various FOP nutrition label formats. In doing so, the review offers a systematic approach for assessing FOP nutrition label format effectiveness. Importantly, the framework offered here suggests that under certain conditions (eg, high amounts of nutrition knowledge or time pressure), label formats that trigger heuristic information processing can be effective in fostering healthy food choices (thus 
providing an explanation for some empirical findings, such as the improved performance of the Green Tick label over the 5-Color Nutrition Label among those 18-30 years of age, Kiesel and Villas-Boas 2013). Heuristics, which are commonly defined as cognitive shortcuts or rules of thumb that simplify decisions, represent a process of substituting a difficult question with an easier one (Kahneman 2011).

\subsection{Paper 1: Nutrition Label Use and Dual-Process Theory}

Traditionally, nutrition label use has been examined according to the standard model of information processing (Grunert and Wills 2007; Grunert, Bolton, and Raats 2012; Hersey et al. 2013; van Kleef and Dagevos 2015). This line of research assumes that consumers process nutrition information deliberately and progress through a sequence of steps that include active search or accidental exposure, perception, liking, understanding, and, ultimately, use of the nutrition label (Becker et al. 2015; Grunert and Wills 2007; Grunert, Wills, and FernandezCelemin 2010; Kiesel and Villas-Boas 2013; van der Merwee et al. 2010). In this sense, standard information-processing models suggest that optimal food choice is only guided by the nutrition labels provided if consumers have specific skills (eg, nutrition knowledge) and characteristics (eg, motivation, desire, interest) (Andrews, Netemeyer, and Burton 2009; Bublitz, Peracchio, and Block 2010; Burton and Kees 2012; Chance, Gorlin, and Dhar 2014; Drescher, Roosen, and Marette 2014; Gomez 2013; Guthrie, Mancino, and Lin 2015; Jacquier et al. 2012; Maubach, Hoek, and Mather 2014; Muller and Prevost 2016; Nikolova and Inman 2015; Roberto and Khandpur 2014; Schulte-Mecklenbeck et al. 2013; Scheibehenne, Miesler, and Todd 2007; Vanhouche and van Osselaer 2009).

In many food purchasing situations, however, these conditions are only partially satisfied. For example, consumers often lack cognitive attention, time, and computing capacity 
(Bublitz, Peracchio, and Block 2010; Guthrie, Mancino, and Lin 2015; Hieke and Taylor 2012; Schulte-Mecklenbeck et al. 2013). Moreover, the majority of consumers do not have high levels of knowledge and motivation regarding nutrition (Grunert, Bolton, and Raats 2012). Therefore, they sometimes rely on simple, fast, and frugal heuristics to satisfy their most important food preferences without needing to make trade-offs (Drescher, Roosen, and Marette 2014; Gomez 2013; Nikolova and Inman 2015; Scheibehenne, Miesler, and Todd 2007; SchulteMecklenbeck et al. 2013).

Although the use of heuristics has been treated as an undesired occurrence in traditional information-processing approaches (Gomez 2013), a subset of studies show that unconscious choices are not necessarily negatively biased but might also be favorable (Vanhouche and van Osselaer 2009). In a similar vein, the dual-process view distinguishes between 2 underlying cognitive processes: one that is automatic and based on heuristics and another that is controlled and subject to reasoning (Chance, Gorlin, and Dhar 2014; Kahneman 2011; Muller and Prevost 2016). Therefore, consistent with other studies maintaining that food choice is better explained in terms of careful deliberation or automatic response to contextual cues (Jacquier et al. 2012), this review examines the available evidence suggesting that the dual-process theory is useful for explaining food choice in real purchasing situations.

Recent developments in human psychology (Dhar and Gorlin 2013; Kahneman 2003; Kahneman 2011; Stanovich and West 2000) contend that the mind consists of 2 systems of thinking: system 1, which handles intuitive processes, and system 2, which handles deliberate processes (Kahneman 2003; Stanovich and West 2000). This integration of careful deliberation and automatic response to contextual cues is important for the present investigation, as is the difference in the cognitive processes adopted by systems 1 and 2 (Chance, Gorlin, and Dhar 2014; Kahneman 2011; Kahneman and Frederick 2005). System 1 is heuristic in nature and 
involves appeal-based preference for a dominant option that stands out within a choice set. However, sometimes consumers encounter difficulty in making a choice using system 1 processing due to low subject-matter fluency or the absence of a dominant option, for example (Dhar and Gorlin 2013; Kahneman 2011). In such cases, system 2 processing is activated to make a choice based on a comparison of attributes and values, opting for the alternative that is in line with one's goals to justify the choice. Specifically, consumers use system 2 processing to make a choice by using either reason-based heuristics or deep processing, depending on the time available, processing capacity, desired level of accuracy, and fatigue (Dhar and Gorlin 2013).

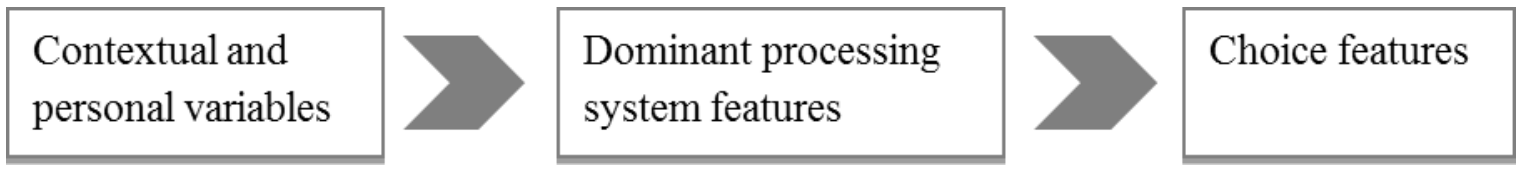

Figure 2 - Conceptual Model of Food Choice Process

Combining the concept of dual-process theory with the findings of food choice studies in the existing literature, this article offers a conceptual model of the food choice process (see Figure 2 - Conceptual Model of Food Choice Process). This model proposes that at any given time a specific processing system (system 1 or 2 ) dominates, leading the consumer to make choices with specific features. When system 1 processing is in control, individuals opt for the more appealing choice. In contrast when system 2 is in control, individuals opt to choose in line with the goal to justify their choice for themselves and to others. This means one selects the option whose features are more compatible with the features of the related processing systems. When a choice features fluency and familiarity, individuals should use system 1 to make a decision, whereas when a choice involves detailed or numerical information, individuals should use 
system 2 to make a decision. Applying this rationale to the context of nutrition labeling, a consumer's response to nutrition label formats depends on the processing system that is dominant, which itself is regulated by a set of personal and contextual variables. More specifically, this article proposes that through different combinations of personal and context variables, a specific FOP nutrition label format is more likely to guide the consumer to a healthy choice.

Previous review articles on the effectiveness of FOP nutrition labels have mainly considered the standard model of information processing (Grunert and Wills 2007; Grunert, Bolton, and Raats 2012; Hersey et al. 2013; van Kleef and Dagevos 2015). This is believed to be the first literature review to examine dual-process theory in relation to nutrition labeling and food choice.

\subsection{Paper 1: Literature Search Method}

The goal of this literature review is to line insights from previous studies about FOP nutrition label effectiveness with the core tenets of dual-process theory. To achieve this goal, articles published between January 1990 and February 2016 that included at least 1 of the key word combinations listed in Table 3 were reviewed. In addition to key words dealing directly with the effectiveness of nutrition labels in food choice, specific key words were used that describe the "nutrition elite" (eg, knowledge and consciousness, Andrews, Netemeyer, and Burton 2009) or situational determinants that affect food choice (eg, stress and depletion, Jacquier et al. 2012). Moreover, key words that hint at information processing modes, such as "deep processing", "elaboration" or "heuristic*" were included. 
Table 3 - Key Words Used in the Electronic Literature Search

\begin{tabular}{ll}
\hline Key word 1 & Key word 2 \\
\hline Nutrition label* & Front-of-pack* \\
Nutrition information & Label use \\
Nutrition knowledge & (Food) choice \\
Nutrition conscious* & Information processing \\
Nutrition motivation & Deep processing \\
Dietary concern & Elaboration \\
Time pressure & Heuristic* \\
Stress & \\
Depletion & \\
Fatigue & \\
\hline
\end{tabular}

The following English-language, peer-reviewed scientific databases were searched: AgEcon, CAB Abstracts, Emerald, Food Science and Technology Abstracts, Oxford Journals, PubMed, ScienceDirect, PsycINFO, Scopus, Springer Link, Web of Science (SCI and SSCI), and Wiley Interscience. Because the main focus of this review is FOP nutrition labeling, studies that focused only on menu labeling, back-of-pack labels, or nutrition and health claims were excluded, resulting in a total sample size of 5556 articles. Studies of nutrition labels that are presented on the front of food packages, such as GDA, traffic light system, scoring systems, health logo, and NuVal were eligible for inclusion. A flow chart of the literature selection rationale and process is presented in Figure 3.

In addition to removing duplicates, articles whose findings lacked generalizability to a comprehensive framework were excluded, leaving a total of 394 articles. The excluded studies were confined to a specific region (eg, a rural area of India, Greece, south Italy), a special group of consumers (eg, parents, low-income families, those with allergies, athletes, Hispanics, children, elders), foods with particular features (eg, functional foods, fresh foods, genetically modified foods, organic foods, fortified foods), and foods with special nutrients (eg, sodium, sugar). 


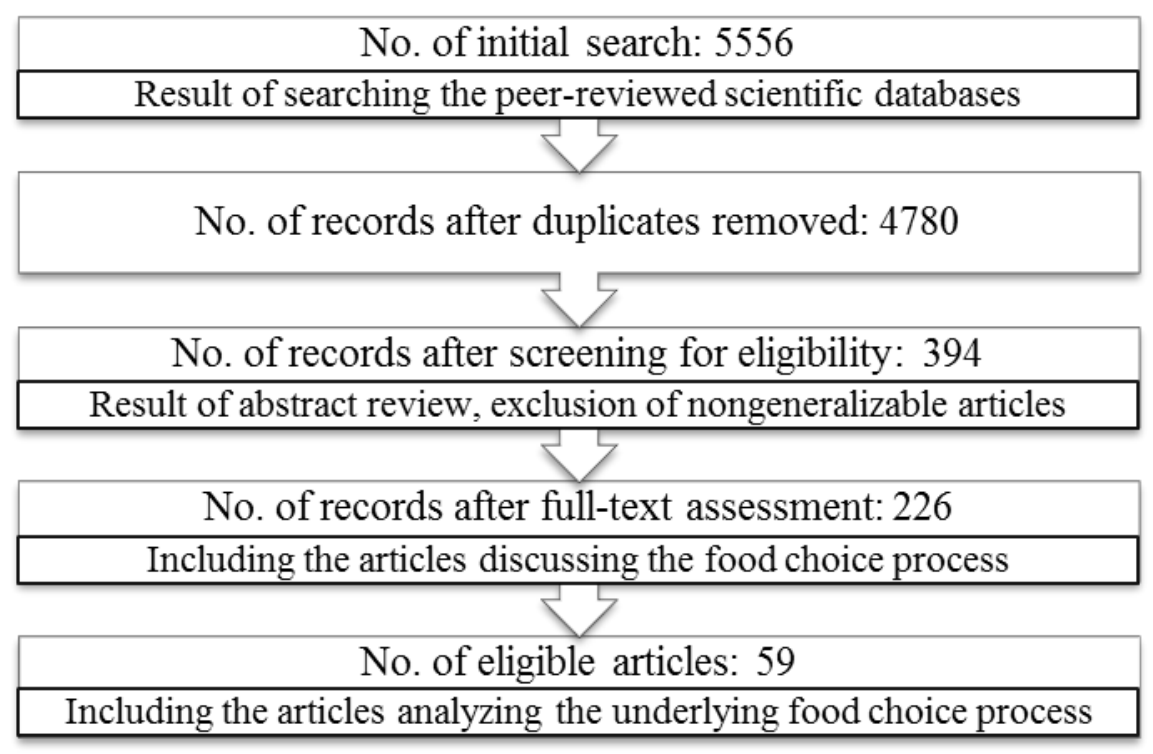

Figure 3 - Flow Diagram of the Literature Search Process

Additional articles were excluded during the full-text assessment, leaving 226 articles that not only studied whether FOP nutrition labeling has an effect on food choice but also studied the underlying mechanism of how nutrition labels work. After thoroughly analyzing the findings of these studies, 59 articles that implicitly provide evidence for the dominance of processing systems were selected. This sample consists of 43 empirical papers, 5 conceptual papers, and 11 review articles.

Among the articles included in the present review, not a single nutrition labeling study referred explicitly to dual-process theory. However, some of the studies included evidence that implicitly supports the intuitive or deliberate processing of nutrition label formats. To investigate how this implicit evidence relates to dual-process theory in the nutrition labeling context, the criteria for the engagement of either intuitive or deliberate processing were derived from the choice literature (see Dhar and Gorlin 2013; Table 4). Table 4 outlines how the 2 processing systems differ by function, choice goal, and cognitive process, as well as how their differences help to construct the criteria for identifying processing systems in the nutrition labeling studies. 
Table 4 - Criteria for Identifying the Dominant Processing System

\begin{tabular}{llll}
\hline $\begin{array}{l}\text { Processing } \\
\text { system }\end{array}$ & $\begin{array}{c}\text { System 1 } \\
\text { (intuitive processing) }\end{array}$ & $\begin{array}{l}\text { System 2 (deliberate } \\
\text { heuristic processing) }\end{array}$ & $\begin{array}{c}\text { System 2 (deliberate } \\
\text { deep processing) }\end{array}$ \\
\hline Function & Appeal-based heuristics & $\begin{array}{l}\text { Reason-based } \\
\text { heuristics }\end{array}$ & Deep processing \\
Choice goal & $\begin{array}{l}\text { Choose an appealing } \\
\text { option }\end{array}$ & Choose a reasonable and justifiable option \\
$\begin{array}{llll}\text { Choice } \\
\text { criteria }\end{array}$ & $\begin{array}{l}\text { - Fluency, familiarity } \\
\text { - Attending to visual, }\end{array}$ & $\begin{array}{l}\text { - Partial comparison } \\
\text { of options }\end{array}$ & $\begin{array}{l}\text { - Engagement of } \\
\text { memory }\end{array}$ \\
& - sensory appeals & $\begin{array}{l}\text { Focus on only a } \\
\text { subset of the } \\
\text { attributes }\end{array}$ & $\begin{array}{l}\text { Total comparison of } \\
\text { options by trading } \\
\text { off attributes }\end{array}$ \\
& & & $\begin{array}{l}\text { Attending to } \\
\text { abstract, numerical } \\
\text { information }\end{array}$ \\
\hline
\end{tabular}

\subsection{Paper 1: Results}

Dual-system literature provides robust evidence supporting the impact of context variables on the dominance of system 1 or system 2 processing (Dhar and Gorlin 2013; Kahneman 2011; Stanovich and West 2000). Parallel to this concept, this review reveals that in the food choice environment a set of personal and contextual variables exists that affects how the nutrition label formats are processed. This article specifically examines the roles of time pressure and depletion as context variables while assessing eating motivation and nutrition knowledge as personal variables because these variables are widely reported on in the nutrition labeling literature. Building upon the findings of the selected studies, Figure 4 illustrates the extended conceptual model. This figure illustrates how the personal and context variables stimulate the 2 processing systems; in turn, the dominance of each processing system determines the effectiveness of specific nutrition label formats. The features of nutrition label formats that make them compatible with intuitive processing, which are a function of system 1 processing, such as familiarity and fluency, are also examined. Fluency is defined as "the metacognitive feeling of ease or difficulty" in a decision task that arises from the choice 
environment and affects the ease with which one can generate an intuitive preference (Dhar and Gorlin 2013).

Contextual and personal variables

\section{Contextual variables:}

\section{- Time pressure:}

(Campos, Doxey, and Hammond 2011; Chalamon and Nabec 2016; Draper et al. 2013; Drichoutis, Lazaridis, and Nayga 2006; Jacquier et al. 2012; Newman, Howlett, and Burton 2014; Silayoi and Speece 2004; Scheibehenne, Miesler, and Todd 2007; Schulte-Mecklenbeck et al. 2013; van Herpen and van Trijp 2011)

\section{- Depletion:}

(Becker et al. 2015; Cohen and Babey 2012; Chalamon and Nabec 2016; Gomez 2013; Guthrie, Mancino, and Lin 2015; Mejean et al. 2013)

\section{Personal variables:}

- Nutrition knowledge:

(Balasubramanian and Cole 2002; Baltas 2001; Barreiro-Hurlé, Gracia, and de-Magistris 2010; Basil, Basil, and Deshpande 2009; Bublitz, Peracchio, and Block 2010; Bucher, Müller, and Siegrist 2015; Burton, Biswas, and Netemeyer 1994; Drichoutis, Lazaridis, and Nayga 2005; Higginson et al. 2002a; Higginson et al. 2002b; Grunert and Wills 2007; Hess, Visschers, and Siegrist 2012; Maubach, Hoek, and Mather 2014; Miller and Cassady 2012; Kees, Royne, and Cho 2014; van Herpen, Seiss, and van Trijp 2012)

\section{- Eating motivation:}

(Aschemann-Witzel et al. 2013; Balasubramanian and Cole 2002; Baltas 2001; Bialkova and van Trijp 2011; Chalamon and Nabec 2016; Guthrie, Mancino, and Lin 2015; Gomez 2013; Hess, Visschers, and Siegrist 2012; Hieke and Taylor 2012; Jacquier et al. 2012; Miller and Cassady 2012; Raghunathan, Naylor, and Hoyer 2006; van Herpen and van Trijp 2011; Visschers, Hess, and Siegrist 2010)
Dominant processing system features

\section{System 1 processing features:}

- Reliance on health-unrelated cues:

(Ares et al. 2014; Balasubramanian and Cole 2002; Cohen and Babey 2012; Gomez 2013; Mai and Hoffmann 2012; Nikolova and Inman 2015; Raghunathan, Naylor, and Hoyer 2006; Silayoi and Speece 2004)

- Reliance on health-related cues: (Balasubramanian and Cole 2002; Bialkova and van Trijp 2010; Campos, Doxey, and Hammond 2011; Gomez 2013; Guthrie, Mancino, and Lin 2015; Hieke and Wilczynski 2012; van Kleef and Dagevos 2015; Watson et al. 2014)

\section{System 2 processing features:}

- Reliance on a subset of attributes:

(Basil, Basil, and Deshpande 2009; Bialkova, Sasse, and Fenko 2016; Bublitz, Peracchio, and Block 2010; Cowburn and Stockley 2005; Draper et al. 2013; Drichoutis, Lazaridis, and Nayga 2005; Higginson et al. 2002a; Higginson et al. 2002b; Mawad et al. 2015; Mai and Hoffmann 2012; Nikolova and Inman 2015)

- Reliance on deep processing:

(Aschemann-Witzel et al. 2013; Ares et al. 2014; Balasubramanian and Cole 2002; Baltas 2001; Drichoutis, Lazaridis, and Nayga 2006; Grunert and Wills 2007; Mai and Hoffmann 2012)
Choice features

FOP nutrition label formats compatible with system 1 vs system 2 processing:

- Fluency of label formats:

(Andrews, Burton, and Kees 2011; Feunekes et al. 2008; Gomez, Werle, and Corneille 2017; Hersey et al. 2013; Hieke and Wilczynski 2012; Muller and Prevost 2016; Newman, Howlett, and Burton 2016)

\section{- Familiarity with label} formats:

(Balcombe, Fraser, and Di Falco 2010; Benn et al. 2015; Bialkova and van Trijp 2010; Drescher, Roosen, and Marette 2014; Moorman 1990; van Herpen, Seiss, and van Trijp 2012) 


\subsection{Paper 1: Contextual and Personal Variables}

Impact of time pressure. Under time pressure, deliberate (system 2) processing is attenuated, and intuitive (system 1) processing is boosted (Dhar and Gorlin 2013; Stanovich and West 2000). Adapting this concept to the nutrition labeling literature, it is expected that under time pressure, consumers will skip deep processing of the nutrition information and only use it heuristically by focusing on a subset of the information.

There is general agreement in the literature that time pressure prohibits consumers from searching, reading, and processing the nutrition labels (Baltas 2001; Campos, Doxey, and Hammond 2011; Drichoutis, Lazaridis, and Nayga 2006; Newman, Howlett, and Burton 2014). In a real-life shopping situation, making comparisons across label formats under time pressure is a frustrating task (Draper et al. 2013) because the limited time does not allow consumers to access the cognitive resources necessary for excessive processing (Jacquier et al. 2012). Therefore, shoppers cope with time pressure by altering their informational search strategy, relying on a heuristic that uses only a fraction of the information available without processing the complete information presented on nutrition labels (Scheibehenne, Miesler, and Todd 2007; Schulte-Mecklenbeck et al. 2013). The ubiquity of time pressure often pushes consumers to quickly inspect FOP nutrition information using shortened interpretation procedures to access only a portion of the information available (Chalamon and Nabec 2016). For example, consumers might briefly peruse the nutrition label of multiple products instead of thoroughly examining the nutrition information of one product (van Herpen and van Trijp 2011). Another possibility is that they rely more on the visual elements (eg, graphics, size and shape of packaging) than on the numerical information, which refers to the affective side of decision making (Silayoi and Speece 2004). In sum, the available evidence supports the notion that consumers under time pressure skip deep processing and apply heuristics when making a choice. 
Impact of depletion. Choice literature provides evidence for the effect of resource depletion on dual-processing systems (Pocheptsova, Labroo, and Dhar 2010). There is robust support for the idea that in the case of resource depletion, system 2 is likely to be dramatically impaired due to a decline in the ability to engage in deliberative processing, leading to the dominance of system 1 processing (Cohen and Babey 2012; Johnson 2008; Kahneman 2003; Pocheptsova et al. 2009). As Cohen and Babey (2012) report, cognitive depletion has a profound influence on food choice. Factors such as fatigue, hunger, an increasing number of alternatives, difficulty in processing the information presented, and multitasking build up the cognitive load and thus impede one's ability to encode external signals (Becker et al. 2015; Cohen and Babey 2012; Guthrie, Mancino, and Lin 2015). As a result, consumers often resort to heuristic-based food choices (Becker et al. 2015; Cohen and Babey 2012).

In the nutrition labeling context, abundant evidence indicates that nutrition information processing is a depleting task that requires a high level of cognitive resources (Gomez 2013). Furthermore, the cognitive workload (depletion) leads to the perception of labels as being complex (Mejean et al. 2013) or confusing (Becker et al. 2015), which might cause consumers to change their response to label formats. For example, one might process nutrition information only partially or rely on heuristic cues to simplify the choice task (Chalamon and Nabec 2016; Cohen and Babey 2012; Guthrie, Mancino, and Lin 2015).

Impact of nutrition knowledge. Nutrition knowledge refers to knowledge of concepts and processes related to nutrition and health (Miller and Cassady 2012), including caloric knowledge and health and obesity consequences knowledge (Andrews, Netemeyer, and Burton 2009). The degree of a consumer's nutrition knowledge substantially moderates the effect of the FOP nutrition label format on label use and healthy choice (Kees, Royne, and Cho 2014).

The findings of the studies reviewed reveal that highly knowledgeable consumers 
believe they know with certainty which product to choose (Bublitz, Peracchio, and Block 2010), leading them to skip deep processing and rely purely on simple calculations and a comparison of key nutrient information (Baltas 2001). Highly knowledgeable consumers appear to care more about certain types of nutrition information-namely, negative nutrients such as saturates and sugar (Balasubramanian and Cole 2002; Basil, Basil, and Deshpande 2009). Similarly, those with low levels of knowledge but high motivation rely on the same heuristics by focusing on the key nutrient information or relevant nutrition label (Bublitz, Peracchio, and Block 2010). Although consumers with low knowledge levels use similar criteria to those used by highly knowledgeable people to evaluate the healthiness of foods (Bucher, Müller, and Siegrist 2015), the way in which they use the range of nutrient information available is different (Higginson et al. 2002a; Higginson et al. 2002b). For example, experts often make judgment decisions heuristically by looking at subcomponents of the nutrients (such as the types of fat, sugar, and sodium) (Higginson et al. 2002a; Higginson et al. 2002b) to minimize sodium and maximize fiber intake (Basil, Basil, and Deshpande 2009), avoid risky nutrients or rely on reference information (Baltas 2001; Grunert and Wills 2007), or attend to extra nutrients, such as fat, vitamins, cholesterol (Drichoutis, Lazaridis, and Nayga 2005), sodium, or saturate (Higginson et al. 2002a). In contrast, consumers with little knowledge tend to neglect the amounts of saturated fat and sodium when making judgments (Bucher, Müller, and Siegrist 2015); instead, they examine the labels to minimize their intake of carbohydrates and maximize protein intake (Basil, Basil, and Deshpande 2009). Highly knowledgeable consumers are more likely to use the informative, complex labels (Barreiro-Hurlé, Gracia, and de-Magistris 2010; Drichoutis, Lazaridis, and Nayga 2005; Hess, Visschers, and Siegrist 2012) because these labels require high levels of nutrition knowledge and numeracy skills (Maubach, Hoek, and Mather 2014). Nevertheless, consumers with high and low levels of nutrition knowledge do not differ in their ability to make a healthy choice when using the nutrition label 
formats (Andrews, Burton, and Kees 2011; Basil, Basil, and Deshpande 2009; Burton, Biswas, and Netemeyer 1994; van Herpen, Seiss, and van Trijp 2012).

On the whole, both groups of consumers use the salient risky nutrients heuristically but in different ways. For example, a highly knowledgeable individual might make a choice by checking sugar and saturates, whereas a less knowledgeable individual may look for calorie and color-coded information. In contrast, previous studies have shown that moderately knowledgeable consumers are more thoughtful with their choices and use their knowledge more effectively by processing the information deeply (Miller and Cassady 2012). Following this reasoning, the findings of the selected articles suggest that low levels of nutrition knowledge stimulate system 1 appeal-based heuristics, whereas high levels of nutrition knowledge are associated with use of system 2 reason-based heuristics. Conversely, when nutrition knowledge is moderate, system 2 deep processing is applied.

Impact of eating motivation. In the nutrition labeling literature, motivation is referred to as “consumers' goal-directed arousal to process nutrition information (Balasubramanian and Cole 2002)." Generally, consumers with health goals are more likely to choose healthy products than consumers with hedonic goals (Gomez 2013; van Herpen and van Trijp 2011). Although some studies refer to this variable as motivation to read the nutrition information, others refer to it as underlying health vs hedonic eating goals. Although these 2 perspectives might seem different, they refer to the same fundamental concept: the presence of health motivation increases one's attention to and use of nutrition labels (Visschers, Hess, and Siegrist 2010), especially when consumers are concerned about specific nutrients (Baltas 2001; van Herpen and van Trijp 2011); likewise individuals with health (hedonic) motivation are more (less) motivated to read the nutrition information.

Previous studies have demonstrated that health-motivated consumers engage in 
complete, deep processing of nutrition information or apply their nutrition knowledge to compare different food labels across a single nutrient (Balasubramanian and Cole 2002; Hieke and Taylor 2012; Miller and Cassady 2012; Visschers, Hess, and Siegrist 2010). The latter strategy (ie, to probe products across one nutrient value) provides evidence that healthmotivated consumers implement heuristics to partially process the information, as argued by Gomez (2013). The reason for this lies in the consumer's limited cognitive capacity, which must be allocated wisely; consumers, therefore, focus on the information most relevant to their shopping goals (Bialkova and van Trijp 2011). Thus, health-motivated consumers use cognitive effort to search and apply the detailed nutrition information, whereas hedonically motivated consumers make less of an attempt to use the available information (Guthrie, Mancino, and Lin 2015).

Accordingly, hedonically motivated consumers are more likely to ignore nutrition label formats when making a food choice (Aschemann-Witzel et al. 2013; Hess, Visschers, and Siegrist 2012; Jacquier et al. 2012; Raghunathan, Naylor, and Hoyer 2006) instead of processing the nutrition information, they look at brand names (Balasubramanian and Cole 2002) and simple, graphic information (Visschers, Hess, and Siegrist 2010). They also apply heuristics such as the availability heuristic (ie, making a choice based upon nutrition information that is easy to recall) and negativity heuristics (ie, relying on information about a limited number of nutrients) to limit the processing of nutrition information to a simpler mental task (Gomez 2013). This conceptualization is also consistent with the findings of Chalamon and Nabec (2016), who maintain that health-motivated consumers actively search for nutrition information (ie, calculating the nutrient content of carbohydrates and protein) and focus on avoiding risky nutrients. Conversely, consumers with hedonic motivation hardly ever read nutrition information — or at least they do not process the nutrition information deeply. These consumers are, however, drawn to labels that reflect excellence, fine taste, product origin, and 
brand reputation (Chalamon and Nabec 2016).

\subsection{Paper 1: Four Emerging Patterns of Nutrition Information Processing}

So far, this review has examined the idea that consumers have differing levels of eating motivation, nutrition knowledge, time pressure, and depletion when making a food choice. Through examination of how these contextual and personal variables impact an individual's processing mode, this article also considers how consumers process nutrition information in different situations. For example, a health-motivated consumer might have medium nutrition knowledge, low time pressure, and low depletion. It can be assumed that the food purchasing situation for this individual is different than one in which motivation is predominantly hedonic, nutrition knowledge is low, and time pressure and depletion are high.

To maintain parsimony, the situations outlined below are characterized by congruent contextual or personal variables. That is, the joint effect of congruent motivation and nutrition knowledge (eg, low nutrition knowledge and hedonic motivation) vis-aa-vis congruent degrees of time pressure and depletion (ie, both are either high or low) are presented instead of considering all possible combinations (eg, no time pressure but high depletion). One reason for limiting the possible combinations in this manner is that the effect of variables related to consumers (personal variables) and variables linked to context (contextual variables) are quite similar. Specifically, personal variables (eg, motivation and nutrition knowledge) have a similar pattern of effects on processing mode. The same holds for contextual variables such as time pressure and depletion. Therefore, 4 prototype situations and their concordant processing styles are presented: (1) ignorance style; (2) glance style; (3) skim style; and (4) elaboration style. 
Situation 1: ignorance style. In situations where quick decision making is encouraged, system 1 processing is more likely to dominate. For the purpose of this review, such situations are referred to as ignorance style because consumers are unlikely to attend to the nutrition information. Rather, they are likely to rely on appeal-based, health-unrelated heuristics to select an intuitively dominant option in a choice set. The articles included in this review reported that consumers sometimes form their judgments based on fluent cues, which refer to the product's appearance and sensory appeal, convenience, and familiarity of shapes, sizes, logos, and brands (Cohen and Babey 2012; Gomez 2013). Hence, consumers in such situations mainly search for health-unrelated cues in the choice set and neglect the nutrition information (Bialkova and van Trijp 2011; Mai and Hoffmann 2012). For example, they look for visually attractive elements (Ares et al. 2014; Nikolova and Inman 2015; Silayoi and Speece 2004), favored taste (Raghunathan, Naylor, and Hoyer 2006), brand name, or lower price (Balasubramanian and Cole 2002; Mai and Hoffmann 2012). Following the previous discussion about the impact of personal and contextual variables, it is concluded that the ignorance style is most pronounced under conditions of high time pressure and high depletion and low levels of nutrition knowledge and hedonic motivation.

Situation 2: glance style. Although the processing style in the previous situation neglected health-related appeals, in other situations, consumers consider health-related information but still apply system 1 heuristics. For example, they might consider intuitive yet reasonable cues, such as graphical and symbolic nutrition labels (Campos, Doxey, and Hammond 2011), a fluent label in terms of presentation style and visual appeal (Guthrie, Mancino, and Lin 2015), labels with easy-to-read display size, or colored FOP labels (Bialkova and van Trijp 2010). Consistent with this idea, Hamlin, McNeill, and Moore (2015) found that the presence of an FOP nutrition label format itself can be used as a heuristic. Consumers in this situation might also apply choice strategies such as reliance on familiar nutrient values 
(Gomez 2013), for example, the declared presence of protein, fiber, calcium, and vitamin $\mathrm{C}$ as well as the declared absence of fat, sugar, and sodium (Hieke and Wilczynski 2012; van Kleef and Dagevos 2015; Watson et al. 2014), or familiar information such as calories (Balasubramanian and Cole 2002). Consumers in this situation just glance at nutrition information.

Drawing from the choice literature, it is proposed that in situations with low time pressure and low depletion consumers have an opportunity to process nutrition information deeply to make a reasonable choice (activation of system 2 processing); however, they might lack nutrition knowledge and health motivation to do so. It is, therefore, concluded that in glance style situations both system 1 processing and system 2 processing are activated and compete to induce the final choice. The simultaneous activation of these systems leads the consumer to look for an option that partially fulfills the considerations of both systems - that is, an intuitive and justifiable option. Therefore, consumers use nutrition labels heuristically in a way that fulfills the requirements of both system 1 processing and system 2 processing.

Situation 3: skim style. As long as consumers develop some skill in using nutrition labels, they are likely to apply system 2 processing. However, there are situations in which consumers merely skim the available information. In this scenario, system 2 processing is modified to involve heuristics by focusing on a subset of nutrition attributes instead of deeply processing all of them to make a justifiable choice. Consistent with this idea, the findings of the selected studies demonstrate that consumers often process nutrition information by using shortcuts to make a justifiable food choice. That is, consumers may skip deep processing and examine nutrition information only partially by comparing alternatives across one or a few nutrient features (Basil, Basil, and Deshpande 2009; Higginson et al. 2002a; Higginson et al. 2002b; Mai and Hoffmann 2012), such as sodium, saturates, cholesterol and vitamins 
(Drichoutis, Lazaridis, and Nayga 2005), protein and carbohydrates (Basil, Basil, and Deshpande 2009), or sugar and fat (Mawad et al. 2015). While performing this partial processing, they may use heuristics, such as avoiding negative nutrients (Cowburn and Stockley 2005) or focusing on specific food categories (Bialkova, Sasse, and Fenko 2016; Bublitz, Peracchio, and Block 2010; Nikolova and Inman 2015). Hence, in this situation consumers are likely to skim the nutrition information to search for a specific piece of nutrition information. These findings provide evidence for the dominance of system 2 reason-based heuristics in this situation.

The likelihood of skim style being employed increases when consumers have high health motivation and low or high levels of nutrition knowledge. When time is limited and depletion is high, consumers are likely to engage in less cognitively taxing processes. For example, they skip text, scan for relevant information, partially compare the alternatives by attributes (Pieters and Warlop 1999), or choose 1 or 2 nutrients as proxies for healthiness on which to base their decisions (Draper et al. 2013).

Situation 4: elaboration style. The fourth situation resembles the one assumed by the standard model of information processing (Grunert and Wills 2007; Grunert, Bolton, and Raats 2012; Hersey et al. 2013; van Kleef and Dagevos 2015). The elaboration style situation is characterized by a deliberate and extensive consideration of nutrition information that involves the engagement of working memory (Dhar and Gorlin 2013). The information-processing tasks that engage the working memory (eg, searching and recalling information) are linked to system 2 deep processing, resulting in making comparisons, concentrating on the numerical and abstract information, and recalling from memory with the aim of justifying one's goals (Dhar and Gorlin 2013).

The findings of studies included in this review indicate that consumers sometimes use 
deep processing when intensively searching for and recalling information (Aschemann-Witzel et al. 2013; Balasubramanian and Cole 2002; Baltas 2001; Grunert and Wills 2007), reading written information and justifying their choices (Ares et al. 2014), or considering a larger set of attributes (Drichoutis, Lazaridis, and Nayga 2006; Mai and Hoffmann 2012). In this "optimal" situation, consumers should hold the relevant personal and context variables to be capable of such deliberate processing. Specifically, they should have acquired medium nutrition knowledge and high health motivation, and they should not suffer from time pressure and depletion. Table 5 summarizes how decision-making situations induce a processing style that in turn affects FOP nutrition label effectiveness.

\subsection{Paper 1: Which nutrition labels work best?}

There is a tendency in nutrition labeling studies to identify the single most effective label format (Aschemann-Witzel et al. 2013; Feunekes et al. 2008; Watson et al. 2014). However, this literature review suggests that, depending on the situation and a consumer's use of system 1 processing or system 2 processing, different types of nutrition label formats can be effective. Consumers process the nutrition label formats that correspond to their dominant processing mode. Nutrition labels differ not only in their visual and informative features but also in their processing features, such as fluency, familiarity, directiveness (see Hodgkins et al. 2012), and fact-vs-criteria basis (see Hamlin, McNeill, and Moore 2015; van Kleef and Dagevos 2015), as well as their compatibility with different situations. 
Table 5 - Integrative Framework for the Situational Processing of Nutrition Labels

\begin{tabular}{|l|l|l|l|l|}
\hline $\begin{array}{l}\text { Components of } \\
\text { the framework }\end{array}$ & Ignorance style & Glance style & Skim style & $\begin{array}{l}\text { Elaboration } \\
\text { style }\end{array}$ \\
\hline $\begin{array}{l}\text { Personal } \\
\text { variables }\end{array}$ & $\begin{array}{l}\text { Hedonic } \\
\text { motivation and } \\
\text { low knowledge }\end{array}$ & $\begin{array}{l}\text { Hedonic } \\
\text { motivation and } \\
\text { low knowledge }\end{array}$ & $\begin{array}{l}\text { Health } \\
\text { motivation and } \\
\text { high knowledge }\end{array}$ & $\begin{array}{l}\text { Health } \\
\text { motivation and } \\
\text { medium } \\
\text { knowledge }\end{array}$ \\
\hline $\begin{array}{l}\text { Contextual } \\
\text { variables }\end{array}$ & $\begin{array}{l}\text { High time } \\
\text { pressure and } \\
\text { depletion }\end{array}$ & $\begin{array}{l}\text { Low time } \\
\text { pressure and } \\
\text { depletion }\end{array}$ & $\begin{array}{l}\text { High time } \\
\text { pressure and } \\
\text { depletion }\end{array}$ & $\begin{array}{l}\text { Low time } \\
\text { pressure and } \\
\text { depletion }\end{array}$ \\
\hline $\begin{array}{l}\text { Processing } \\
\text { system }\end{array}$ & $\begin{array}{l}\text { System 1 } \\
\text { health-unrelated } \\
\text { heuristics }\end{array}$ & $\begin{array}{l}\text { System 1 } \\
\text { health-related } \\
\text { heuristics }\end{array}$ & $\begin{array}{l}\text { System 2 } \\
\text { reason-based } \\
\text { heuristics }\end{array}$ & $\begin{array}{l}\text { System 2 deep } \\
\text { processing }\end{array}$ \\
\hline Label format & No difference & $\begin{array}{l}\text { Criteria-based, } \\
\text { familiar }\end{array}$ & $\begin{array}{l}\text { Directive, } \\
\text { fluent, familiar }\end{array}$ & $\begin{array}{l}\text { Fact-based, } \\
\text { unfamiliar }\end{array}$ \\
\hline
\end{tabular}

Nutrition labeling studies have implicitly identified the features of nutrition labels that correspond to intuitive processing. For example, fluency is a feature associated with system 1 processing. If one considers the ease of comprehending nutrition label formats as a sign of fluency, FOP labeling formats such as the traffic light, summary labels (eg, choice tick and smart choice icon), $\mathrm{NuVal}$, and scoring stars are easier to process (enabling higher fluency). The scoring star displays a ranking of 0 to 3 stars to communicate degrees of healthiness, helping consumers compare products and make reasonable choices (Hersey et al. 2013). NuVal labels compute a summary nutrition score (ranging from 1 to 100) for a food's nutrient content (Nikolova and Inman 2015). These labels are also more effective in reducing the complexity of food choice and driving healthy decisions than the more detailed and complex nutrition labels such as GDA (Andrews, Burton, and Kees 2011; Feunekes et al. 2008; Gomez, Werle, and Corneille 2017; Hersey et al. 2013; Hieke and Wilczynski 2012; Muller and Prevost 2016). Because these labels include less numerical information, processing them is easier and less time-consuming (Siegrist, Leins-Hess, and Keller 2015). Newman, Howlett, and Burton (2016) demonstrate that in a comparative setting (which resembles a real-life purchase situation), the evaluative cues (such as health logo) increase perceived fluency, evaluation, and purchase 
intention (Newman, Howlett, and Burton 2016). Therefore, it is suggested that fluent labels are particularly helpful when system 1 processing or system 2 heuristics are activated (i.e., situation 2 (glance style) or situation 3 (skim style)).

Familiarity is another intuitive processing feature associated with system 1 processing. Consistent with the dual-process model, it is proposed that when system 1 processing dominates, familiar attributes in the FOP nutrition labels contribute to healthy food choice. This is consistent with the findings of previous studies that have shown how familiarity with the nutrition label format leads consumers to skip deep processing and involve easier processing (Bialkova and van Trijp 2010; Kahneman and Frederick 2005; van Herpen, Seiss, and van Trijp 2012). Familiar labels are effective for healthy choice when system 1 or system 2 heuristics dominate.

Familiarity with nutrition labels can be considered in 2 ways: First, some types of nutrition labels are perceived to be inherently familiar because they have borrowed familiar elements from other contexts. For example, healthy tick summary labels represent the correct choice by including the tick sign for correctness. Similarly, color-coded labels such as the traffic light use the familiar meaning of colors to convey a product's healthiness, allowing consumers to use the label heuristically and avoid a shopping basket with risky foods by focusing on excluding those with nutrients highlighted in red or amber (Balcombe, Fraser, and Di Falco 2010; Drescher, Roosen, and Marette 2014; Siegrist, Leins-Hess, and Keller 2015). This type of familiarity reveals the presence of system 1 processing. Second, some nutrition labels are at first unfamiliar, but with frequent exposure and consequently gaining knowledge about the label, familiarity with the label increases over time (Bialkova and van Trijp 2010). This type of familiarity shows the activation of system 2 processing through the process of learning the label cues. Although this familiarity leads to consumer confidence regarding their 
ability to process information, it does not necessarily improve their actual acquisition, elaboration, and comprehension of that information (Benn et al. 2015; Moorman and Matulich 1993).

When consumers are in situation 2 (glance style) or situation 3 (skim style), familiarity with elements of the nutrition label format may foster a heuristic choice. Building on Hodgkins et al. (2012)'s classifications of FOP nutrition labeling based on the degree to which directives are employed and van Kleef and Dagevos (2015)'s classification of fact-based vs criteria-based FOP nutrition labels, several suggestions are made here regarding the use of FOP nutrition labels. These suggestions were arrived at by considering the most directive nutrition label formats (eg, health logo), semi-directive labels (eg, traffic lights, color-coded nutrition tables), and nondirective labels (eg, GDA), while referring to both criteria-based labels (eg, summary labels, traffic-light labels, NuVal, guiding star) and fact-based labels (eg, GDA label). This evaluation revealed that the more directive nutrition label formats are more effective in engendering healthy choice when time pressure and depletion are high. Because consumers in glance style (situation 2) need a quick cue to help them make decisions fast and intuitively, criteria-based label formats that include familiar elements are the most effective in this situation. In such situations, health logos or smart choice labels are the most effective summary indicators for getting consumers to make healthy choices. These labels also act as heuristic cues because they are presented on the healthier variants of foods (Andrews, Burton, and Kees 2011).

In skim style (situation 3), nutrition labels that provide consumers with an opportunity to partially compare the alternatives are the most effective. These include directive labels that represent the specific nutrient information by using familiar or fluent symbols, such as the traffic light, NuVal, and guiding star (van Kleef and Dagevos 2015). Finally, in elaboration 
style situations (situation 4), nutrition labels should include familiar content in a new, unfamiliar structure or design to encourage knowledgeable consumers to read them thoroughly. Fact-based labels, such as nutrition facts panels (Balcombe, Fraser, and Di Falco 2010) and GDA labels (Andrews, Burton, and Kees 2011), allow consumers to process the information deeply, but they require more time for processing (Siegrist, Leins-Hess, and Keller 2015).

\subsection{Paper 1: Conclusion}

The depth of processing of FOP information ranges from a mere glance to reliance on partial information and deep processing (van Herpen, Seiss, and van Trijp 2012). This explains the variable effectiveness of a single nutrition label format across situations. Consistent with this idea, this review concludes that consumers are likely to use nutrition label formats in different ways. It is reasoned that a consumer's processing mode causes them to process nutrition information using a specific processing style. For example, traffic-light labels contain evaluative, interpretive, and preprocessed information with less need for deliberate thought (Ares et al. 2014; Hersey et al. 2013; Maubach, Hoek, and Mather 2014). However, the amount of information provided on traffic-light labels is close to the amount on GDA labels; the difference is that GDA labels also present the information in percentage values. Hence, consumers might use traffic light labels in various ways: they may (1) quickly look for foods without a red light; (2) skim the products for ones that have a green light for fat; or (3) deeply process the information to assess the amount of a risky nutrient such as fat and compare it with their daily intake. This reasoning thus demonstrates that the processing of nutrition information varies across situations and processing styles.

The findings of studies published in the reviewed literature on choice can be explained using the reasoning from the 4 situations in this article. In ignorance style (situation 1), the 
presence of a nutrition label does not substantially impact a consumer's choice, regardless of the type of label provided. This could explain the conflicting results in the literature about the effect of nutrition label formats on food choice (Aschemann-Witzel et al. 2013; Sacks et al. 2011). For example, Aschemann-Witzel et al. (2013) declared that for hedonic motivated consumers, FOP label formats do not impact food choice, and Sacks et al. (2011) showed that the traffic-light label does not impact choice in an online purchasing setting. It also explains those that found no evidence that the new labeling regulation shifted choices to more healthful foods (Boztug et al. 2015; Sacks et al. 2011,).

In glance style (situation 2), consumers might face a conflict because of the discrepancy in choice criteria (appeal-based choice through health-related heuristics). This reasoning clarifies the surprising findings of previous studies that examined choice in conflicting contexts, such as nutrition labels on unhealthy food categories. For example, Berning, Chouinard, and McCluskey (2010) found that the presence of nutrition labels decreased sales of healthy popcorn and increased sales of unhealthy popcorn, and Aschemann-Witzel et al. (2013) found that in a snack choice set, nutrition labels did not increase consumer motivation to read labels. Furthermore, it is argued that consumers are less likely to read the nutrition information when buying unhealthy foods than when buying healthy foods because consumers buying unhealthy foods want to fully indulge and hence avoid looking at any nutrition information (see Talati et al. 2016). This is consistent with studies that show consumers' use of FOP labels differs across food categories (Elshiewy, Jahn, and Boztug 2016; Grunert and Wills 2007; Raghunathan, Naylor, and Hoyer 2006; Talati et al. 2016).

Skim style (situation 3) can explain why consumers make mistakes in their choices. In this situation, consumers use nutrition labels to justify their selections because system 2 processing is activated. However, due to a lack of time and cognitive capacity, they are likely 
to rely on framing of the information and make a biased choice. This might explain how the health halo bias effect occurs as a result of over-reliance on the framing of information (Hamlin, McNeill, and Moore 2015).

Finally, the elaboration style (situation 4) is consistent with studies that reveal deep processing is predominantly used by consumers with moderate nutrition knowledge because high knowledge can act as a barrier to deeply elaborating externally provided information (Bublitz, Peracchio, and Block 2010; Hess, Visschers, and Siegrist 2012).

This review article offers an integrative framework for understanding how consumers use FOP nutrition labels and emphasizes that nutrition label formats are not always effective. Instead, their effectiveness is determined by the consumer's dominant processing systems. Whereas a nutrition label format may lead to a healthier choice in one situation, its presence in another situation may lead to undesirable outcomes (such as ignorance, conflict, or bias). This article reveals that the way a consumer responds to FOP nutrition labels is influenced by a set of personal and contextual variables. This conclusion is consistent with previous studies that imply that the effect of nutrition labels differs depending on the consumer's motivation and nutrition knowledge (Balasubramanian and Cole 2002; Jacquier et al. 2012) and contextual variables (Cowburn and Stockley 2005). The integration of the impact of personal variables and context variables and the examination of their interrelated effects, as reported in this article, add to existing knowledge of nutrition label effectiveness. This article, thus, clarifies how differing levels of these variables alter the processing system and contends that the most effective FOP nutrition label format is the one whose features are compatible with the dominant processing mode of the situation.

This literature review contributes to current research in several ways. First, it answers the question of whether nutrition labeling is effective in encouraging healthier food choices. 
The findings indicate that nutrition labeling is only effective when there is harmony between nutrition label format and the consumer's dominant processing system at the time a choice is made. Second, this review addresses the conflicting findings (Aschemann-Witzel et al. 2013; Berning, Chouinard, and McCluskey 2010) regarding consumer preference for nutrition label formats. The literature indicates that an individual may prefer different nutrition label formats in different situations and may process unique nutrition label formats in various ways. Consumers may construct their preference regarding nutrition labeling on the spot, depending on the purchase environment and the consequent dominant processing system. Therefore, it is necessary not only to improve nutrition labels to fit a variety of situations but also to revise expectations for nutrition labeling.

There are important public policy implications from this review. According to the integrative framework presented here, 3 of the 4 situations involve the use of heuristics without deep processing. Therefore, a greater focus should be placed on improving criteria-based and heuristic labels (eg, the health logo, scoring system, NuVal, and traffic light). There is room for increasing the fluency and attractiveness of summary FOP labels by implementing familiar elements, attractive colors, and fluent terms. Furthermore, traffic lights, scoring systems, and $\mathrm{NuVal}$ can be processed by system 2 processing, which is related to memory; therefore, the use of consistent formats across products would help consumers learn and use them in subsequent purchases. This is in line with the findings of studies conducted in real-world shopping environments (using sales data) that show consumers' shift to purchasing more healthy foods when the same FOP label is consistently applied to all products in a store (Rahkovsky et al. 2013; Sacks, Rayner, and Swinburn 2009; Sacks et al. 2011; Sutherland, Kaley, and Fischer 2010). It would also be beneficial to occasionally apply new elements to or alter the format of the fact-based, nondirective FOP labels (eg, GDA) to motivate consumers to read the nutrition information more deliberately. 
Furthermore, numerical labels are likely ignored on products assessed at the end of a shopping trip (when consumers are under time pressure or are depleted and too fatigued to make a deliberate choice). To address this possibility, one option is to vary the format of nutrition labels based on the product's placement in the supermarket. Moreover, using digital shelf-labeling technologies would allow the more fluent nutrition label formats (compatible for fatigued and depleted consumers under time pressure) to be presented in the afternoon, whereas the more informative labels that aid deliberate decision making could be shown in the morning. For online shopping, allowing consumers to choose which FOP nutrition label format they wish to view could aid their decision making. For example, an option to toggle the labels back and forth could be included in the online shopping environment. Another option for online shoppers is to alter the FOP nutrition labels based on the online shopper's personal information. For example, nutrition knowledgeable consumers, shoppers with special diets, or consumers responsible for shopping for the household are likely to experience higher levels of depletion and, thus, a more detailed nutrition label format would not be suitable. Additionally, consumers with a high workload, bargain hunters, or consumers shopping for special occasions (eg, a party) are more likely to rely on simple, directive FOP nutrition labels because important factors other than healthiness are impacting their decision.

Despite wide diversity in nutrition labeling research, specific areas deserve greater attention. For example, this review found few studies that focused on real choice situations by manipulating time pressure or depletion. More research is needed to investigate the effect of personal variables such as time pressure, distraction, depletion, and fatigue on the consumer's use of nutrition labeling and food purchases. It is also important to examine the interplay of variables such as nutrition knowledge and motivation, rather than only studying their effects independently. Furthermore, there are plenty of studies in the literature that examine the effect of different variables on choice without considering any theory or rationale. It is now necessary 
to go beyond reporting the interrelated variables and elucidate the underlying mechanism of food choice in consumers' cognitive systems.

\section{Acknowledgments}

Author contributions. This review was designed by all authors. S. S. Sanjari and S. Jahn contributed equally across all stages of this research. Y. Boztug extensively reviewed and commented on all previous drafts of the manuscript.

Funding/support. This study is part of S.S. Sanjari's dissertation and is funded by an Erasmus Mundus scholarship (2SAL1302220) under the framework of the SALAM (Study Abroad, Learning and Mobility) project (Grant agreement 2013-2437/001-001).

Disclosure statement. The authors have no relevant interests to declare. 


\section{Paper \#2: One Label, Two Choices: How Time Pressure and Nutrition Knowledge Impact Use of Front-of-Package Nutrition Labels}

(With Steffen Jahn, and Yasemin Boztug) ${ }^{2}$

To be submitted to Journal of Consumer Psychology.

A prior version of the manuscript is submitted to:

- One Label, Two Choices: How Time Pressure and Nutrition Knowledge Impacts Use of Front-of-Package Nutrition Labels. EMAC conference, Glasgow, UK on May 29- June 1, 2018.

- How One Label Leads to Two Food Choices: Investigating the Processing of Front-ofPackage Nutrition Labels. European ACR conference, Ghent, 2018.

\footnotetext{
${ }^{2}$ This paper was created in cooperation with the listed co-authors. I was responsible for the literature review, the theoretical foundation, the hypotheses development, the methodology, and the empirical analysis and developing the paper.
} 


\section{One Label, Two Choices: How Time Pressure and Nutrition Knowledge Impact Use of Front-of-Package Nutrition Labels}

\subsection{Paper 2: Introduction}

Front-of-Package (FOP) nutrition label formats communicate nutrition information through their prominent placement on the front of food packages, with the goal of helping consumers make healthful food choices (Boztug et al. 2015; Emrich et al. 2015; Talati et al. 2016). Since the introduction of the Nutrition Labeling and Education act in 1990 (Public Law 101-535) different FOP nutrition label formats have been introduced, varying in terms of presentation style and information content (Hersey et al. 2013; Newman, Howlett, and Burton 2016). One classification of FOP nutrition labels divides the nutrition labels into two groups, evaluative cues (that provide interpretive information about a product's overall healthfulness) and objective cues (that offer specific quantitative information) (Newman, Howlett, and Burton 2016). Research in nutrition labeling literature focuses on identifying which of these label formats outperform the others in terms of guiding consumers healthful choices (e.g., Aschemann-Witzel et al. 2013; Feunekes et al. 2008). However, the findings of these papers failed to identify one label that fits all shopping situations (for a review see Hersey et al. 2013).

Recent research has offered a situational processing perspective to explain the effectiveness of FOP labels and argues that a label leads to a healthful choice only in specific situations (e.g., Newman, Howlett, and Burton 2016). Specifically, depending on the context, one type of FOP nutrition label outperforms the rest in inducing healthful choice situations (e.g., Newman, Howlett, and Burton 2016; Sanjari, Jahn, and Boztug 2017). For example, Newman, Howlett, and Burton (2014) showed that when consumers comparatively evaluate 
different food products at once, evaluative cues have a larger impact on purchase intention of healthful foods than objective cues. They reason that using objective cues is a time-consuming task, which only complicates the cognitive challenge associated with comparative contexts. This reasoning suggests that in these contexts, consumers do not read the nutrition labels thoroughly but rather rely on the labels that provide evaluative cues.

However, there is evidence that questions the proposition that one label format (e.g., evaluative cues) is helpful for making choices in a comparative context. Previous studies have shown that in a comparative context, not only evaluative cues but also objective cues might lead to healthful choices. For example, nutrition elites (consumers with high nutrition knowledge) effectively use the detailed nutrition information in comparative contexts (Andrews, Netemeyer, and Burton 2009). In addition, it has been shown that when time pressure is absent, consumers prefer using objective information to make a healthy choice. In other words, under severe time pressure, consumers fail to read the detailed nutrition information (Drichoutis, Lazaridis, and Nayga 2006; Newman, Howlett, and Burton 2014).

In this paper, we extend the findings of the study by Newman, Howlett, and Burton (2016) and suggest that depending on time pressure and nutrition knowledge, the use of a label (either evaluative or objective cue) might lead to healthy choice in a comparative context. Our reasoning suggests that depending on time pressure and nutrition knowledge, consumers use a label in different ways, namely intuitively (by relying on inherent heuristic cues) or deliberately (by using detailed nutrition information). This argument is consistent with the dual-process theory and choice literature (Dhar and Gorlin 2013; Kahneman 2003) which states that time pressure leads consumers to look for heuristic cues and rely on intuitive processing; whereas, when no time pressure is present, consumers implement detailed information and rely on deliberate processing to make a healthful choice. In the same way, consumers with high 
nutrition knowledge are more likely to rely on detailed information (Hess, Visschers, and Siegrist 2012), in contrast, less knowledgeable individuals tend to employ heuristic cues (Andrews, Netemeyer, and Burton 2009).

We contribute to extending nutrition labeling literature by investigating the effect of time pressure and nutrition knowledge on information processing, the use of a FOP label and consequently, food choice. Previous studies examined the impact of time pressure and nutrition knowledge in isolation. Drawing from recent conceptual work (Sanjari, Jahn, and Boztug 2017), we empirically examine their interplay.

\subsection{Paper 2: Theoretical Foundation}

\subsubsection{Dual-process theory and use of FOP nutrition label formats}

Consumers use nutrition label information in different ways. Nutrition labeling research has shown that although consumers are expected to thoroughly read the detailed nutrition information (Andrews, Burton, and Kees 2011), they sometimes skip reading this information and rely on heuristic cues (for a review see Sanjari, Jahn, and Boztug 2017). Nevertheless, consumers might use the nutrition labels by relying on graphical and symbolic cues (such as colored lights in Traffic light) (Gomez 2013; Silayoi and Speece 2004). Also, they might look for visually attractive packaging cues (Ares et al. 2014) such as a brand or favored taste (for a review see Chandon 2013).

In order to outline the different ways FOP nutrition labels can be used, we build on dualprocess theory (Dhar and Gorlin 2013; Kahneman 2003) and nutrition labeling literature (Ares et al. 2014; Gomez, Werle, and Corneille 2017; Grunert, Bolton, and Raats 2012; Newman, Howlett, and Burton 2016; Sanjari, Jahn, and Boztug 2017). The dual-process theory asserts that people make choices using two modes of processing, either deliberate processing by relying 
on detailed information or intuitive processing by relying on heuristics (Dhar and Gorlin 2013). Dual-process literature refers to the processing mode as a mental process and defines it as the degree to which the working memory is engaged (Dhar and Gorlin 2013, Kahneman and Frederick 2005). These modes of processing lead to different choices. In the nutrition labeling context, we propose that depending on the processing mode, consumers process the available nutrition information either intuitively or deliberately. This original proposition is based on previous studies showing that consumers sometimes use one label heuristically (e.g., by relying on colors in Traffic lights) (Drescher, Roosen, and Marette 2014; Gomez, Werle, and Corneille 2017; Maubach, Hoek, and Mather 2014), and sometimes use the detailed information (Siegrist, Leins-Hess, and Keller 2015).

Consistent with the concept of processing mode, previous studies have shown that objective labels are more helpful for making a choice in deliberate processing mode and evaluative labels better fit intuitive processing mode (see Newman, Howlett, and Burton 2016). As an example, Traffic light label format has a potential to be used in different ways. Specifically it presents the amount of four critical nutrients (sugars, fat, saturated fat and salt) against standardized nutrition profiles (Drescher, Roosen, and Marette 2014) that communicate nutrients value by using color codes of red (high), amber (medium) or green (low) (Hersey et al. 2013; Siegrist, Leins-Hess, and Keller 2015).

In this research, we propose that depending on the processing mode, the Traffic light label can be used differently resulting in different choices. Unlike most of the previous studies that consider the choice as a healthy-unhealthy variant, we draw on dual process model and consider the choice as an intuitive-deliberate variant. Clearly, we assume that making a choice based on inherent heuristic cues in FOP nutrition labels (such as colors in Traffic light) or packaging cues (such as brand, color, taste) is associated with intuitive choice whereas making 
a choice based on deliberate cues such as nutrition information presented on FOP labels is linked to deliberate choice.

H1: Intuitive processing mode leads to a choice based on packaging cues. Deliberate processing mode leads to a choice based on nutrition information.

\subsubsection{Impact of nutrition knowledge and time pressure on processing mode}

Prior research showed that processing mode is influenced by a set of context variables (e.g., comparative, non-comparative setting, Newman, Howlett, and Burton 2016) or personal variables (e.g., nutrition knowledge, Gomez, Werle, and Corneille 2017). In the current study, we focus on the comparative context and investigate the impact of time pressure and nutrition knowledge on processing mode. Nutrition labeling studies typically confirm the positive direct effect of high nutrition knowledge leading to thoroughly reading the nutrition information (e.g., Andrews, Netemeyer, and Burton 2009; for a review see Miller and Cassady 2012). In contrast, there is evidence showing that highly knowledgeable consumers are too confident about their choice, therefore, skip reading the nutrition information and rely on heuristic cues (Grunert, Bolton, and Raats 2012; Hess, Visschers, and Siegrist 2012; Hieke and Taylor 2012). Relying on dual-process theory, we propose that nutrition knowledge moderates the effect of processing mode on choice. So, we predict:

$\mathrm{H} 2$ : Effect of processing mode on choice is moderated by nutrition knowledge. Intuitive processing leads to more intuitive choice (based on packaging cues) for highly knowledgeable than less knowledge consumers. Contrarily, deliberate processing mode leads to more deliberate choice (based on nutrition information) for highly knowledgeable than less knowledge consumers. 
It has been shown that under time pressure, deliberate (system 2) processing is attenuated, and intuitive (system 1) processing is boosted (Dhar and Gorlin 2013). In the context of food choice, nutrition labeling literature asserts that time pressure prohibits consumers from deeply reading and processing the nutrition labels (Baltas 2001; Drichoutis, Lazaridis, and Nayga 2006; Campos, Doxey, and Hammond 2011; Newman, Howlett, and Burton 2014). Thus they cope with time pressure by relying on a heuristic that uses only a fraction of the information available without processing the information presented on nutrition labels (Schulte-Mecklenbeck et al. 2013). Therefore, we predict:

H3: Processing mode moderates the effect of time pressure on food choice. High time pressure will lead to more intuitive processing mode and intuitive choice (based on packaging cues) for highly knowledgeable consumers rather than less knowledgeable ones. Contrarily, low time pressure will lead to more deliberate processing mode and deliberate choice (based on nutrition information) for highly knowledgeable consumers rather than less knowledgeable ones.

\subsection{Paper 2: Study 1}

\subsubsection{Method}

The purpose of this study was to empirically investigate the interaction of nutrition knowledge and processing mode on choice. To assess the processing mode, we borrowed the concept of thinking style (analytical versus holistic) (from Norenzayan et al. 2002) to represent deliberate and intuitive processing mode. This study recruited 383 participants. We focused on participants' thinking style by using a visual test to differentiate holistic thinkers versus analytical thinkers. All participants were provided with a question sheet that showed two groups of flowers and a "target" flower (see Appendix 1). Then, participants were asked to 
decide which group of flowers the target object belongs to. They could judge the target object to be holistically similar to all members of group 1 (intuitive group) because it shared a large number of features with them, even though no one feature characterized all members of the group. Alternatively, the target object shared a single feature with all category members of Group 2 (deliberate group). Consistent with Norenzayan et al.'s (2002) argument, the choice of group 1 indicates holistic thinkers and choice of group 2 represents analytical thinkers.

After this task, participants were asked to identify the healthier option within three choice sets from real products in the market (first choice set: yogurt chocolates versus buttercookie chocolates; second choice set: strawberry yogurt versus yogurt with $40 \%$ fat; third choice set: yogurt-strawberry chocolate versus raisin and nuts chocolate). The choice sets were selected such that one intuitively looked more healthful however was indeed less healthful according to nutritional values. The nutrition information table on the back-of-package was available.

In addition to the difference between the options in each choice set in terms of nutritional values, each choice set had specific features with regard to packaging cues (see Table 6). In the first and third choice set, two chocolate alternatives were identical in terms of brands and different in flavors and nutrient values. In the third choice set both alternatives had a simplified FOP nutrition label on the package (showing weight per portion (gr), calories per portion and per 100 grams (kj and $\mathrm{kcal}$ ) and share of daily energy per portion (4\%)). Therefore, we expect that participants in intuitive processing mode will rely on packaging cues (package color and flavor) and make an intuitive choice; contrarily individuals in deliberate processing mode will rely on nutrition information to make a deliberate choice. In the second choice set, the yogurt options had different brands, thus we propose that participants in intuitive processing 
mode will choose the strawberry yogurt and individuals in deliberate processing mode are more likely to choose the yogurt with $40 \%$ fat (see Appendix 2).

Table 6 - Description of the three choice sets in paper 2, study 1.

\begin{tabular}{|c|c|c|}
\hline & Intuitive option & Deliberate option \\
\hline \multirow{2}{*}{$\begin{array}{l}\text { Choice set } 1 \\
\text { (Identical brands) }\end{array}$} & Yogurt chocolate & Butter-cookie chocolate \\
\hline & $\begin{array}{l}\text { White package color, Picture of } \\
\text { yogurt }\end{array}$ & $\begin{array}{l}\text { Dark brown package color, } \\
\text { Picture of biscuit }\end{array}$ \\
\hline \multirow[t]{2}{*}{ Choice set 2} & Strawberry yogurt & Yogurt with $40 \%$ fat \\
\hline & $\begin{array}{l}\text { A brand known for fine creamy } \\
\text { products, picture of strawberry }\end{array}$ & $\begin{array}{l}\text { A brand known for organic } \\
\text { products }\end{array}$ \\
\hline \multirow{2}{*}{$\begin{array}{l}\text { Choice set } 3 \\
\text { (Identical brands } \\
\text { and colors) }\end{array}$} & Yogurt-strawberry chocolate & Raisin and nuts chocolate \\
\hline & $\begin{array}{l}\text { Purple package color, Picture of } \\
\text { strawberry and yogurt, } \\
\text { Simplified FOP nutrition label }\end{array}$ & $\begin{array}{l}\text { Purple package color, Picture of } \\
\text { nuts and raisin, Simplified FOP } \\
\text { nutrition label }\end{array}$ \\
\hline
\end{tabular}

We also designed a test to indirectly measure participants' nutrition knowledge. After the choice task, participants were shown five products that had different serving sizes (cola, nuts and raisins snack, chocolate, energy drink (Iso Aktiv), and smoothie) and were asked to guess how many sugar cubes each product contains. We considered the responses as correct if they stated the correct number of sugar cubes, \pm 2 per product. Then we accumulated the correct responses and split them according to the median (median $=1)$. Thus if participants answered no or one question correctly they are in the low knowledge group, but if they answer two or more questions correctly they are in the high knowledge group.

\subsubsection{Results of Study 1}

The result of the first choice set shows that analytical thinkers were more likely to make deliberate choices $(\mathrm{M}=.66)$ than holistic thinkers $(\mathrm{M}=.58 ; \mathrm{F}(2,373)=2.91 ; p<.05)$. The results are consistent with the first hypothesis that holistic thinkers compared to analytical 
thinkers are more likely to use nutrition information to make a deliberate choice. In the first choice set, there is an interaction between the thinking style and nutrition knowledge on choice $(\mathrm{F}(1,376)=4.22, p<.05)$. As shown in Figure 5, the pattern of result in choice set 1 shows that analytical thinking led to a more deliberate choice when consumers had high nutrition knowledge $(\mathrm{M}=.80$ vs. $\mathrm{M}=.58 ; \mathrm{F}(1,69)=3.69 ; \mathrm{p}<.05)$. However holistic thinking did not lead to significantly different choices when nutrition knowledge was high $(\mathrm{M}=.56)$ versus low $(\mathrm{M}=.60 ; \mathrm{F}(1,306)=.156: \mathrm{p}>.05)$.

Moreover, the results confirm that high nutrition knowledge leads to a more deliberate choice for analytical thinkers $(\mathrm{M}=.80)$ than holistic thinkers $(\mathrm{M}=.56 ; \mathrm{F}(1,119)=7.41 ; \mathrm{p}<$ .01). The holistic thinkers are more likely to rely on packaging cues (in this case color/flavor of the packages), hence nutrition knowledge does not alter their choice. However, analytical thinkers are likely to use nutrition information to make a deliberate choice; therefore highly knowledgeable consumers can implement their knowledge and make a deliberate choice.

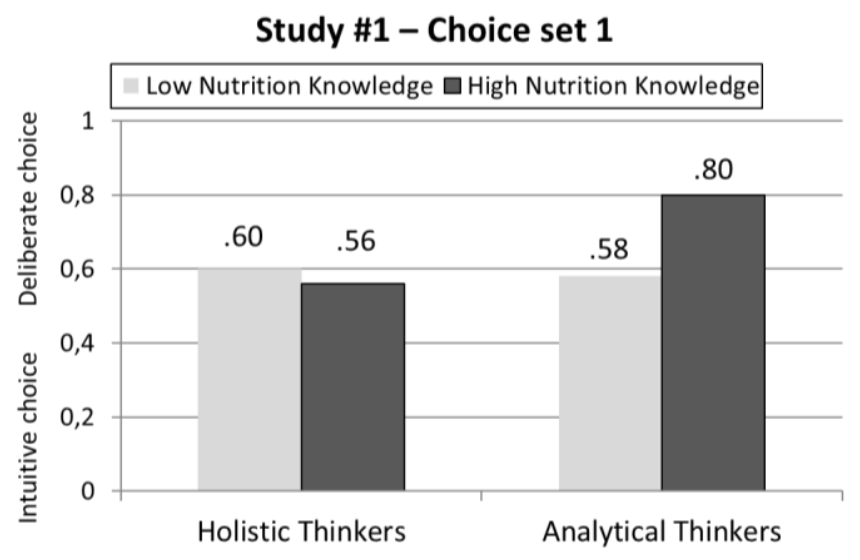

Figure 5 - Interaction of Thinking Style and Nutrition Knowledge (Paper 2, study 1)

The result of the second choice set shows no significant difference in choice of holistic thinkers $(\mathrm{M}=.89)$ and analytical thinkers $(\mathrm{M}=.88 ; \mathrm{F}(1,376)=.03 ; \mathrm{p}>.05)$. The results did not support the interaction of knowledge and thinking style on the choice set 2 (see Figure 6). 
In other words, nutrition knowledge did not substantially alter the choice of holistic thinkers and analytical thinkers. We suggest that because of the salient effect of a brand, participants with either high or low nutrition knowledge did not apply their knowledge.

Study \#1 - Choice set 2

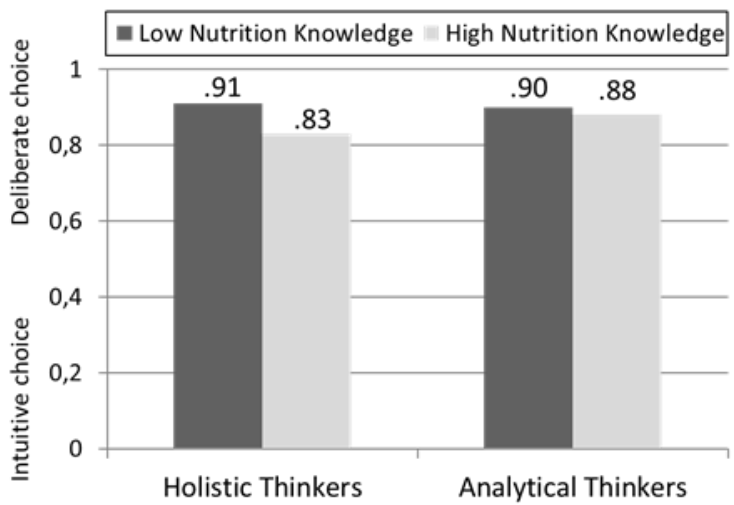

Study \#1 - Choice set 3

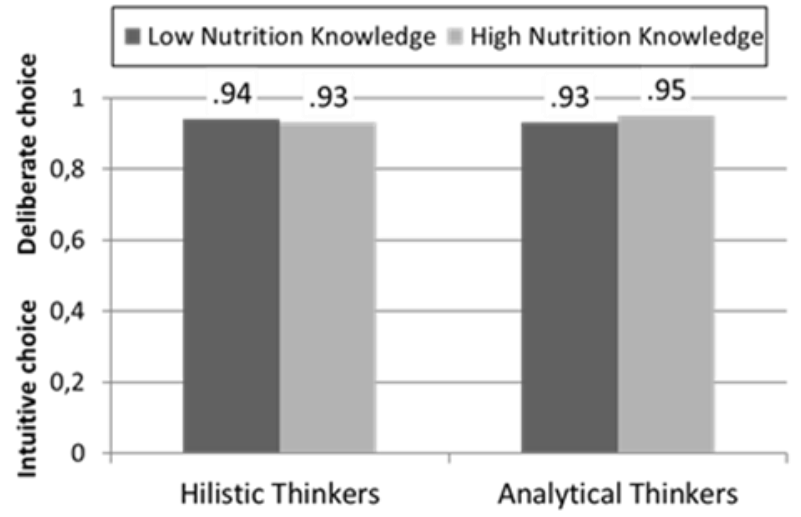

Figure 6 - Interaction of Thinking Style and Nutrition Knowledge (Paper 2, Study 1)

The result of the third choice set shows that analytical thinkers tend to choose the more deliberate choice $(\mathrm{M}=.96)$ than holistic thinkers $(\mathrm{M}=.93, \mathrm{~F}(2,377)=7.78 ; \mathrm{p}<.001)$. However, similar to the second choice set, there was no interaction between nutrition knowledge and thinking style (see Figure 6). Specifically, the presence of FOP label on the options of this choice set leads participants with either high or low nutrition knowledge to make similar choices.

\subsubsection{Discussion of Study 1}

The purpose of study 1 was to examine the effects of deliberate versus intuitive processing mode and nutrition knowledge on food choice (deliberate choice based on nutrition information or intuitive choice based on packaging cues). The findings of this study showed that in general, participants were more likely to choose the deliberate option using nutrition 
information. Given the atmosphere of a field study, participants could infer that the goal of the study is to make a healthful choice. Therefore, the study itself invoked a higher likelihood of engaging in an analytical thinking style.

The results provided preliminary support for our proposition that holistic thinking (intuitive processing) is more likely to lead to a food choice based on packaging cues (brand, package color, flavor) for highly knowledgeable consumers than less knowledgeable ones. Contrarily, analytical thinking (deliberate processing) is more likely to induce a choice based on nutrition information when they have higher rather than lower nutrition knowledge.

This finding supports our argument that consumers' use of nutrition knowledge varies depending on the processing mode at the shopping situation. In intuitive processing mode, highly knowledgeable consumers are confident about their choice, therefore relying on heuristic cues (e.g., light/white color, ingredients (yogurt) or brand (well-known for organic products) and skip using the labels. In contrast, in deliberate processing mode, the same group of highly knowledgeable consumers rely on nutrition information to make a choice. Moreover, as a result of the dominant effect of heuristic cues (such as brand) or FOP nutrition label, nutrition knowledge does not differentiate consumers' choice. This pattern of results supports hypotheses 1 and 2 and offers an initial insight on the impact of processing on choice.

The holistic/analytical thinking approach assumes a permanent state of mind, however the main construct of our model, i.e. processing mode refers to consumers' processing style at the shopping situation. However, in the first study, due to the lack of methodological tools, we used the thinking style concept. In order to measure the processing mode differently, in study 2 we measure processing mode with a subjective single-item scale. The second study also serves to expand on the insights gained in study 1 regarding how processing mode is generated to impact consumer choice. Therefore, study 2 more strongly focuses on the effect of time 
pressure as a contextual variable on consumers' choice through processing mode. We aim to show that time pressure impacts processing mode (intuitive or deliberate), which in turn leads to a specific choice depending on high and low nutrition knowledge.

\subsection{Paper 2: Study 2}

\subsubsection{Method}

This study examines the effect of time pressure on processing mode and choice, and how this effect is moderated by nutrition knowledge. Participants were exposed to two choice sets and were asked to indicate which of two breakfast cereal options is more healthful. Similar to study 1, one option looked more healthful; however, the other option is indeed more healthful with regard to nutrient values (see Table 7). The first choice set (intuitive option: "whole grain oat" with light blue color; deliberate option: "chocolate" cereal) includes only amber colored Traffic light labels. The second choice set, the intuitive option is "chocolate cereal" with a green Traffic light label for fat and the deliberate option is "yogurt" cereal with an all-amber Traffic light (the more healthful option).

In the first choice set, we expect that in the intuitive processing mode highly knowledgeable consumers are apt to making more intuitive choices (based on packaging cues) than less knowledgeable consumers. In the intuitive processing mode, highly knowledgeable consumers will skip deep processing and rely on simple health-related heuristic and consequently will choose the intuitive option ("whole grain oat" cereal); whilst less knowledgeable consumers will choose the more deliberate option ("chocolate" cereal) by heuristically using nutrition information. In contrast, in the deliberate processing mode, consumers with low nutrition knowledge will utilize heuristics to choose the intuitive option ("whole grain oat" cereal) and the ones with high nutrition knowledge will apply deliberate 
processing mode and therefore, will choose the deliberate option ("chocolate" cereal). We used the chocolate cereal as a representative for the deliberate option because people often avoid chocolate and consider it as unhealthy without precisely reading the nutrition information (see Appendix3).

In the second choice set, both of the alternatives had Traffic light, however, option A included one green light while option B included only amber lights. We expect that Traffic light label format with one green light is considered a heuristic for less knowledgeable consumers in both intuitive and deliberate processing mode. Therefore, in intuitive processing mode, we expect that less knowledgeable consumers will choose a deliberate option ("chocolate" cereal) while high knowledgeable individuals will skip reading the labels and rely on packaging cues to choose an intuitive option ("yogurt flavored" cereal). In contrast, highly knowledgeable consumers in deliberate processing mode are expected to read the nutrition information deliberately to choose the deliberate option ("yogurt flavored" cereal). In contrast, less knowledgeable individuals in deliberate processing mode are likely to choose less deliberate option ("chocolate" cereal).

Nutritional values of the options presented by FOP labels could distinctively show the difference in nutritional profile of the more healthful and less healthful options. Nevertheless, we relied on the FSA nutrient profiling system, which is in line with current EU regulations concerning nutritional values (Crosetto, Muller, and Ruffieux 2016; Julia et al. 2015). The FSA score of the options in choice sets supports the difference in the nutritional profile of choice set 1 ("whole grain oat" cereal: 5, "chocolate" cereal: 3 ) and choice set 2 ("chocolate" cereal: 4 , “yogurt flavored" cereal: 3). 
Table 7 - Stimuli Profile in terms of deliberate versus intuitive cues. (in each pair, the dominant cues are shown in bold)

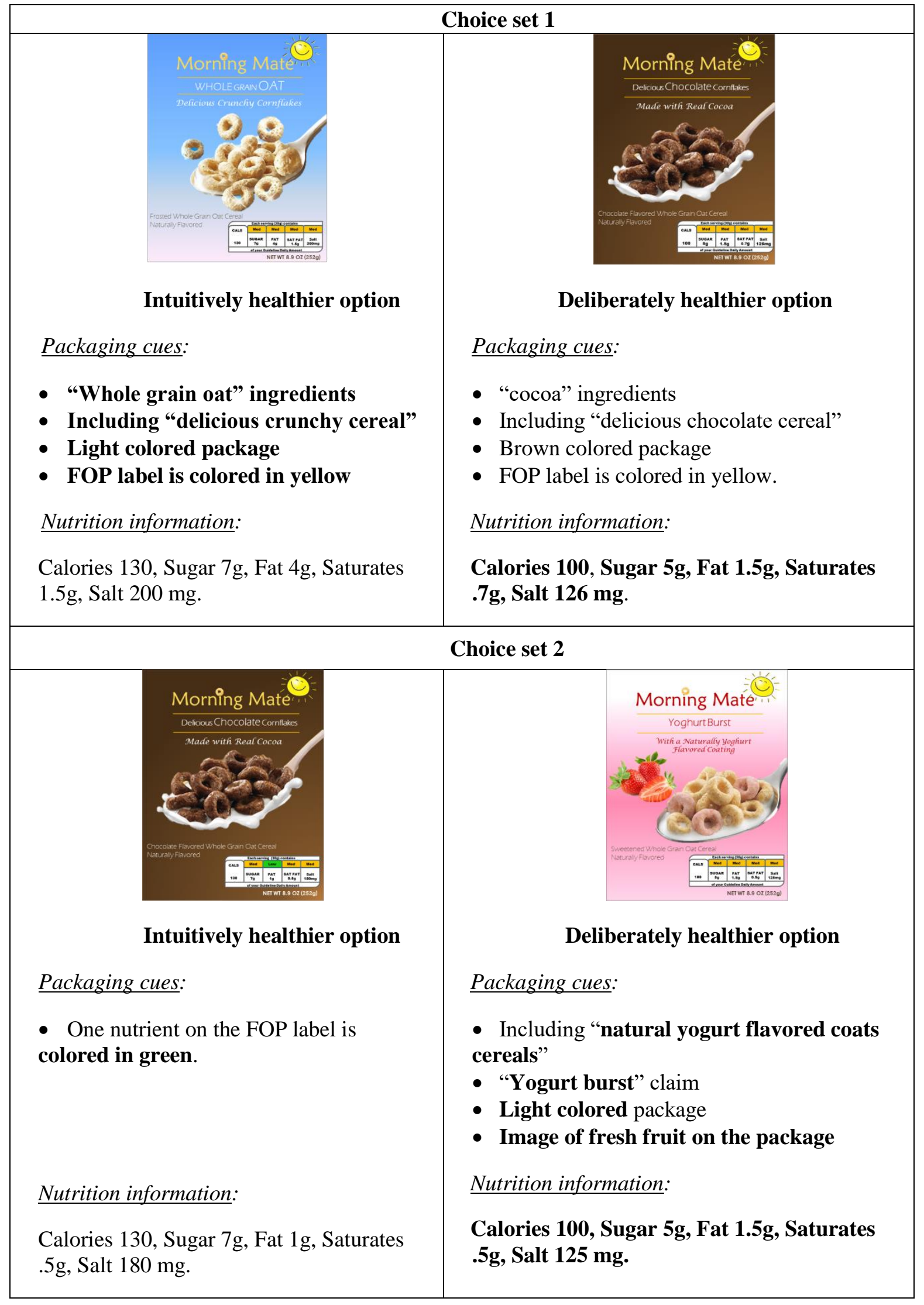


We conducted a pretest to estimate how much time pressure is required to carry out the choice task. 240 individuals from a university student panel voluntarily participated in this pretest. Participants were randomly assigned to two low and high time pressure conditions. Following prior studies (e.g., van Herpen and van Trijp 2011), we adopted the time limits of 8 and 12 seconds for each choice task in the current study. Then participants were asked to follow the same task as the choice sets in study 2 (to choose the more healthful option). We used three seven-point scale items to determine perceptions of time pressure (adopted from Suri and Monroe 2003) and checked the items constructs for reliability (Cronbach's alpha: .87). The findings of this pretest showed a significant difference between the perception of a low $(\mathrm{M}=$ $.43)$ versus a high time pressure $(\mathrm{M}=1.24 ; \mathrm{F}(1,240)=15.32, \mathrm{p}<.001)$. The result shows that 8 seconds time pressure not only provided participants with enough time for answering the test quickly but also better reflects the dominance of intuitive processing mode. Therefore, in the main study, we will apply two time pressure conditions of high ( 8 seconds) and no time pressure.

In the main study, 369 paid participants were recruited through MTurk and randomly assigned to one of the two experimental conditions ("high time pressure": 8s, "no time pressure": no time limit instructions). A manipulation check for time pressure was measured through one item (adopted from van Herpen and van Trijp 2011). To assess the objective nutrition knowledge, participants answered seven questions (scale adopted from Andrews, Netemeyer, and Burton 2009). In the analysis, we will split the knowledge score by mean into two high and low nutrition knowledge groups. We also measured the processing mode by using one 7-point scale ( $1=$ very intuitive, $7=$ very deliberate). Processing mode is coded based on standard deviation leading to two groups (intuitive and deliberate processing mode). 


\subsubsection{Results of Study 2}

The manipulation check (adopted from van Herpen and van Trijp 2011) showed higher perception of time pressure in $8 \mathrm{~s}(\mathrm{M}=5.13)$ than no time limit $(\mathrm{M}=2.75 ; \mathrm{F}(1,349)=14.58$, $p<.001)$. On average, consumers in high time pressure spent 7.6 seconds for making a choice, though consumers in no time pressure spent $16.8 \mathrm{~s}$ time to complete the same task. To familiarize participants with the procedure of choice under time pressure conditions, we added a trial choice set at the beginning of the survey. In high time pressure condition, participants missed out $19 \%$ of answers in the trial choice set. But participants learned about the time limit and in the subsequent choice sets missed fewer questions (around 3.5\%) and were automatically directed to the next question. Also, the manipulation check shows that $82 \%$ of participants noticed the FOP label on the packages.

In the first comparison set, the "whole grain oat" cereal was colored in light blue to provide an impression of light and healthful option (see Table 7). In contrast, the "chocolate" cereal illustrated chocolate-flavored cereals in dark brown with the slogan of "delicious chocolate cornflakes" to resemble a less healthful choice. Therefore, "whole grain oat" cereal is considered as the intuitively healthy option while the "chocolate" cereal is indeed the healthier option and thus, the deliberate option.

The result of the first choice set supports the interaction between the processing mode and nutrition knowledge $(\mathrm{F}(1,359)=6.02, \mathrm{p}<.05 ;$ Figure 7$)$. In intuitive processing mode, the difference between choice of highly knowledgeable consumers $(\mathrm{M}=-.52)$ and less knowledgeable individuals was not significant $(\mathrm{M}=-.07 ; \mathrm{F}(1,179)=1.72 ; \mathrm{P}>.05)$. In the deliberate processing mode condition, consumers with high nutrition knowledge made more deliberate choices $(\mathrm{M}=1.24)$ than individuals with low nutrition knowledge $(\mathrm{M}=.46, \mathrm{~F}(1$, 179) $=4.50, \mathrm{p}<.05)$ 
This finding reveals that less knowledgeable participants made similar choices in both intuitive $(\mathrm{M}=-.07)$ and deliberate conditions $(\mathrm{M}=.46 ; \mathrm{F}(1,136)=1.73 ; \mathrm{p}>0.05)$. Contrarily, an analysis of variance (ANOVA) shows that highly nutrition knowledgeable individuals make intuitive choices (based on packaging cues) more in intuitive processing mode $(\mathrm{M}=-.52)$ than deliberate processing mode $(\mathrm{M}=1.24 ; \mathrm{F}(1,222)=35.12, \mathrm{p}<.001)$. This result is consistent with previous studies (Grunert et al. 2012, Hieke and Taylor 2012, Hess et al. 2012) showing that highly knowledgeable participants skip thoroughly reading the labels. Findings also show the detrimental effect of low nutrition knowledge even in deliberate processing mode on choice. Subsequently, when consumers have low nutrition knowledge, thinking more about the choice leads to an unfavorable choice.

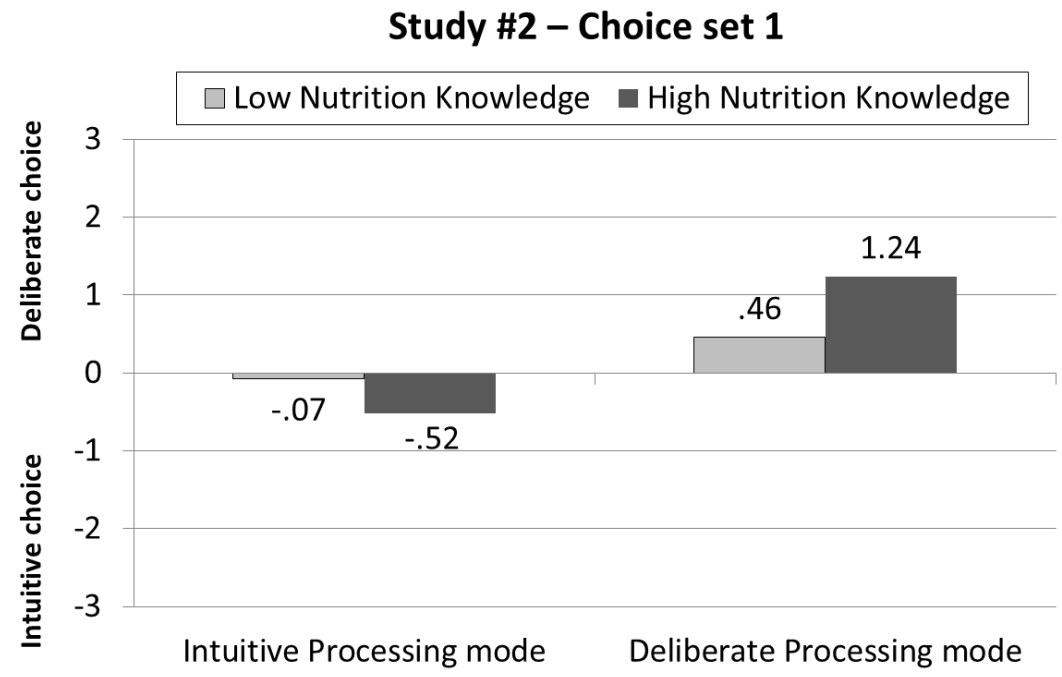

Figure 7 - Impact of Nutrition Knowledge and Processing Mode on Choice (study 2, choice set 1)

In the second choice set, the "yogurt flavored" cereal has lower calorie, sugar, salt and saturates, therefore is more healthful (less unhealthful), however the "chocolate" cereal is only eligible for having a green light for fat value but has higher calories, sugar, salt and saturates, 
therefore is generally less healthful. Therefore, "yogurt flavored" cereal represents a deliberate choice whereas "chocolate" cereal refers to an intuitive choice. Contrarily to the first choice set, the result of the second choice set will show how consumers make choices if the FOP label format contains a heuristic cue. This set was designed to test our proposition that in intuitive processing mode, high knowledgeable participants prefer packaging cues ("yogurt flavor" and light blue color) over heuristic cue on the FOP label ("green light").

An analysis of variance (ANOVA) on choice supports the interaction between the processing mode and nutrition knowledge $(\mathrm{F}(1,355)=7.35, \mathrm{p}<.05$; see Figure 8$)$. In the intuitive processing mode condition, choice of highly knowledgeable participants $(M=1.03)$ and less nutrition knowledgeable individuals did not differ significantly $(\mathrm{M}=1.15 ; \mathrm{F}(1,176)$ $=.16 ; \mathrm{p}>.05)$. In the deliberate processing mode, however, individuals with high nutrition knowledge made more deliberate choices $(M=1.59)$ than individuals with low nutrition knowledge $(\mathrm{M}=.58, \mathrm{~F}(1,178)=39.25 ; \mathrm{p}<.05)$. Consistent with our expectations, the results showed that when other packaging cues (such as light color or yogurt flavor ingredients) are presented, heuristics on the Traffic light does not redirect consumers' choice under time pressure. The findings showed that in the deliberate processing mode, consumers are less likely to rely on heuristic cues and thus are less susceptible to health halos.

An analysis of variance (ANOVA) shows that high nutrition knowledgeable consumers are more likely to make a choice based on nutrition information in deliberate processing mode $(\mathrm{M}=1.59)$ than in intuitive processing mode $(\mathrm{M}=1.03 ; \mathrm{F}(1,219)=5.35, \mathrm{p}<.05)$. Also, results show that choice of low nutrition knowledgeable individuals in intuitive processing mode $(M=1.15)$ and deliberate processing mode does not differ significantly $(\mathrm{M}=.58 ; \mathrm{F}(1$, $135)=2.58, \mathrm{p}>.05)$ 


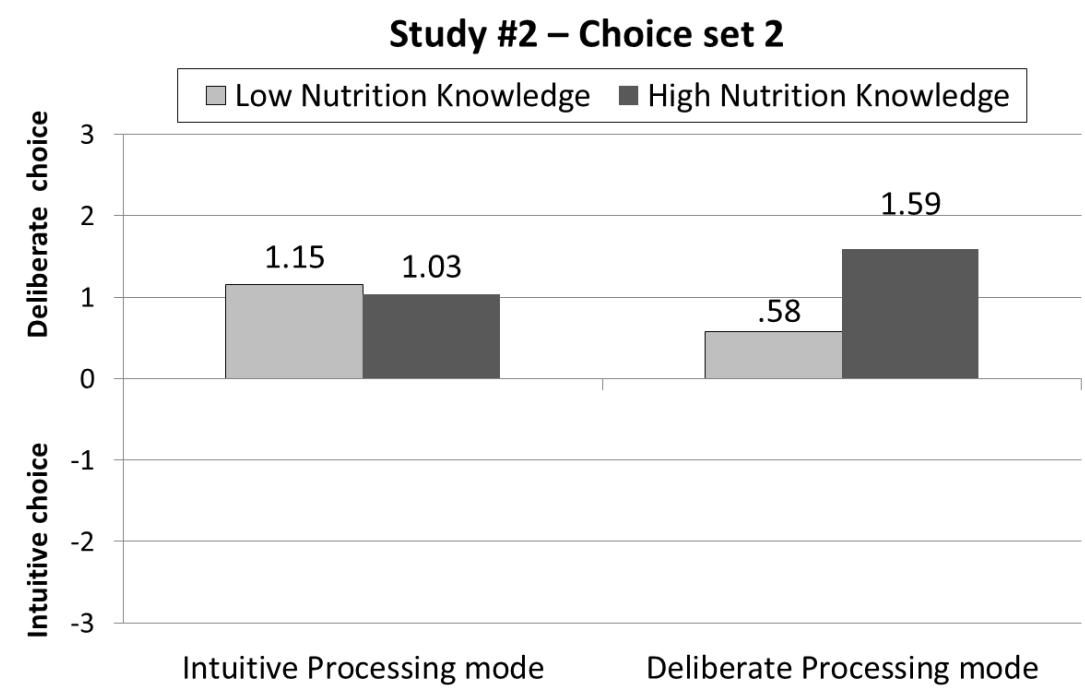

Figure 8 - Impact of Nutrition Knowledge and Processing Mode on Choice (study2, choice set 2)

Mediation Analysis. We conducted moderated mediation analyses (PROCESS model 58; Hayes 2013) to test whether processing mode would mediate the effects of time pressure on choice in nutrition knowledge conditions when Traffic light label (with/without heuristic cue) is presented. Time pressure was used as the predictor variable, nutrition knowledge as the moderating variable, processing mode as the mediator, and food choice (based on nutrition information or packaging cues) as the dependent variable. In all mediation analyses, the 95\% confidence intervals (CIs) used to generate each indirect effect were conducted at 10,000 bootstrap samples.

We performed the moderated mediation analysis separately for each choice set (see Table 8). Consistent with our predictions, there was a direct effect of low time pressure on deliberate choice (i.e. chocolate cereal) (E: -1.12; CI $[-1.6,-.66])$. The result of mediated moderation revealed the indirect effect of high time pressure on choice through intuitive processing mode when nutrition knowledge is high (Indirect Effect: -.13; 95\% CI [-.65, -.14]). In contrast, moderated mediation analysis of choice set 2 showed a direct effect of high time pressure on intuitive choice (i.e. yogurt flavored cereal) (E: .43; CI [.036, .84]). We suggest 
that this is because of packaging intuitive cues on the yogurt flavored cereal. The result of mediated moderation choice set 2 also shows the indirect effect of high time pressure on choice through intuitive processing mode when nutrition knowledge is high (IE: -.12; CI [-.32, -.01]). In both sets, the results support the proposition that the effect of high (no) time pressure on choice through intuitive (deliberate) processing mode when nutrition knowledge is high.

Table 8 - Mediating role of processing mode for the effect of time pressure on choice moderated by nutrition knowledge

\begin{tabular}{lllll}
\hline & \multicolumn{2}{l}{ Choice set 1 (without colored light) } & Choice set 2 (with colored light) \\
\hline Independent Variables & $\begin{array}{l}\text { Final choice evaluation (with added } \\
\text { mediator) }\end{array}$ & $\begin{array}{l}\text { Final choice evaluation (with added } \\
\text { mediator) }\end{array}$ \\
\cline { 2 - 5 } & Coefficient & t-value & Coefficient & t-value \\
\hline Time Pressure & -1.12 & $-4.76^{* * *}$ & .44 & $2.14^{*}$ \\
\hline Processing mode & .17 & 1.63 & -.15 & -1.67 \\
\hline Nutrition Knowledge & -.02 & -.09 & .10 & .41 \\
\hline $\begin{array}{l}\text { Processing mode x } \\
\text { Nutrition Knowledge }\end{array}$ & .27 & $2.01^{* *}$ & .30 & $2.60^{* *}$ \\
\hline
\end{tabular}

NOTE.- All coefficients are unstandardized, and nutrition knowledge was coded as $0=$ low nutrition knowledge, $1=$ High nutrition knowledge. Index of moderated mediation for processing mode was significant for TL with a single colored light (Index: -.22; CI [-.51, -.05]). *p<.05, **p<.01, ***p<.001.

\subsection{Paper 2: General Discussion}

The majority of extant research on nutrition labels is conceived with comparing the effectiveness of label formats. Shifting the perspective, in this research we demonstrated that even a single FOP label is used differently, and we identified the mechanism that causes the different usages. Building on the situational processing perspective (Newman, Howlett, and Burton 2016; Sanjari, Jahn, and Boztug 2017), this paper empirically demonstrated that different usages of FOP nutrition labels is explained by processing mode which itself is a 
function of nutrition knowledge and time pressure. Importantly, the present work is the first to consider the use of a single label both heuristically or deliberately. The current study offers new conceptual insight into the relationship between personal and context variables, processing mode and FOP nutrition label format. Drawing from dual process theory (Dhar and Gorlin 2013; Kahneman 2011), we highlighted the importance of distinguishing between different situations driven by time pressure and nutrition knowledge and predicting their influence on the choice.

This study adds to the literature by providing a theoretical explanation about how highly/less knowledgeable consumers use the FOP labels to make a food choice. First, the findings showed that high nutrition knowledge leads to different choices depending on processing mode. That is, highly knowledgeable consumers in intuitive processing mode are more likely to make intuitive choices (based on nutrition information) than less knowledgeable ones. This is consistent with findings of prior studies (Grunert, Bolton, and Raats 2012; Hess, Visschers, and Siegrist 2012; Hieke and Taylor 2012) that highly knowledgeable consumers skip deep processing and make intuitive choices. We add to these findings by explicitly explaining when this situation occurs. Second, the findings of this study also revealed that highly knowledgeable consumers implement their nutrition knowledge only when deliberate processing mode dominates (when there is no time pressure). This is in contrast to the finding of studies that support the unconditional positive influence of high nutrition knowledge on healthful choice (Burton, Biswas, and Netemeyer 1994; Miller and Cassady 2012). Third, the findings show that providing consumers with less nutrition knowledge an excessive amount of time to elaborate on a choice task does not help in making a healthful choice and could even have a detrimental effect, leading to unfavorable results. 
Furthermore, our study portrays an exhaustive picture of consumers' use of FOP label format and shows that consumers are often overwhelmed with distracting packaging information which hinders further attention to the FOP label formats. Specifically, whether consumers make a choice based on heuristic packaging cues or nutrition information largely depends on the different levels of time pressure and nutrition knowledge. That is, consumers often rely on packaging cues under high time pressure (intuitive processing mode). This is a promising result since it addresses conflicting findings of consumers' choice when it is accompanied by a packaging cue (for a review see Chandon 2013). We address this debate by providing an explanation in order to identify and predict situation (based on time pressure and nutrition knowledge) where either of these two (nutrition information or packaging cues) prevail. The findings also specify the situations in which consumers use labels deliberately and are therefore less vulnerable to health halos. The health halo occurs when one aspect of the food appears to be healthier than it is (Chandon 2013; Chandon and Wansink 2012). This study showed that only when consumers have sufficient time, they make choices by deliberate processing. Otherwise, when consumers lack time to make food choices, health halo can prevail.

The present findings have implications for public policymakers and retailers. First, using these findings, it is possible to predict consumers' choice pattern based on specific consolidations of time pressure and nutrition knowledge. Also, since FOP nutrition label formats do not always result in a healthy choice, policymakers should not expect nutrition information label formats to always guide consumers to a healthy choice. Moreover, the findings of this paper showed that in majority of purchase situations consumers rely on heuristic cues (either on packaging cues or on FOP nutrition label heuristics). Therefore, retailors can benefit by improving heuristic cues on the packages to guide consumers to make favorable choices. Also, this paper showed that only choices from highly knowledgeable 
consumers differ across processing mode and time pressure situations. Thus, we suggest that retailors should be attentive to this sensitive consumer group and watch out for disadvantages arising from misleading cues on the packages. 
4. Paper \#3: Choosing Fast and Slow: Processing Mode and Consumer Response to FOP Nutrition Label Formats

(With Steffen Jahn, and Yasemin Boztug) ${ }^{3}$

This paper is published as:

- Choosing Fast and Slow: Processing Mode and Consumer Response to FOP Nutrition Label Formats. Winter AMA (American Marketing Association), Orlando, US, 2017.

\footnotetext{
${ }^{3}$ This paper was created in cooperation with the listed co-authors. I was responsible for the literature review, the theoretical foundation, the hypotheses development, the methodology, and the empirical analysis and developing the paper.
} 


\section{Choosing Fast and Slow: Processing Mode and Consumer Response to FOP Nutrition Label Formats}

\subsection{Paper 3: Introduction}

There is an increasing awareness of the relationship between food and the role it plays in health among consumers. In response, numerous food manufacturers and retailers implement front-of-package (FOP) nutrition labeling to inform consumers about the nutritional benefits and costs of food items (Grunert, Bolton, and Raats 2012) and influence their food choice. Different FOP nutrition label formats such as GDA (Guideline Daily Amounts), traffic light, smart choice, NuVal have been introduced which vary greatly in terms of information content and presentation format (Newman, Howlett, and Burton 2016). Despite the diversity, they all aim to facilitate the food decision-making process by differentiating healthy and unhealthy food products (Boztug et al. 2015; Cowburn and Stockley 2005). However, the types of FOP nutrition label formats that best impact the consumers' decision-making process are still poorly understood (Hersey et al. 2013).

Many studies tried to answer this question by comparing nutrition label formats such as GDA and traffic light label (Bussell 2005; Maubach, Hoek, and Mather 2014). These two labels has received considerable attention in the literature because they contain nearly similar information, however they differ in presentation style: GDA label provides numerical information in grams and percentage of calories and total fat, saturated fat, sugar, sodium or salt; whereas the traffic light label use colors to display a ranking (e.g., high, medium, or low) of risky nutrients (Hersey et al. 2013). Similarly to the GDA, when employed, traffic light label appears on all food products (Hodgkins et al. 2012). 
Studies have reported mixed results on whether a simplified label e.g., the traffic light is easier to interpret and more influential for healthy choice than a more complex one e.g., GDA (Drescher, Roosen, and Marette 2014; Hersey et al. 2013). Some findings support the impact of GDA label (Bussell 2005; Grunert, Wills, and Fernandez-Celemin 2010) whereas others advocate the effectiveness of traffic light label (Lobstein and Davies 2009; Maubach, Hoek, and Mather 2014) for healthy food choice. Studies supporting the GDA label claim that traffic light is overly simple and thus unable to convey the true nutritional value of a food (e.g., Maubach, Hoek, and Mather 2014). In contrast, the studies supporting the impact of traffic light discuss that consumers prefer this label because it simply communicate the healthiness of the food (Grunert and Wills 2007) and significantly impact the food choice especially for less healthy products (Maubach, Hoek, and Mather 2014). Besides, findings show that consumers' response to these labels differs across personal features such as nutrition knowledge (Drichoutis, Lazaridis, and Nayga 2006; Grunert, Wills, and Fernandez-Celemin 2010), motivation (van Herpen and van Trijp 2011) and socio-demographics (Balcombe, Fraser, and Di Falco 2010). Contrarily, other studies argue that these two labels do not result in substantially different food choices (Hodgkins et al. 2012; Siegrist, Leins-Hess, and Keller 2015).

Taken together, previous studies provide mixed findings about whether traffic light and GDA label differ in their impact on the healthy food choice. One reason for this disparity is that the cognitive processes by which consumers utilize these nutrition labels to make food choices are unclear (see Aschemann-Witzel et al. 2013; Grunert, Bolton, and Raats 2012; Jacquier et al. 2012). This paper aims to address this gap and uncover the food choice process by building on the dual-system view of mind (Kahneman 2003) and its implementation in the choice literature (see Dhar and Gorlin 2013). For the first time, we borrow the concept of processing mode from dual-system view and empirically examined how consumers' processing 
mode impacts the effect of FOP nutrition label formats e.g., GDA and traffic light labels on healthy food choice. We also investigate how consumers' personal features e.g., nutrition knowledge and motivation to read the labels impact their processing mode. This research contributes the current literature by providing insight into the underlying mechanism of FOP nutrition label effectiveness and clarifying the complex relationship between consumers' personal characteristics, nutrition label formats, and processing mode.

\subsection{Paper 3: Conceptual Background}

\subsubsection{Deliberate and Intuitive Use of Nutrition Information}

Traditionally, the nutrition labeling research has focused on how nutrition label formats impact healthy food choice from a holistic perspective. That is, it engaged with general characteristics that affect nutrition label effectiveness and stresses that consumers actively collect, store and interpret available nutrition information by weighing different criteria and combining them into an overall evaluation (Cohen and Babey 2012). However, when faced with time pressure, distraction and stress, consumers often skip these sequential processes (Hieke and Taylor 2012; Schulte-Mecklenbeck et al. 2013) and rely on the fast and frugal heuristics (Gomez 2013; Jacquier et al. 2012; Scheibehenne, Miesler, and Todd 2007).

Whilst the traditional approach views heuristics as just a residual process of nutrition information processing, we take a different approach to explain food choice by including both systematic processing of nutrition information and the use of heuristics. We build on the dualsystem view since it covers both of the underlying cognitive processes, one which is intuitive and heuristic-based and another which is deliberate and subject to reasoning (Kahneman 2011). Therefore, consistent with other studies (e.g., Chance, Gorlin, and Dhar 2014; Muller and Prevost 2016), we reason that the dual-system approach provides a better mindset to explain 
the food choice in real purchase situations. We propose that consumers' dominant processing mode i.e. intuitive vs. deliberate explains consumers' response to a FOP nutrition label format.

\subsubsection{The Mediating Role of Processing Mode}

According to the dual-system view, the consumers can make a favorable choice when the resources available for making a choice matches those required for a given task (Dhar and Gorlin 2013). It is important to highlight that a favorable choice can be made by either deliberate processing or use of heuristics. Within the context of the current research, this reasoning suggests that consumers make a healthy food choice when the type of provided FOP nutrition label format best matches the consumers' dominant processing mode. Hence, the healthiness of the choice largely depends on the congruence between the FOP nutrition information format and the consumers' processing mode.

In this study, we compare the processing of GDA label and traffic light as two important FOP label formats. GDA label requires more deliberate tasks e.g., search, comparison, attending to the numerical and abstract information and recall from memory. Thus, we assume that GDA is a more complex label and related to the deliberate processing mode. On the contrary, traffic light label contains evaluative, interpretive and pre-processed information with less need for deliberate thought (Ares et al. 2012; Maubach, Hoek, and Mather 2014). Traffic light is used by consumers as a color-coded simplifying heuristic (Drescher, Roosen, and Marette 2014), hence we assume that it is related to intuitive processing mode. Taken together, we expect that the GDA label leads to a healthy food choice when consumers are in deliberate processing mode, whereas the TL label impacts healthy food choice when consumers are in intuitive processing mode. This conceptualization is demonstrated in Figure 9 as the proposed conceptual model. 


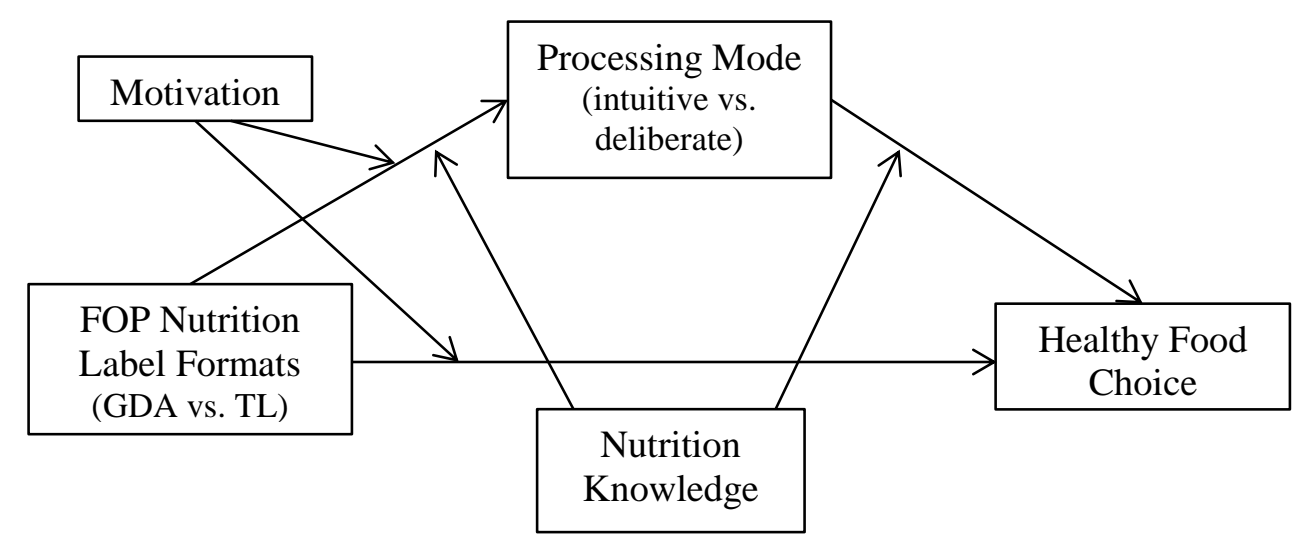

Figure 9 - Proposed Conceptual Model (Paper 3)

Furthermore, studies have reported that the high health motivated consumers are more likely to read the detailed nutrition information (Balasubramanian and Cole 2002). On the contrary, consumers with low health motivation are likely to ignore the nutrition label formats when making a food choice (Aschemann-Witzel et al. 2013; Hess, Visschers, and Siegrist 2012; Jacquier et al. 2012). Therefore, we expect that the impact of GDA and traffic light label formats on healthy choice depends on the consumers' motivation to read the labels. Thus, the following hypothesis is offered:

H1: The impact of a FOP nutrition label format (GDA or traffic light) on healthy food choice is moderated by consumers' motivation to read the label.

\subsubsection{The Role of Motivation and Nutrition Knowledge}

According to the choice literature, processing modes can arise from different levels of task and context features e.g., time pressure, depletion, fatigue or hunger (Dhar and Gorlin 2013). Adapting this idea to the context of nutrition labeling, consumers' response to nutrition label formats depends on the dominant processing system, which itself is regulated by a set of 
personal features. In this study, we focus on the motivation and nutrition knowledge as consumers' personal features because they were widely discussed in previous literature.

Prior research has shown that low- and high-knowledgeable consumers, both process the FOP nutrition labels heuristically (Basil, Basil, and Deshpande 2009; Higginson et al. 2002a). Specifically, high knowledgeable consumers have less actual label use, because they feel they know "by heart" which products to choose and they may find it unnecessary to look at nutrition labels (Grunert, Bolton, and Raats 2012; Hess, Visschers, and Siegrist 2012; Hieke and Taylor 2012). On the other hand, low-knowledgeable consumers look for the salient nutrient information (Balasubramanian and Cole 2002) e.g., calorie and color-coded information. In contrast, moderate knowledgeable consumers are more thoughtful about their choice and use their knowledge more efficiently by deeply processing the information (Miller and Cassady 2012). This evidence supports our proposition regarding the impact of nutrition knowledge on processing mode. Therefore, we expect that high and low levels of nutrition knowledge lead to intuitive processing mode, however the medium level of nutrition knowledge induce deliberate processing mode.

Consumers' level of motivation also impacts their processing mode. Regarding the previous literature, highly-motivated consumers engage in a deep processing of the nutrition information (Hieke and Taylor 2012). However, low-motivated consumers implement heuristics by attending health unrelated cues e.g., brand names and simple graphic information or quality labels (Gomez 2013; Visschers, Hess, and Siegrist 2010). Thus, we expect that high motivation to read the label should lead to deliberate processing mode, however low motivation to read the labels induce intuitive processing mode.

Based on dual-system view and our conceptualization, we expect that a more complex FOP nutrition label e.g., GDA label is more compatible with the deliberate processing mode 
than a simple label. As such, the consumers with a moderate level of nutrition knowledge and high motivation to read the label acquire available resources to perform deliberate tasks and are more likely to assess the detailed nutrition information. Taken together, we expect that consumers with high motivation and medium nutrition knowledge tend to employ deliberate processing which in turn influence the impact of GDA as a more complex FOP nutrition label format on healthy choice. Therefore, we formulize the hypothesis as:

H2: The effect of a FOP nutrition label formats on healthy food choice is mediated by processing mode. Specifically, the effect of a more (less) complex label format on healthy food choice is mediated by deliberate (intuitive) processing

H3a: When consumers have medium nutrition knowledge and high motivation to read the label, the impact of a more complex FOP nutrition label e.g., GDA on healthy food choice is mediated by deliberate processing mode.

By contrast, we expect that traffic light label format will lead to healthy food choice when mediated by intuitive processing. Therefore, we expect that consumers with low motivation and also low and high levels of nutrition knowledge are more likely to be in intuitive processing mode which in turn leads to a higher effect of a traffic light label format on healthy food choice. Thus, the hypothesis as:

H3b: When consumers have high or low levels of nutrition knowledge and low motivation to read the label, the impact of a less complex FOP nutrition label e.g., traffic light label on healthy food choice is mediated by intuitive processing mode.

\subsection{Paper 3: Method}

This study was a 2 (FOP nutrition label format: GDA label, Traffic light label) x 2 (motivation: targeted, non-targeted) between-subjects online experiment. The total number of 155 American participants from Amazon Mechanical Turk (MTurk) were recruited for pay and 
randomly assigned to one of four experimental conditions. The manipulations of the FOP nutrition label formats were placed on the front of a hypothetical frozen pizza package. To prevent the difficulty in viewing the detailed information due to the small size of the labels, the bigger scheme of the FOP nutrition label was shown at the bottom of the pizza package. Pizza was chosen because it was widely used in previous studies as a nutritionally mixed product (Andrews, Burton, and Kees 2011; Newman, Howlett, and Burton 2016).

The nutrient values of the pizza in this experiment was manipulated, however it reflects the nutritional features of a similar pizza on the market. These two pizza items (Pizza Alfa and Pizza Beta) were identical in the design and graphics however they contained different yet similar nutrition values. Therefore, to resemble the real purchase situation, the choice task was designed to be a difficult one. Besides the FOP nutrition labels, the participants were asked if they would like to see the back-of-package label and then they had the opportunity to view the detailed nutrition information. The pizza Beta was considered as the healthier choice (less unhealthy choice), containing $264 \mathrm{kcal}$ energy, 11.07 gram fat (17\%), 3.4 gram saturated fat (17\%), $483 \mathrm{mg}$ Sodium (20\%) and 3.7 gram sugar. The pizza Alfa was adopted as the unhealthier choice and contained $260 \mathrm{kcal}$ energy, 12.28 gram fat (19\%), 3.8 gram saturated fat (18\%), 477 mg Sodium (20\%) and 5.14 gram sugar (see Appendix 4).

Considering the nutrient profile of two pizza items, the pizza Alfa contains slightly less calorie and less sodium (though the same percentage). However, in pizza Alfa, the amount of fat, and sugar are higher and amount of fiber, protein, and vitamins are less than the other option. Therefore, the traffic light label for pizza Alfa contained all nutrients in amber light (whereas the pizza Beta contained a green light for sugar). Taken together, we assume that the pizza Alfa is the unhealthier choice and pizza Beta is the healthier one. We especially expect high motivation group to choose pizza Beta as healthier option. Because we manipulated the 
motivation to read the label by instructing subjects to imagine that their physician has recommended them to follow a healthy diet that is low in fat and salt. By using the adjective "low", we encourage motivation to information search. Non-targeted motivation participants did not receive any instruction (adopted from Balasubramanian and Cole 2002).

Two different nutrition label formats varying in level of complexity including the "Traffic light" as a less complex label and the "GDA" as a more complex label were employed in this study. As a part of this experiment, we measured perceived complexity of FOP nutrition label formats by asking participants of how complex versus easy it was to understand the labels. The contrast between the FOP label formats indicate that the GDA $(\mathrm{M}=4.50)$ label format was perceived a more complex FOP nutrition label than TL $(\mathrm{M}=4.13)$ label $(\mathrm{F}(1,93)=4.031$, $\mathrm{p}<.05)$. Therefore, hereafter we consider GDA as a more complex and TL as a less simple FOP nutrition label.

After viewing the manipulations, each participant was exposed to a pair of identical pizza packages which only differed in the type of the FOP nutrition label formats. Participants were asked to indicate which pizza they would prefer without hinting them about choosing a healthier option (If these pizzas were the only choices you had, which one would you choose? $-2=$ Definitely Pizza Alfa, $-1=$ Probably Pizza Alfa, $0=$ Neither of them, $1=$ Probably Pizza Beta, 2= Definitely Pizza Beta).

We focused in how intuitive versus deliberate was the final choice of pizza given the different FOP nutrition label formats. Processing mode was assessed through one 5-point bipolar scale with endpoints (Just a moment ago you made a choice from two pizza items. Do you believe that your final choice was: $1=$ Intuitive, $5=$ Deliberate). To assess the objective nutrition knowledge, participants answered seven questions about caloric knowledge and obesity consequences knowledge (Scale adopted form Andrews, Netemeyer, and Burton 2009). 


\subsection{Paper 3: Results}

Effect of FOP label formats on healthy choice. The analysis revealed that there was no significant difference between the GDA label and the traffic light label in their impact on healthy food choice. The result of insignificant direct effect reconfirm the problem we addressed in literature, that is when considering the FOP nutrition labels alone (by ignoring the mediating effect of processing mode) there is no systematic difference among the FOP nutrition label formats in their impact on healthy food choice. This result is consistent with previous findings in the literature that show that these two labels do not differ significantly in their impact on food choices (see Hodgkins et al. 2012; Siegrist, Leins-Hess, and Keller 2015). Moreover, the direct effect of FOP nutrition label formats is neither moderated by consumers' motivation to read the label nor by nutrition knowledge.

Effect of FOP label formats on processing mode. There is a significant difference between nutrition label formats in their impact on processing mode $(F(1,154)=10.081$, $\mathrm{p}<0.005)$. Processing mode was most deliberate for GDA group $(\mathrm{M}=4.43)$ and most intuitive for TL group (M=3.96). This result shows that GDA label and traffic light label are processed differently.

Effect of FOP label formats and motivation on processing mode. The results of comparing the means show that the FOP label formats $\mathrm{X}$ motivation interaction was not significant for processing mode. Targeting the motivation to read the label increased the deliberate processing mode among GDA label group $(4.35$ vs. $4.5, F(1,77)=.597, \mathrm{p}>.01)$ as well as traffic light label group (3.77 vs. $4.11, \mathrm{~F}(1.77)=2.22$, $\mathrm{p}>.01)$. However, this increase was not significant. The plot of means is shown in Figure 10. This finding shows that targeting 
consumers' motivation to read the label had no additional effect on processing mode across GDA and TL groups.

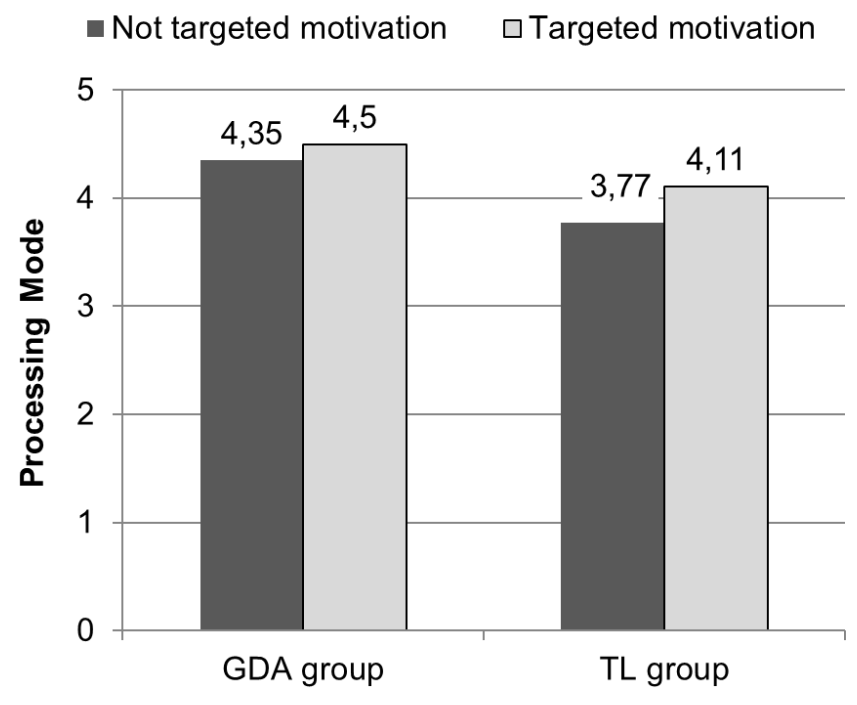

Figure 10 - Effect of FOP Nutrition Label Formats and Motivation on Processing Mode

Indirect effect of FOP label formats for healthy choice via processing mode. The result of mediation analysis indicates that the indirect effect GDA and TL nutrition label formats on healthy food choice through processing mode was significant (coef. $=-.1636$; CI [-.3807, .0425]. This result supports H2, declaring GDA label and traffic light label are processed differently.

Indirect effect of FOP label formats for healthy choice via processing mode across consumers' personal features.

Another objective of this study was to examine the indirect effect of GDA label on healthy choice via processing mode across the different consumer groups. We performed a mediation analysis using 5000 samples in PROCESS Model 62 (Hayes 2013) (with IV=GDA label, DV=healthy food choice, mediator $\mathrm{M}=$ =processing mode, moderator $\mathrm{Z}=$ motivation to read the label, moderator $\mathrm{W}=$ nutrition knowledge). The results demonstrate that the indirect effect 
of the GDA label format through deliberate processing for healthy choice was significant only for consumer with targeted-motivation when having a medium level of nutrition knowledge (IE: .1720; CI [.0003, .3905]) (support for H3a) (The direct effect was not supported).

We then analyzed the complete conceptual model to assess the hypothesis $3 \mathrm{~b}$. The results showed that the indirect effect of TL on healthy choice via intuitive processing mode was significant only for consumer with targeted-motivation when having high nutrition knowledge (IE: -.2665; CI [-.5820, -.0020]) (support for H3b) (The direct effect was not supported). This indirect effect for TL on healthy choice via intuitive processing mode was moderated neither by low nutrition knowledge nor by low motivation.

\subsection{Paper 3: Conclusion}

Uncovering the underlying processes by which consumers use FOP nutrition labels is growing in importance as consumers face increasing amount of information in the food choice environment. In real purchase situations, consumers usually lack enough cognitive capacity (Newman, Howlett, and Burton 2016), enough time, motivation (Hieke and Taylor 2012; Schulte-Mecklenbeck et al. 2013) to process nutrition labels thoroughly. Consumers therefore often rely on intuitive processing to process a subset of information provided on the nutrition labels. However, it is still unclear, though, how and when FOP nutrition labeling is processed intuitively or deliberately. Moreover, prior research has given little consideration to how the effects of types of FOP nutrition labels may differ across consumers with different characteristics.

Drawing from dual-system view, this is the first study to empirically examine the consumers' processing mode when using nutrition label format for making a food choice. The result of this study supports our propositions that processing mode mediates the impact of FOP 
nutrition label format on healthy choice. The findings revealed that the influence of GDA and traffic light nutrition labels on healthy food choice is explained by processing mode. Specifically, the findings demonstrate that consumers make a healthy choice by processing the GDA label deliberately and the traffic light intuitively.

Findings further revealed that specific groups of consumers are more likely to make a healthy food choice. Specifically, GDA label impacts healthy food choice when it is processed deliberate by consumers with high motivation and medium level of nutrition knowledge. On the other hand, the traffic lights label impact healthy choice when it is intuitively processed by consumers with high motivation to read the label and high nutrition knowledge. This finding is consistent with previous studies that argue that consumers with high motivation are less likely to process the information deeply (see Grunert, Bolton, and Raats 2012; Hieke and Taylor 2012). However, it contributes to the existing knowledge in nutrition labeling literature by explicitly explaining how consumers processing mode influence the effectiveness of different nutrition label formats. It also clarifies how the consumers' personal features lead to activation of a processing mode and consequently, impact their food choice.

This study addressed some important limitations of many previous nutrition labeling articles by examining the interactive effects of FOP label formats and consumers' features (motivation and knowledge) in order to portray a more realistic view of the decision-making situations. We also introduced the concept of processing mode and identified intuitive versus deliberate processing as important mechanism that underlies the favorable impact of FOP nutrition label formats on healthy food choice. Future studies may consider the potential usefulness of this construct and whether it can be adapted for use on other research context. 


\section{General discussion}

Obesity has reached epidemic proportions globally, with at least 2.8 million people dying each year as a result of being overweight or obese. A healthy diet helps protect against obesity and malnutrition in all its forms, as well as diabetes, heart disease, stroke, and cancer. To support a healthy diet, relevant nutritional information is fundamental in shaping consumers' choices and thereby preventing overweight and obesity. At the individual level, consumers are advised to limit energy intake from total fats and sugars and reduce sodium consumption. At the societal level, policymakers should support individuals in following nutritional recommendations by enacting policies that make healthier dietary choices available, affordable, and easily accessible to everyone (World Health Organization 2017). One way of promoting healthy food choices is to provide consumers with nutritional information about food choices and then encouraging them to opt for the healthier food alternatives.

As an important tool for promoting healthful choices, FOP nutrition labels provide nutritional information on the front of food packages (Talati et al. 2016). Providing FOP nutrition labeling was expected to reduce unhealthy food intake and obesity. However the number of obese adults more than doubled between 1980 and 2014 (World Health Organization 2015). This discrepancy led to doubts about the effectiveness of nutrition labeling as a policy tool. A large amount of research in nutrition labeling supports the effectiveness of FOP nutrition labeling (for a review see Cowburn and Stockley 2005; Grunert and Wills 2007; Hieke and Taylor 2012). However, recent studies have implied that FOP nutrition labels are not effective in all shopping situations (e.g., Drichoutis, Lazaridis, and Nayga 2005; Hersey et al. 2013; van Kleef and Dagevos 2015). Nevertheless, no study has investigated when and how FOP nutrition labels are effective in promoting healthful food choice. 
This dissertation outlined the lack of consensus in nutrition labeling research about the effectiveness of nutrition labels on food choice. Previous studies have also highlighted the urgent need for employing a comprehensive framework for understanding the use of FOP labels (see Grunert, Bolton, and Raats 2012; Newman, Howlett, and Burton 2014). From the conceptual perspective, prior research lacks a unifying framework to explain and predict the use and effectiveness of FOP labels and its boundary conditions. From the practical perspective, the conditions under which FOP labels are used by consumers and may impact the choice is the main challenge for policy makers and retailers. In sum, this dissertation offers new insight into the question of when and how FOP nutrition label formats impact food choice.

Within three papers, we addressed the above-mentioned necessity in nutrition labeling literature. In the first paper, we suggested a novel perspective, i.e. situational processing perspective, and developed the integrative framework for the effectiveness of FOP nutrition labels accordingly. Integrating an extensive review of the nutrition labeling literature, this work implemented the dual-process model to offer a framework and explain the findings of previous studies. The integrative framework introduced in this paper reveals that the effectiveness of each FOP nutrition label format depends on the harmony among the personal and contextual variables (situations), the processing system triggered, and features of the label format. The concept of situational processing discussed in this paper reveals that consumers might prefer different FOP nutrition label formats in different situations. They might also respond differently to the same label format depending on the processing situations.

In general, the findings of this research project are line with prior studies discussing the role of using heuristics in choice (e.g., Gomez 2013; Nikolova and Inman 2015; Scheibehenne, Miesler, and Todd 2007; Schulte-Mecklenbeck et al. 2013). Unlike these studies, which focus on one possible combination of personal and contextual variables and its impact on the use of 
FOP labels, our framework offers a comprehensive view that enables researchers to predict the consumer's response to any possible combination of personal and contextual variables. Moreover, prior studies (e.g., Cohen and Babey 2012; Grunert, Bolton, and Raats 2012; Newman, Howlett, and Burton 2016) have focused on specific features such as fluency and familiarity to represent heuristic processing. In contrast, our research provides a conclusive framework that allows the analysis to be extended to other attributes of FOP nutrition labels.

To address the practicality of this framework, the second and third papers provide empirical results. The second study relied on the integrative framework offered in the first one, proposing that a label might be processed and used in different ways, resulting in different choices. This study focused on the effect of time pressure and nutrition knowledge on processing mode (intuitive and deliberate) and the use of FOP labels. In doing so, it was able to demonstrate that consumers under time pressure ignore nutrition labels and rely on heuristic cues.

Contrary to the prevailing assumption that one format of FOP nutrition label is only effective in a specific situation (e.g., Aschemann-Witzel et al. 2013; Lobstein and Davies 2009; Maubach, Hoek, and Mather 2014), the findings of the second study reveal that one FOP label format can be used in various ways, depending on a set of personal and contextual variables (e.g., time pressure and nutrition knowledge). Furthermore, in direct opposition to studies maintaining the unconditional positive influence of high nutrition knowledge on healthful food choice (e.g., Burton, Biswas, and Netemeyer 1994; Miller and Cassady 2012), our findings suggest that high nutrition knowledge only has a favorable effect on healthful choice when consumers are not under time pressure, with the unhealthful choice being selected otherwise. This finding provides support for the argument that consumers with high nutrition knowledge do not always make a healthful choice (e.g., Grunert, Bolton, and Raats 2012; Hess, Visschers, 
and Siegrist 2012; Hieke and Taylor 2012). While these studies suggest that highly knowledgeable consumers believe that they know "by heart" which products to choose and therefore find it unnecessary to look at nutrition labels, the third paper clearly specifies when highly knowledgeable consumers skip using the FOP labels.

The third paper follows another stream of the integrative framework presented in the first paper. While the second paper focuses on the various ways of processing a single FOP nutrition label, the third paper compares the processing of two FOP nutrition label formats, namely the GDA and traffic light labels. This paper is based on the proposition that different FOP nutrition labels are processed differently, depending on relevant personal variables such as nutrition knowledge and motivation. The findings of this study demonstrate that processing mode (intuitive versus deliberate processing) explains the favorable impact of FOP nutrition label formats on healthy food choice.

Previous studies have also argued that high nutrition knowledge increases the use of all types of FOP nutrition labels formats (e.g., Basil, Basil, and Deshpande 2009; Grunert, Wills, and Fernandez-Celemin 2010; Higginson et al. 2002b). In line with this argument, the third paper reveals that high nutrition knowledge increases use of traffic light labels, while medium nutrition knowledge influences the use of GDA labels.

\subsection{General Contribution}

The major findings from the three studies contribute to the literature of nutrition labeling in several ways. The first paper offers a novel framework for understanding how consumers use FOP nutrition labels. Relying on the dual-process framework, this paper presents a framework demonstrating that nutrition label formats are not always effective. Instead, their effectiveness is determined by the consumer's dominant processing system. This framework 
specifies four distinctive situations according to personal variables (motivation and nutrition knowledge) and contextual variables (time pressure and depletion). In each of these situations, it predicts consumers' responses to the FOP nutrition labels as well as the type of FOP label that best fits the situation to induce a healthful choice. Thus, this framework provides a unique theoretical contribution to nutrition labeling literature by advancing our understanding of food choice processes and the underlying mechanisms.

In addition to contributing theoretically to the nutrition labeling literature, the second paper advances the understanding of consumers' responses to FOP labels by revealing that consumers can use one label in different ways. Specifically, its findings demonstrate that the use and effectiveness of FOP labels on healthy choice vary depending on time pressure and consumers' nutrition knowledge. Hence, one label may be used in various ways, resulting in different choices. By focusing on the interplay of time pressure and nutrition knowledge as a key antecedent of processing mode, we provide fresh insights about the situational processing of FOP labels. The third paper highlights the difference in processing of two types of FOP nutrition labels. Its findings demonstrate the conditions (in terms of motivation and nutrition knowledge) under which either GDA or traffic light labels are effective for healthy food choice.

In general, this research project provided a comprehensive framework that offers a coherent picture of the use and effectiveness of FOP nutrition labels. It concentrated on the fundamentals of a processing mode and empirically examined the effect of personal variables and contextual variables on use of FOP labels.

\subsection{Managerial Implications}

The findings of this research hold value for both policymakers and retailers. The revelation that consumers use heuristics without deep processing in specific purchase situations 
suggests that a greater focus on improving heuristic-based labels is advisable (e.g., the health logo, scoring system, NuVal, and traffic light). Enhancing the fluency and attractiveness of these labels by implementing familiar elements, attractive colors, and fluent terms would increase the chance of use by consumers and thus the likelihood of healthful choices. Furthermore, results show that the use of traffic lights, scoring systems, and NuVal is related to memory; therefore, using consistent formats across products would help consumers become acquainted with them and employ them in subsequent purchases.

Policymakers should also benefit from the framework suggested in this research project by categorizing products according to the attributes of their target group (e.g., nutrition knowledge) and then allocating the appropriate FOP nutrition label format to the products that are commonly used by each group. For example, if a specific product's target group is likely to be less knowledgeable, then more easy-to-read and fluent FOP nutrition labels (e.g., summary labels) should be used on the product. If, on the other hand, the target group of a specific product (e.g., ready-made soup) is made up of consumers that often lack time, policymakers should employ easy-to-use and heuristic FOP labels (e.g., summary labels). In contrast, products that are often bought by highly knowledgeable consumers (e.g., organic products) should present more detailed nutrition information (e.g., GDA). Similarly, there are products that are often bought by consumers who are likely to have more time (e.g., ingredients for specific traditional and time-consuming dishes). These products are also advised to implement more extensive nutrition information in FOP nutrition labels, such as GDA or traffic light labels.

The findings presented above also contain insights for retailers. As it was revealed that difficult-to-process labels, such as numerical ones, are likely to be ignored at the end of a shopping trip (when consumers are under time pressure or are depleted and too fatigued to 
make a deliberate choice). retailers should vary the format of nutrition labels based on the product's placement in the supermarket. Moreover, using digital shelf-labeling technologies would allow the more fluent nutrition label formats (compatible for fatigued and depleted consumers under time pressure) to be presented in the afternoon, whereas the more informative labels that aid deliberate decision making could be shown in the morning.

In general, given the complex nature of food choice in supermarkets, policymakers and retailers can use the framework offered in this research to identify the situations (based on personal and contextual variables) that best fit the desired outcome in terms of increasing healthful purchases or enhancing sales.

\subsection{Limitations and Future Research}

While our research sheds new light on the effectiveness of FOP nutrition labels, it has certain limitations that provide room for further research. This paper investigates the use and effectiveness of FOP labels through the specific impacts of time pressure as a contextual variable and nutrition knowledge and motivation as personal variables. One general recommendation for future researchers is to test the propositions of the integrative framework. We expect that other studies would achieve similar findings that would enhance the validity of this framework. For example, further studies should examine the impact of the variables discussed in the conceptual framework, such as health consciousness and depletion, fatigue, or hunger. It would also be interesting to examine the interplay of these variables rather than only studying their effects independently. To represent FOP labeling features associated with processing, current research has mainly focused on GDA and traffic light labels. Future research should expand these features and focus on other nutrition label formats, such as $\mathrm{NuVal}$ or summary labels. 
In addition, while our framework considered the impact of personal and contextual variables, we suggest that future studies investigate the impact of demographic attributes, such as gender, age, BMI, number of people in household, income, or number and composition of people in household on processing and thus food choice. Another domain that is less addressed in our framework is that of dietary goals. We advise future studies to examine the impact of dietary goals (e.g., functional, symbolic, and hedonic; Bublitz, Peracchio, and Block 2010) and expect there to be an association between different modes of processing and types of dietary goals. It would also be interesting to investigate how processing mode affects the use of FOP labels when shopping for healthy versus hedonic products; we expect to witness the dominance of either intuitive or deliberate processing mode when consumers intend to purchase either hedonic or healthy foods, respectively.

In this project, we learned about various FOP nutrition label formats in terms of fluency and familiarity, which led to the heuristic use of these labels. Further studies should expand the features of FOP nutrition labels associated with heuristic processing. For example, research regarding the presentation of different serving sizes on FOP nutrition labels or readability in term of font size and label positioning could add to the findings of this research project.

\subsection{Conclusion}

The findings presented above provide an insightful perspective into the influence of FOP nutrition labels on healthy food choice. This research exceeds the status quo by suggesting a comprehensive framework that incorporates the findings of previous literature to clarify and predict the effect of nutrition labeling for healthy food choice. The findings of our study indicate that the effectiveness of FOP nutrition labels depends on the situation in which consumers confront them. These situations can be characterized by a set of personal and 
contextual variables and their interplay. Based on these conditions, consumers then use FOP nutrition labels either deeply or heuristically. A set of personal and context variables and their interplay characterize these situations. Given the features of these situations, a FOP label is used in different ways. Also, one FOP label might better fit each situation. The results hold value for both policy makers and retailers. 


\section{Appendix}

Appendix 1: The Visual Question in Paper\#2, Study 1

Bitte betrachten Sie die Blumen in den beiden Gruppen:
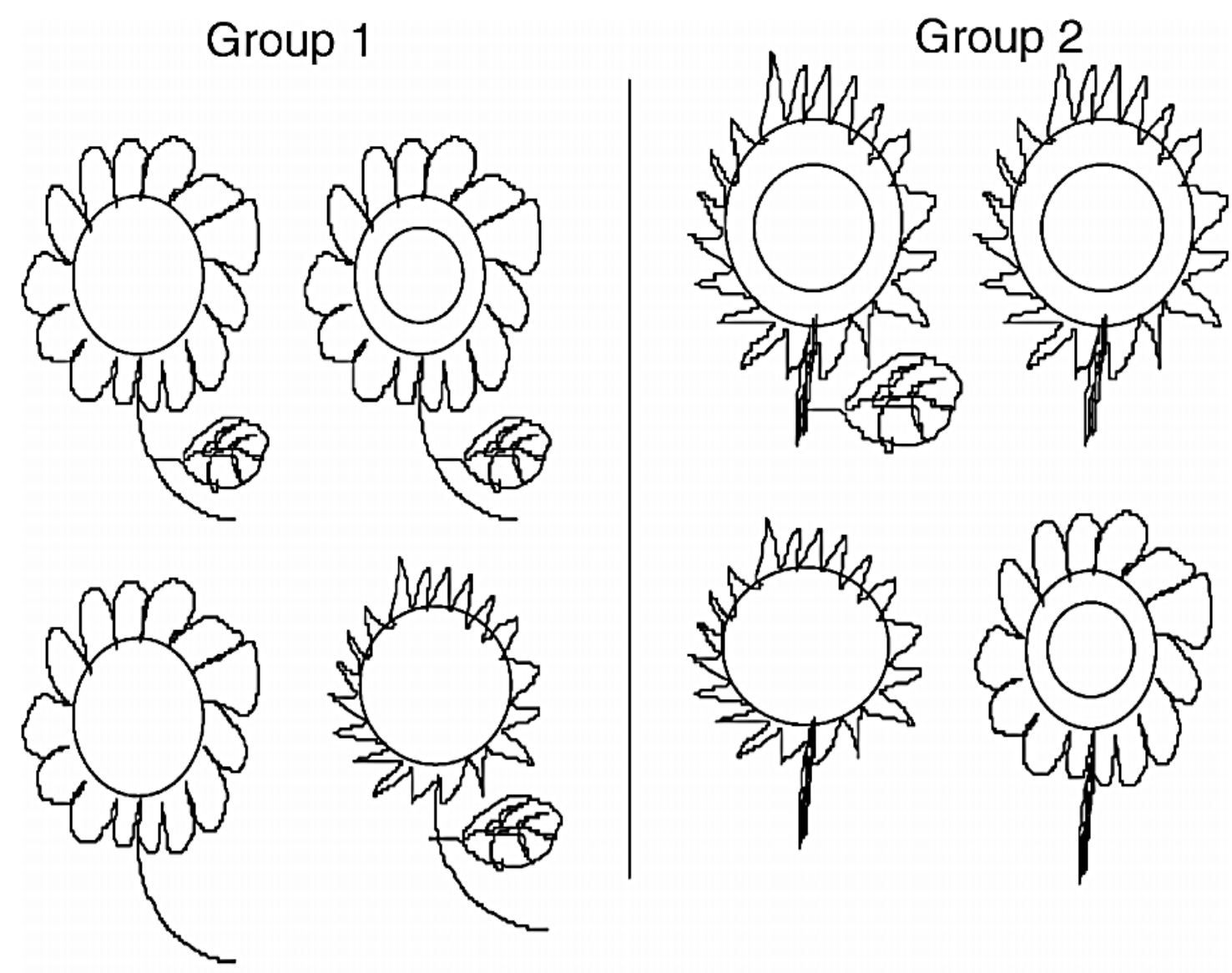

Zu welcher der beiden Gruppen gehört die nachfolgende Blume? Gruppe 1 oder Gruppe 2?

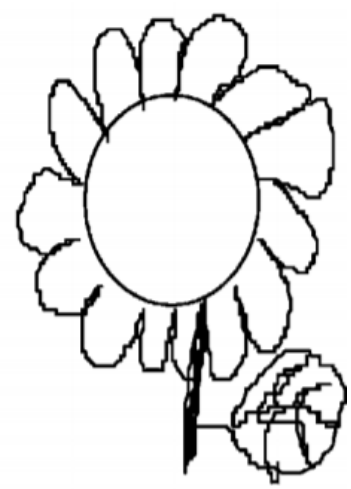


Appendix 2: Choice Sets in Paper\#2, Study 1

Which product is healthier?

Choice set 1: yogurt chocolates versus butter-cookie chocolates

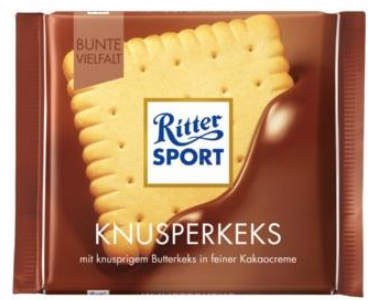

Calorie per 100g: $555 \mathrm{kcal}$

Fat: 34 gr

Sugar: 56 gr

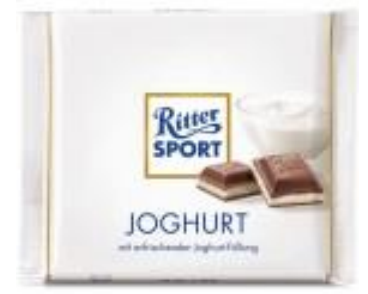

Calorie per 100g: $574 \mathrm{kcal}$

Fat: 38 gr

Sugar: 49 gr

Choice set 2: strawberry yogurt versus yogurt with $40 \%$ fat

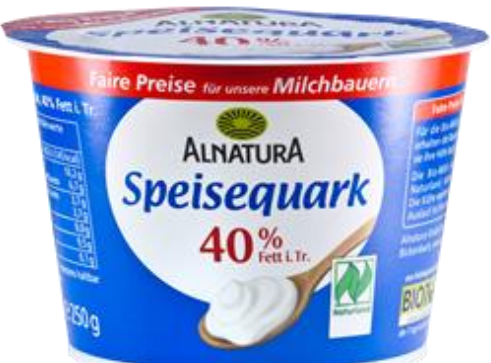

Calorie per serving: $145 \mathrm{kcal}$

Fat: 10,2 gr

Sugar: 3,7 gr

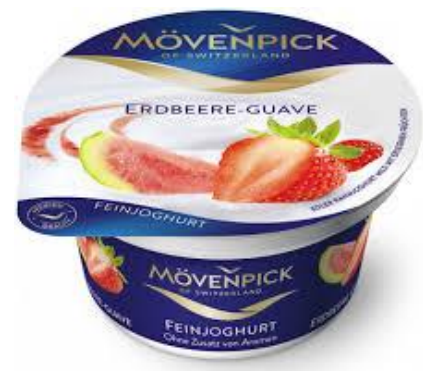

Calorie per serving: $163 \mathrm{kcal}$

Fat: 10,0 gr

Sugar: $14.4 \mathrm{gr}$

Choice set 3: yogurt-strawberry chocolate versus raisin and nuts chocolate

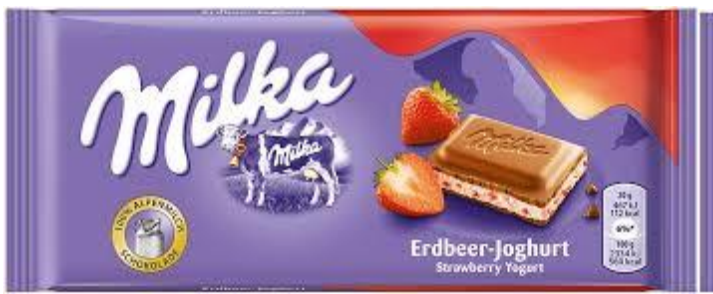

Calorie per serving: $121 \mathrm{kcal}$

Fat: $10 \mathrm{gr}$

Sugar: 9 gr

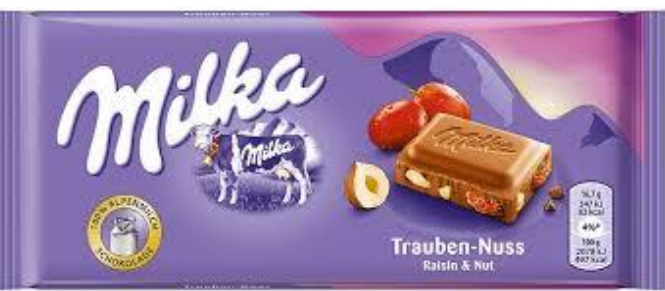

Calorie per serving: $94 \mathrm{kcal}$ Fat: 6 gr

Sugar: $8.7 \mathrm{gr}$ 
Appendix 3: Choice Sets in Paper\#2, Study 2

Choice set 1:
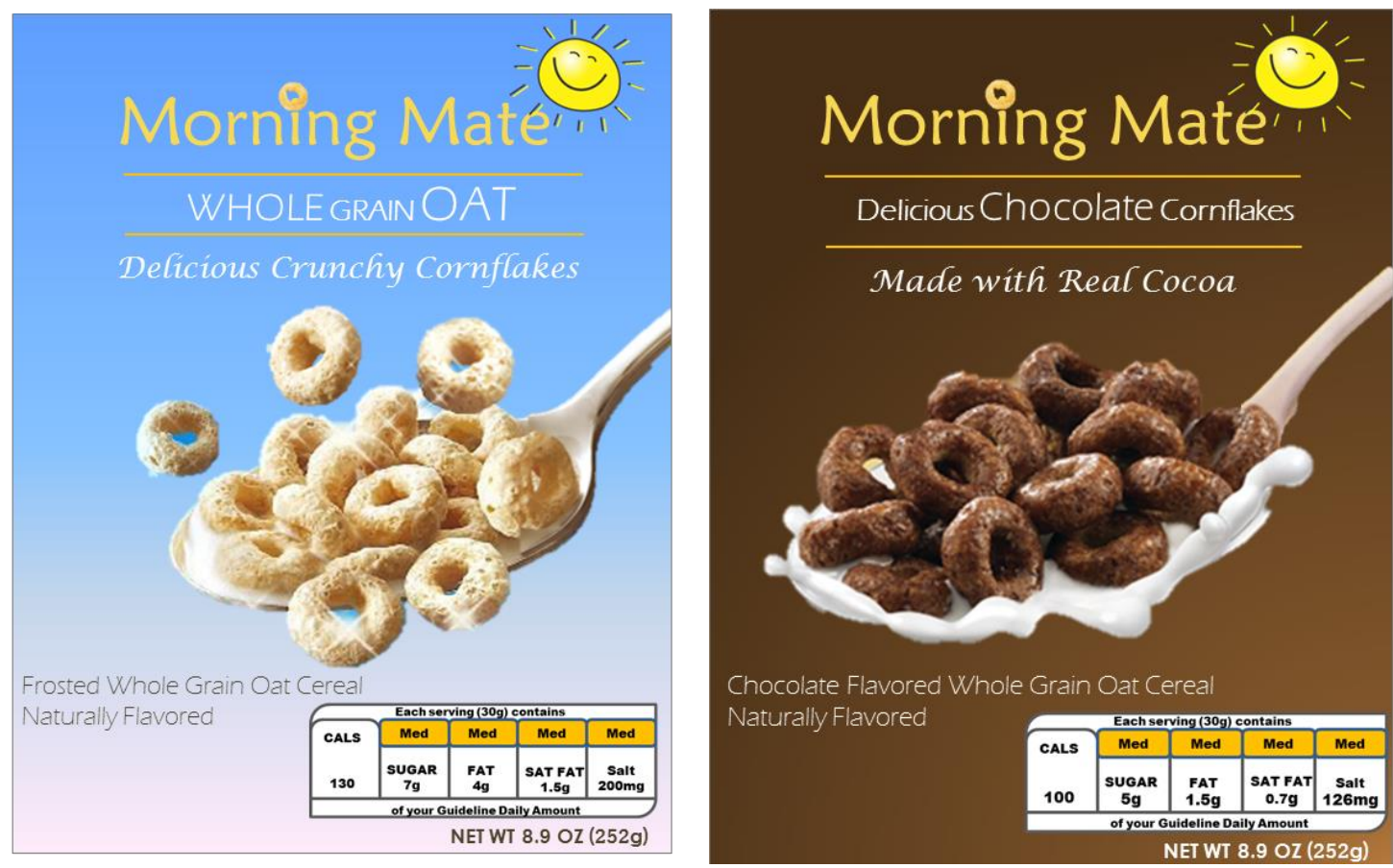

Choice set 2:
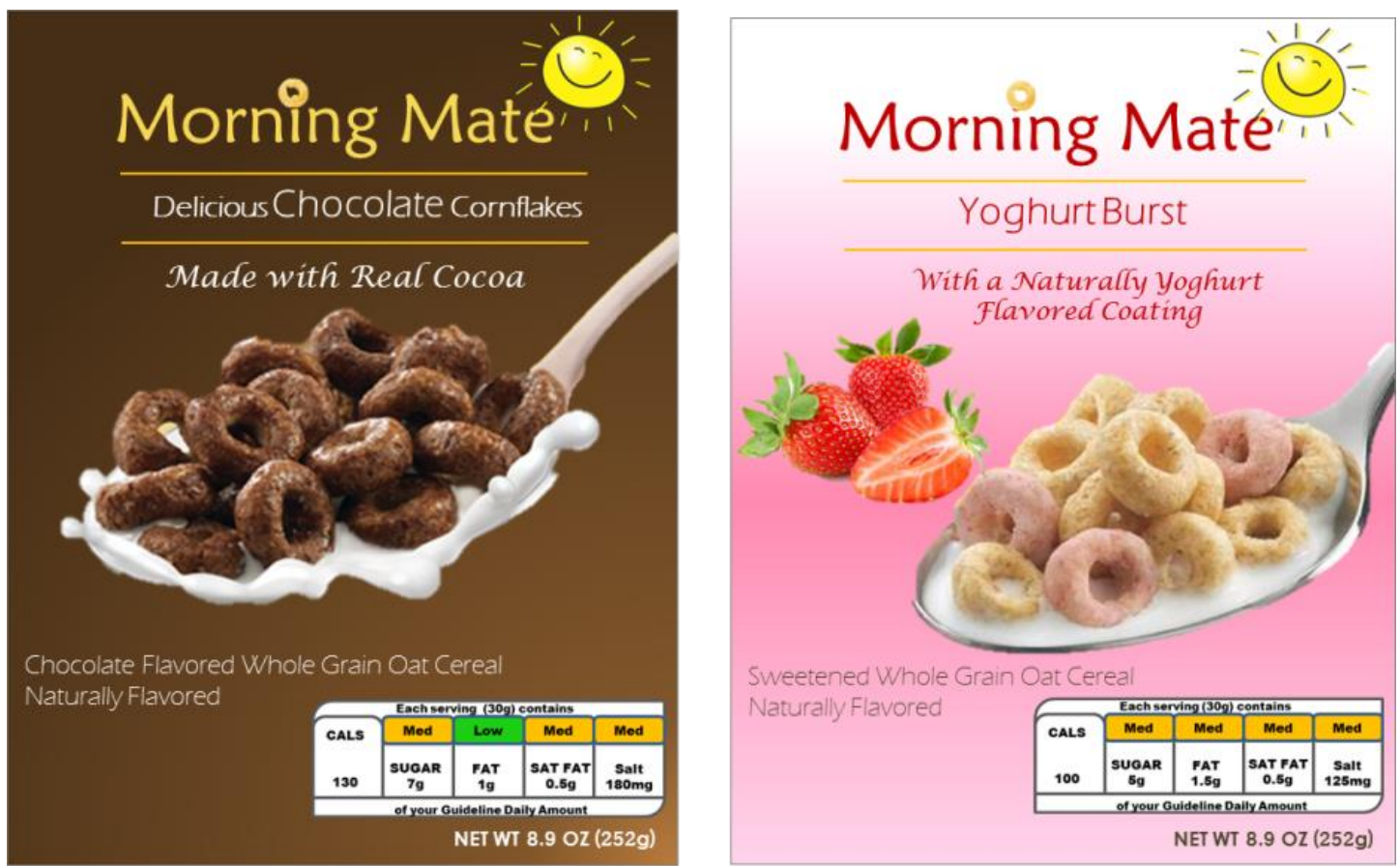
Appendix 4: Choice Sets in Paper\#3

Choice set 1
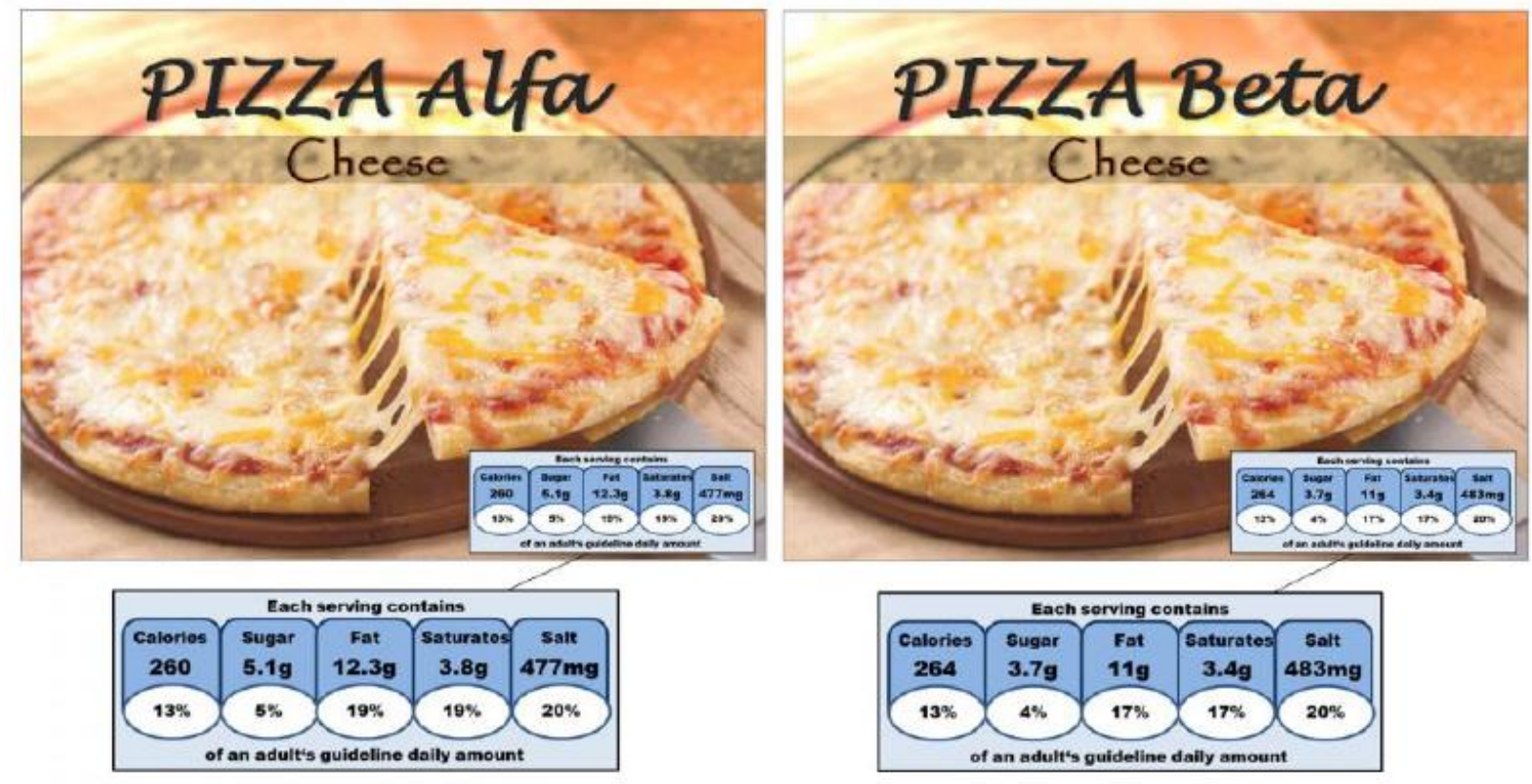

Choice set 2
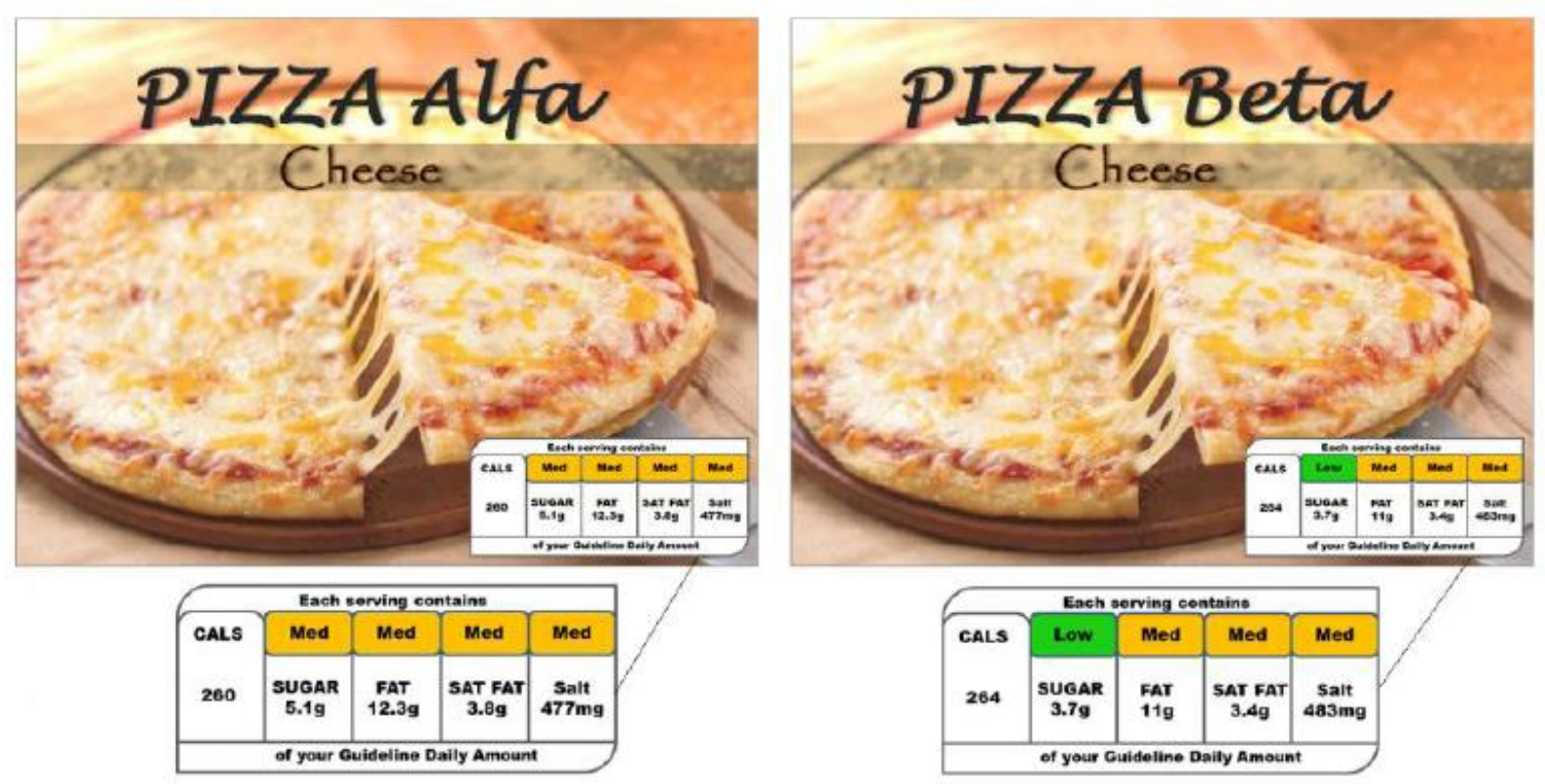
Choice set 2
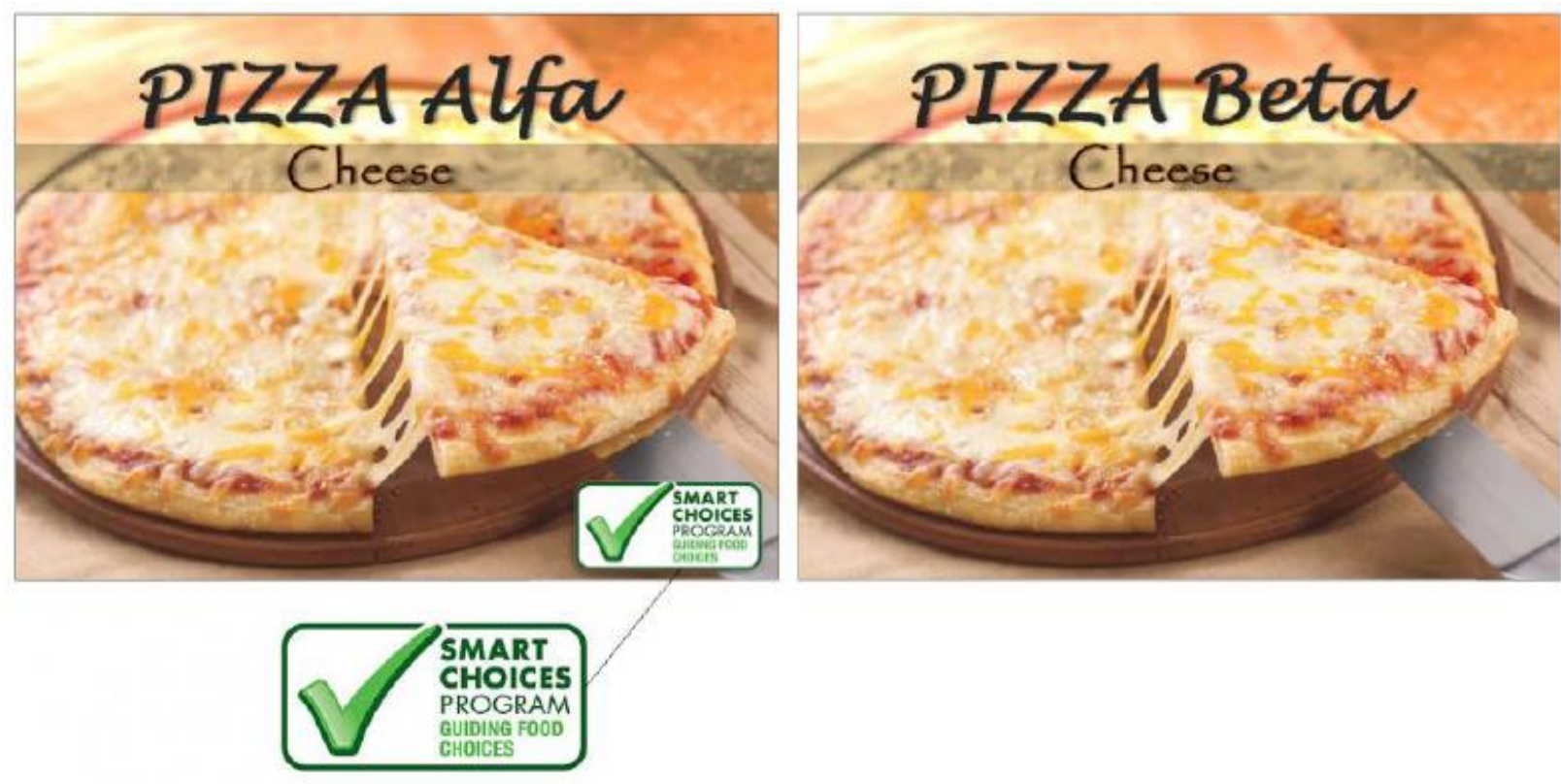


\section{References}

Andrews, J. Craig, Scot Burton, and Jeremy Kees (2011), "Is Simpler Always Better? Consumer Evaluations of Front-of-Package Nutrition Symbols," Journal of Public Policy \& Marketing, 30 (2), 175-90.

-, Richard G. Netemeyer, and Scot Burton (2009), "The Nutrition Elite: Do Only the Highest Levels of Caloric Knowledge, Obesity Knowledge, and Motivation Matter in Processing Nutrition Ad Claims and Disclosures?," Journal of Public Policy \& Marketing, 28 (1), 41-55.

Ares, Gastón, Ana Giménez, Fernanda Bruzzone, Lucía Antúnez, Alejandra Sapolinski, Leticia Vidal, and Alejandro Maiche (2012), "Attentional capture and understanding of nutrition labelling: a study based on response times," International Journal of Food Sciences and Nutrition, 63 (6), 679-88.

_, Franco Mawad, Ana Giménez, and Alejandro Maiche (2014), "Influence of rational and intuitive thinking styles on food choice. Preliminary evidence from an eye-tracking study with yogurt labels," Food Quality and Preference, 31, 28-37.

Aschemann-Witzel, Jessica, Klaus G. Grunert, Hans C.M. van Trijp, Svetlana Bialkova, Monique M. Raats, Charo Hodgkins, Grazyna Wasowicz-Kirylo, and Joerg Koenigstorfer (2013), "Effects of nutrition label format and product assortment on the healthfulness of food choice," Appetite, 71, 63-74.

Balasubramanian, Siva K. and Catherine Cole (2002), "Consumers' Search and Use of Nutrition Information: The Challenge and Promise of the Nutrition Labeling and Education Act," Journal of Marketing, 66 (3), 112-27.

Balcombe, Kelvin, Iain Fraser, and Salvatore Di Falco (2010), "Traffic lights and food choice: A choice experiment examining the relationship between nutritional food labels and price," Food Policy, 35, 211-20.

Baltas, George (2001), "Nutrition labelling: issues and policies," European Journal of Marketing, 35 (5/6), 708-21.

Barreiro-Hurlé, Jesús, Azucena Gracia, and Tiziana de-Magistris (2010), "Does nutrition information on food products lead to healthier food choices?," Food Policy, 35, 221-29.

Basil, Michael D., Debra Z. Basil, and Sameer Deshpande (2009), "A Comparison of Consumers and Dieticians: Nutrition Focus, Food Choice, and Mental Accounting," Journal of Nonprofit \& Public Sector Marketing, 21, 283-97.

Becker, Mark W., Nora M. Bello, Raghav P. Sundar, Chad Peltier, and Laura Bix (2015), "Front of pack labels enhance attention to nutrition information in novel and commercial brands," Food Policy, 56, 76-86. 
Benn, Yael, Thomas L. Webb, Betty P. I. Chang, and John Reidy (2015), "What information do consumers consider, and how do they look for it, when shopping for groceries online?," Appetite, 89, 265-73.

Berning, J. P., H. H. Chouinard, and J. J. McCluskey (2010), "Do Positive Nutrition Shelf Labels Affect Consumer Behavior? Findings from a Field Experiment with Scanner Data," American Journal of Agricultural Economics, 93(2), 364-369.

Berning, Joshua P. and David E. Sprott (2011), "Examining the Effectiveness of Nutrition Information in a Simulated Shopping Environment," Journal of Food Distribution Research, $42(3), 60-76$.

Bialkova, Svetlana, Klaus G. Grunert, Hans Jørn Juhl, Grazyna Wasowicz-Kirylo, Malgorzata Stysko-Kunkowska, and Hans C.M. van Trijp (2014), "Attention mediates the effect of nutrition label information on consumers' choice. Evidence from a choice experiment involving eye-tracking," Appetite, 76, 66-75.

_ Lena Sasse, and Anna Fenko (2016), "The role of nutrition labels and advertising claims in altering consumers' evaluation and choice," Appetite, 96, 38-46.

and Hans van Trijp (2010), "What determines consumer attention to nutrition labels?," Food Quality and Preference, 21, 1042-51.

and Hans C.M. van Trijp (2011), "An efficient methodology for assessing attention to and effect of nutrition information displayed front-of-pack," Food Quality and Preference, 22 (6), 592-601.

Borgmeier, Ingrid and Joachim Westenhoefer (2009), "Impact of different food label formats on healthiness evaluation and food choice of consumers: a randomized-controlled study," BMC Public Health, 9 (184), 1-12.

Boztug, Yasemin, Hans Jørn Juhl, Ossama Elshiewy, and Morten Berg Jensen (2015), "Consumer response to monochrome Guideline Daily Amount nutrition labels," Food Policy, 53, 1-8.

Bublitz, Melissa G., Laura A. Peracchio, and Lauren G. Block (2010), "Why did I eat that? Perspectives on food decision making and dietary restraint," Journal of Consumer Psychology, 20, 239-58.

Bucher, T., B. Müller, and M. Siegrist (2015), "What is healthy food? Objective nutrient profile scores and subjective lay evaluations in comparison," Appetite, 95, 408-14.

Burton, Scot, Abhijit Biswas, and Richard Netemeyer (1994), "Effects of Alternative Nutrition Label Formats and Nutrition Reference Information on Consumer Perceptions, Comprehension, and Product Evaluations," Journal of Public Policy \& Marketing, 13 (1), $36-47$. 
, Elizabeth Howlett, and Andrea Heintz Tangari (2009), "Food for Thought: How Will the Nutrition Labeling of Quick Service Restaurant Menu Items Influence Consumers' Product Evaluations, Purchase Intentions, and Choices?," Journal of Retailing, 85 (3), 25873.

and Jeremy Kees (2012), "Flies in the Ointment? Addressing Potential Impediments to Population-Based Health Benefits of Restaurant Menu Labeling Initiatives," Journal of Public Policy \& Marketing, 31, 232-39.

Bussell, Gaynor (2005), "Nutritional profiling vs guideline daily amounts as a means of helping consumers make appropriate food choices," Nutrition \& Food Science, 35 (5), 337-43.

Campos, Sarah, Juliana Doxey, and David Hammond (2011), "Nutrition labels on prepackaged foods: a systematic review," Public Health Nutrition, 14, 1496-506.

Chalamon, Isabelle and Lydiane Nabec (2016), "Why Do We Read On-Pack Nutrition Information so Differently? A Typology of Reading Heuristics Based on Food Consumption Goals," Journal of Consumer Affairs, 50 (2), 403-29.

Chance, Zoe, Margarita Gorlin, and Ravi Dhar (2014), "Why Choosing Healthy Foods is Hard, and How to Help: Presenting the 4Ps Framework for Behavior Change," Customer Needs and Solutions, 1, 253-62.

Chandon, Pierre (2013), "How Package Design and Packaged-based Marketing Claims Lead to Overeating," Applied Economic Perspectives and Policy, 35 (1), 7-31.

and Brian Wansink (2012), "Does food marketing need to make us fat? A review and solutions," Nutrition Reviews, 70 (10), 571-93.

Cohen, Deborah A. and Susan H. Babey (2012), "Contextual Influences on Eating Behaviors: Heuristic Processing and Dietary Choices," Obesity Review, 13 (9), 766-79.

Cowburn, Gill and Lynn Stockley (2005), "Consumer understanding and use of nutrition labelling: a systematic review," Public Health Nutrition, 8 (1), 21-28.

Crosetto, Paolo, Laurent Muller, and Bernard Ruffieux (2016), "Helping consumers with a front-of-pack label. Numbers or colors?," Journal of Economic Psychology, 55, 30-50.

Dhar, Ravi and Margarita Gorlin (2013), "A dual-system framework to understand preference construction processes in choice,” Journal of Consumer Psychology, 23 (4), 528-42.

Draper, Alizon K., Ashley J. Adamson, Sue Clegg, Sally Malam, Malcolm Rigg, and Sue Duncan (2013), "Front-of-pack nutrition labelling. Are multiple formats a problem for consumers?," European Journal of Public Health, 23 (3), 517-21. 
Drescher, Larissa S., Jutta Roosen, and Stéphan Marette (2014), "The effects of traffic light labels and involvement on consumer choices for food and financial products," International Journal of Consumer Studies, 38, 217-27.

Drichoutis, Andreas C., Panagiotis Lazaridis, and Rodolfo M. Nayga (2005), "Nutrition knowledge and consumer use of nutritional food labels," European Review of Agricultural Economics, 32 (1), 93-118.

— - - (2006), "Consumers' Use of Nutritional Labels: A Review of Research Studies and Issues,” Academy of Marketing Science Review, 9 (1-22).

Elshiewy, Ossama, Steffen Jahn, and Yasemin Boztug (2016), "Seduced by the Label. How the Recommended Serving Size on Nutrition Labels Affects Food Sales," Journal of the Association for Consumer Research, 1 (1), 104-14.

Emrich, Teri E., Ying Qi, Joanna E. Cohen, Wendy Y. Lou, and Mary L. L'Abbe (2015), "Front-of-pack symbols are not a reliable indicator of products with healthier nutrient profiles," Appetite, 84, 148-53.

Feunekes, Gerda I. J., Ilse A. Gortemaker, Astrid A. Willems, René Lion, and Marcelle van den Kommer (2008), "Front-of-pack nutrition labelling. Testing effectiveness of different nutrition labelling formats front-of-pack in four European countries," Appetite, 50 (1), 5770.

Gomez, Pierrick (2013), "Common biases and heuristics in nutritional quality judgments: a qualitative exploration,” International Journal of Consumer Studies, 37, 152-58.

, Carolina O. C. Werle, and Olivier Corneille (2017), "The pitfall of nutrition facts label fluency. Easier-to-process nutrition information enhances purchase intentions for unhealthy food products," Marketing Letters, 28 (1), 15-27.

Grunert, Klaus G., Lisa E. Bolton, and Monique M. Raats (2012), Processing and acting upon nutrition labeling on food: The state of knowledge and new directions for transformative consumer research. Transformative Consumer Research for Personal and Collective Wellbeing, Mick DG, Pettigrew S, Pechmann C, et al, eds. Routledge, NY: Taylor \& Francis.

and Josephine M. Wills (2007), “A review of European research on consumer response to nutrition information on food labels," Journal of Public Health, 15, 385-99.

understanding of nutrition information on food labels among consumers in the UK," Appetite, 55, 177-189.

Guthrie, Joanne, Lisa Mancino, and Chung-Tung Jordan Lin (2015), "Nudging Consumers toward Better Food Choices: Policy Approaches to Changing Food Consumption Behaviors," Psychology \& Marketing, 32 (5), 501-11. 
Hamlin, Robert P., Lisa S. McNeill, and Vanessa Moore (2015), "The impact of front-of-pack nutrition labels on consumer product evaluation and choice. An experimental study," Public Health Nutrition, 18 (12), 2126-34.

Hassan, Louise M., Edward M. K. Shiu, and Nina Michaelidou (2010), "The Influence of Nutrition Information on Choice: The Roles of Temptation, Conflict and Self-Control," Journal of Consumer Affairs, 44 (3), 499-515.

Hayes, Andrew F. (2013), Introduction to Mediation, Moderation, and Conditional Process Analysis. A Regression-Based Approach. New York, NY: A Division of Guilford Publications, Inc.

Helfer, Peter and Thomas R. Shultz (2014), "The effects of nutrition labeling on consumer food choice: a psychological experiment and computational model," New York Academy of Sciences, 1331, 174-85.

Hersey, James C, Kelly C Wohlgenant, Joanne E Arsenault, Katherine M Kosa, and Mary K Muth (2013), "Effects of front-of-package and shelf nutrition labeling systems on consumers," Nutrition Reviews, 71 (1), 1-14.

Hess, Rebecca, Vivianne H. Visschers, and Michael Siegrist (2012), "The role of healthrelated, motivational and sociodemographic aspects in predicting food label use: a comprehensive study," Public Health Nutrition, 15 (3), 407-14.

Hieke, Sophie and Charles R. Taylor (2012), "A Critical Review of the Literature on Nutritional Labeling," The Journal of Consumer Affairs, 46 (1), 120-56.

and Petra Wilczynski (2012), "Colour Me In- an empirical study on consumer responses to the traffic light signposting system in nutrition labelling," Public Health Nutrition, 15 (5), 773-82.

Higginson, C. S., T. R. Kirk, M. J. Rayner, and S. Draper (2002a), "How do consumers use nutrition label information?," Nutrition \& Food Science, 32 (4), 145-52.

- M. J. Rayner, S. Draper, and T. R. Kirk (2002b), "The nutrition label - which information is looked at?," Nutrition \& Food Science, 32 (3), 92-99.

Hodgkins, Charo, Julie Barnett, Grazyna Wasowicz-Kirylo, Malgorzata Stysko-Kunkowska, Yaprak Gulcan, Yesim Kustepeli, Sedef Akgungor, George Chryssochoidis, Laura Fernández-Celemin, Stefan S. g. Bonsmann, Michelle Gibbs, and Monique Raats (2012), "Understanding how consumers categorise nutritional labels: A consumer derived typology for front-of-pack nutrition labelling," Appetite, 59, 806-17.

Jacquier, Caroline, Françoise Bonthoux, Monica Baciu, and Bernard Ruffieux (2012), "Improving the effectiveness of nutritional information policies: assessment of unconscious 
pleasure mechanisms involved in food-choice decisions," Nutrition Reviews, 70 (2), 11831.

Johnson, Eric J. (2008), "Man, my brain is tired. Linking depletion and cognitive effort in choice," Journal of Consumer Psychology, 18 (1), 14-16.

Julia, Chantal, Pauline Ducrot, Sandrine Péneau, Valérie Deschamps, Caroline Méjean, Léopold Fézeu, Mathilde Touvier, Serge Hercberg, and Emmanuelle Kesse-Guyot (2015), "Discriminating nutritional quality of foods using the 5-Color nutrition label in the French food market. Consistency with nutritional recommendations," Nutrition Journal, 14 (100), $1-12$.

Kahneman, Daniel (2003), "Maps of Bounded Rationality: Psychology for Behavioral Economics," The American Economic Review, 93 (5), 1449-75.

— (2011), Thinking, Fast and Slow. NY: Farrar, Straus and Giroux.

and Shane Frederick (2005), A Model of Heuristic Judgment. The Cambridge Handbook of Thinking and Reasoning, Holyoak KJ, Morrison RG, eds. New York, NY.

Kees, Jeremy, Marla B. Royne, and Yoon-na Cho (2014), "Regulating Front-of-Package Nutrition Information Disclosures. A Test of Industry Self-Regulation vs. Other Popular Options," Journal of Consumer Affairs, 48 (1), 147-74.

Kiesel, Kristin and Sofia B. Villas-Boas (2013), "Can information costs affect consumer choice? Nutritional labels in a supermarket experiment," International Journal of Industrial Organization, 31 (2), 153-63.

Koenigstorfer, Joerg, Andrea Groeppel-Klein, and Friederike Kamm (2014), "Healthful Food Decision Making in Response to Traffic Light Color-Coded Nutrition Labeling," Journal of Public Policy \& Marketing, 33 (1), 65-77.

Lobstein, T. and S. Davies (2009), "Defining and labelling 'healthy' and 'unhealthy' food," Public Health Nutrition, 12 (3), 331-40.

Mai, Robert and Stefan Hoffmann (2012), "Taste lovers versus nutrition fact seekers: How health consciousness and selfefficacy determine the way consumers choose food products," Journal of Consumer Behaviour, 11, 316-28.

Maubach, Ninya, Janet Hoek, and Damien Mather (2014), "Interpretive front-of-pack nutrition labels. Comparing competing recommendations," Appetite, 82, 67-77.

Mawad, Franco, Marcela Trías, Ana Giménez, Alejandro Maiche, and Gastón Ares (2015), "Influence of cognitive style on information processing and selection of yogurt labels. Insights from an eye-tracking study," Food Research International, 74, 1-9. 
Mejean, C., P. Macouillard, S. Péneau, S. Hercberg, and K. Castetbon (2013), "Consumer acceptability and understanding of front-of-pack nutrition labels," Journal of Human Nutrition and Dietetics, 26 (5), 494-503.

Miller, Lisa M. Soederberg and Diana L. Cassady (2012), "Making healthy food choices using nutrition facts panels. The roles of knowledge, motivation, dietary modifications goals, and age," Appetite, 59, 129-39.

Moorman, Christine and Erika Matulich (1993), "A Model of Consumers' Preventive Health Behaviors: The Role of Health Motivation and Health Ability," Journal of Consumer Research, 20 (2), 208-28.

Muller, L. and M. Prevost (2016), "What cognitive sciences have to say about the impacts of nutritional labelling formats," Journal of Economic Psychology, 55, 17-29.

Newman, Christopher L., Elizabeth Howlett, and Scot Burton (2014), "Shopper Response to Front-of-Package Nutrition Labeling Programs: Potential Consumer and Retail Store Benefits," Journal of Retailing, 90 (1), 13-26.

$\longrightarrow$ - $\longrightarrow$, and (2016), "Effects of Objective and Evaluative Front-of-Package Cues on Food Evaluation and Choice: The Moderating Influence of Comparative and Noncomparative Processing Contexts," Journal of Consumer Research, 42, 749-66.

Nikolova, HRISTINA Dzhogleva and J. Jeffrey Inman (2015), "Healthy Choice: The Effect of Simplified POS Healthy choice: the effect of simplified POS nutritional information on consumer food choice behavior," Journal of Market Research, 52, 817-35.

Norenzayan, Ara, Edward E. Smith, Beom J. Kim, and Richard E. Nisbett (2002), "Cultural preferences for formal versus intuitive reasoning," Cognitive Science, 26 (5), 653-84.

Orquin, Jacob L. and Joachim Scholderer (2015), "Consumer judgments of explicit and implied health claims on foods: Misguided but not misled," Food Policy, 51, 144-57.

Pham, Nguyen, Naomi Mandel, and Andrea C. Morales (2016), "Messages from the Food Police: How Food-Related Warnings Backfire among Dieters," Journal of Consumer Research, 1 (1), 1-16.

Pieters, Rik and Luk Warlop (1999), "Visual attention during brand choice: The impact of time pressure and task motivation," International Journal of Research in Marketing, 16, 1-16.

Pocheptsova, Anastasiya, On Amir, Ravi Dhar, and Roy F. Baumeister (2009), "Deciding Without Resources: Psychological Depletion and Choice in Context," Journal of Market Research, 46, 344-55.

Aparna A. Labroo, and Ravi Dhar (2010), "Making Products Feel Special: When Metacognitive Difficulty Enhances Evaluation," Journal of Marketing Research, XLVII, 1059-69. 
Raghunathan, Rajagopal, Rebecca Walker Naylor, and Wayne D. Hoyer (2006), "The Unhealthy = Tasty Intuition and Its Effects on Taste Inferences, Enjoyment, and Choice of Food Products," Journal of Marketing, 70 (4), 170-84.

Rahkovsky, Ilya, Biing-Hwan Lin, Chung-Tung Jordan Lin, and Jonq-Ying Lee (2013), "Effects of the Guiding Stars Program on purchases of ready-to-eat cereals with different nutritional attributes," Food Policy, 43, 100-07.

Roberto, C. A. and N. Khandpur (2014), "Improving the design of nutrition labels to promote healthier food choices and reasonable portion sizes," International Journal of Obesity, 38 Suppl 1, S25-33.

Rothman, Alexander J., Paschal Sheeran, and Wendy Wood (2009), "Reflective and Automatic Processes in the Initiation and Maintenance of Dietary Change," Annual Behavioral Medicine, 38 (1), S4-S17.

Saarela, Anna-Maria, Anja T. Lapveteläinen, Hannu M. Mykkänen, Teuvo T. Kantanen, and Riitta L. Rissanen (2013), "Real-life setting in data collection. The role of nutrition knowledge whilst selecting food products for weight management purposes in a supermarket environment," Appetite, 71, 196-208.

Sacks, Gary, Mike Rayner, and Boyd Swinburn (2009), "Impact of front-of-pack 'traffic-light' nutrition labelling on consumer food purchases in the UK," Health Promotion International, 24 (4), 344-52.

, Kim Tikellis, Lynne Millar, and Boyd Swinburn (2011), "Impact of 'traffic-light' nutrition information on online food purchases in Australia," Australian and New Zealand Journal of Public Health, 35 (2), 122-26.

Sanjari, S. Setareh, Steffen Jahn, and Yasemin Boztug (2017), "Dual-process theory and consumer response to front-of-package nutrition label formats," Nutrition Reviews, 75 (11), $871-82$.

Savoie, Nathalie, Karine Barlow, Karen L. Harvey, Mary A. Binnie, and Laura Pasut (2013), "Consumer Perceptions of Front-of-package Labelling Systems and Healthiness of Foods," Canadian Journal of Public Health, 104 (5), 359.

Scheibehenne, Benjamin, Linda Miesler, and Peter M. Todd (2007), "Fast and frugal food choices: Uncovering individual decision heuristics," Appetite, 49, 578-89.

Schulte-Mecklenbeck, Michael, Matthias Sohn, Emanuel de Bellis, Nathalie Martin, and Ralph Hertwig (2013), "A lack of appetite for information and computation. Simple heuristics in food choice," Appetite, 71, 242-51. 
Siegrist, Michael, Rebecca Leins-Hess, and Carmen Keller (2015), "Which front-of-pack nutrition label is the most efficient one? The results of an eye-tracker study," Food Quality and Preference, 39, 183-90.

Silayoi, Pinya and Mark Speece (2004), "Packaging and purchase decisions: An exploratory study on the impact of involvement level and time pressure," British Food Journal, 106 (8), 607-28.

Stanovich, K. E. and R. F. West (2000), “Advancing the rationality debate," Behavioral and Brain Science, 23, 701-17.

Suri, Rajneesh and Kent B. Monroe (2003), "The Effects of Time Constraints on Consumers' Judgments of Prices and Products," Journal of Consumer Research, 30 (1), 92-104.

Sutherland, Lisa A., Lori A. Kaley, and Leslie Fischer (2010), "Guiding stars. The effect of a nutrition navigation program on consumer purchases at the supermarket," The American Journal of Clinical Nutrition, 91 (4), 1090S-1094S.

Szanyi, Jason M. (2010), "Brain Food: Bringing Psychological Insights to Bear on Modern Nutrition Labeling Efforts,” Food Drug Law Journal, 65, 159.

Talati, Zenobia, Simone Pettigrew, Bridget Kelly, Kylie Ball, Helen Dixon, and Trevor Shilton (2016), "Consumers' responses to front-of-pack labels that vary by interpretive content," Appetite, 101, 205-13.

U.S. Food \& Drug Administration (1994), "GUIDE TO NUTRITION LABELING AND EDUCATION ACT (NLEA) REQUIREMENTS. (Editorial Changes - February 1995),”

van 't Riet, Jonathan (2012), "Sales effects of product health information at points of purchase: a systematic review," Public Health Nutrition, 16 (3), 418-29.

van der Merwee, Daleen, Elizabeth L. Kempen, Sophia Breedt, and Hanli de Beer (2010), "Food choice: student consumers' decision-making process regarding food products with limited label information," International Journal of Consumer Studies, 34, 11-18.

van Herpen, Erica, Ellen Seiss, and Hans C.M. van Trijp (2012), "The role of familiarity in front-of-pack label evaluation and use. A comparison between the United Kingdom and The Netherlands," Food Quality and Preference, 26 (1), 22-34.

and Hans C. M. van Trijp (2011), "Front-of-pack nutrition labels. Their effect on attention and choices when consumers have varying goals and time constraints," Appetite, $57,148-60$.

van Kleef, Ellen and Hans Dagevos (2015), "The growing role of front-of-pack nutrition profile labelling: A consumer perspective on key issues and controversies," Critical Reviews in Food Science and Nutrition, 55, 291-303. 
Vanhouche, Wouter and Stijn M. J. van Osselaer (2009), "The Accuracy-Enhancing Effect of Biasing Cues," Journal of Consumer Research, 36 (2), 317-27.

Visschers, Vivianne H., Rebecca Hess, and Michael Siegrist (2010), "Health motivation and product design determine Health motivation and product design determine consumers' visual attention to nutrition information on food products," Public Health Nutrition, 13 (7), 1099106.

Watson, Wendy L., Bridget Kelly, Debra Hector, Clare Hughes, Lesley King, Jennifer Crawford, John Sergeant, and Kathy Chapman (2014), "Can front-of-pack labelling schemes guide healthier food choices? Australian shoppers' responses to seven labelling formats," Appetite, 72, 90-97.

World Health Organization (2015), "Healthy diet. Fact sheet N³94,"

- (2017), "Obesity and overweight. Fact sheet," 